OPEN ACCESS

Edited by:

J. Gregory Shellnutt,

National Taiwan Normal University,

Taiwan

Reviewed by:

Saskia Erdmann,

UMR 7327 Institut des Sciences de la

Terre d'Orléans (ISTO), France

George Bergantz,

University of Washington,

United States

*Correspondence:

Katie E. Ardill

ardill@csus.edu

${ }^{\dagger}$ Present address: Katie E. Ardil

California State University, Sacramento, CA, United States

Specialty section

This article was submitted to

Petrology,

a section of the journal

Frontiers in Earth Science

Received: 03 March 2020

Accepted: 12 May 2020

Published: 24 July 2020

Citation:

Ardill KE, Paterson SR,

Stanback J, Alasino PH, King JJ and

Crosbie SE (2020) Schlieren-Bound

Magmatic Structures Record Crystal

Flow-Sorting in Dynamic

Upper-Crustal Magma-Mush

Chambers. Front. Earth Sci. 8:190.

doi: 10.3389/feart.2020.00190

\section{Schlieren-Bound Magmatic Structures Record Crystal Flow-Sorting in Dynamic Upper-Crustal Magma-Mush Chambers}

\author{
Katie E. Ardill ${ }^{1 * t}$, Scott R. Paterson ${ }^{1}$, Jonathan Stanback ${ }^{1}$, Pablo H. Alasino ${ }^{2,3}$, \\ James J. King ${ }^{4,5}$ and Simon E. Crosbie ${ }^{4}$
}

\begin{abstract}
${ }^{1}$ Department of Earth Sciences, University of Southern California, Los Angeles, CA, United States, ${ }^{2}$ Centro Regional de Investigaciones Científicas y Transferencia Tecnológica de LaRioja (Prov. de LaRioja-UNLaR-SEGEMAR-UNCaCONICET), Anillaco, Argentina, ${ }^{3}$ Instituto de Geología y Recursos Naturales, Centro de Investigación e Innovación Tecnológica, Universidad Nacional de LaRioja (INGeReN-CENIIT-UNLaR), La Rioja, Argentina, ${ }^{4}$ Department of Earth Sciences, Durham University, Durham, United Kingdom, ${ }^{5}$ Department of Earth Sciences, University of Oxford, Oxford, United Kingdom
\end{abstract}

The size, longevity, and mobility of upper-crustal magma mushes, and thus their ability to mix and interact with newly arriving magma batches, are key factors determining the evolution of magma reservoirs. Magmatic structures in plutons represent local sites of structural and compositional diversity and provide an opportunity to test the extent of physical and chemical processes that operated through time. Regional compilation of compositionally defined magmatic structures, specifically those involving schlieren, in the Tuolumne Intrusive Complex (TIC), yields a synthesis of $\sim 1500$ schlieren-bound structure measurements. Field observations, petrography, and whole-rock geochemistry were integrated to test schlieren formation mechanisms. At a local scale ( $1 \mathrm{~mm}-1 \mathrm{~m})$, we find that schlieren-bound structures formed from the surrounding host magma during dynamic magmatic processes such as crystal flow-sorting, magmatic faulting, and folding. Fluidization of the magma mush, interpreted from $1 \mathrm{~m}$ to $1 \mathrm{~km}$ wide domains of clustered schlieren-bound structures, appears to have operated within a hydrogranular medium, or "crystal slurry" (Bergantz et al., 2017). At the regional scale (10's km), outward younging patterns of troughs, migrating tubes, and plumes indicate that the mush convected, driven by intrusion of new pulses. Troughs and planar schlieren are weakly oriented parallel to nearby major unit contacts, which could be related to internal mush convection or effects of high thermochemical gradients at internal unit boundaries. We hypothesize that these younging patterns and orientations have the potential to constrain the size of mobile magma mixing regions, that in the TIC extended to a minimum of $150 \mathrm{~km}^{2}\left(\sim 1500 \mathrm{~km}^{3}\right)$ and were long-lived (>1 m.y). These require the generation of extensive melt-present reservoirs that could flow magmatically, 
formed from the amalgamation of intruding magma pulses, and precludes dike, sill, or laccolith emplacement models. We conclude that schlieren-bound structures are faithful recorders of the multi-scale, hypersolidus evolution of upper-crustal magma bodies, and represent useful tools for studying plutonic systems.

Keywords: magmatic structures, schlieren, flow sorting, crystal mush, magmatic fabric, Tuolumne Intrusive Complex, Sierra Nevada

\section{INTRODUCTION}

On the path to solidification, magma reservoirs reside in the crust as a crystal-rich mush (Marsh, 1981). Current debates relate to the size and longevity of magma mushes, and the extent to which they can be mobilized by internal (magmatic) and external (tectonic) forces (e.g., Annen et al., 2015; Bachmann and Huber, 2016; Paterson et al., 2016; Bartley et al., 2018; Holness, 2018; Jackson et al., 2018). Each of these factors controls the importance, and spatiotemporal extent, of physical and chemical magmatic processes that drive differentiation within magma reservoirs (e.g., Spera and Bohrson, 2018). Thus, these factors have implications for understanding transcrustal magmatic plumbing systems, and how material is transported and differentiated vertically in the crust (e.g., Lipman, 2007; Cashman et al., 2017). Additionally, the size, longevity, and mobility of magma mushes in the uppercrust is closely coupled with eruptive behavior at volcanic centers (e.g., Bachmann and Bergantz, 2004).

Investigating the evolving behavior of magma reservoirs is a multi-faceted issue due to the multiphase nature of magmas as well as the effects of incremental emplacement, magmahost rock interactions, and local and regional stresses on the magmatic plumbing system. In addition, magma experiences a substantial transition in effective viscosity during crystallization, between 10 and 20 orders of magnitude, emphasizing that a wide range of behaviors are possible (e.g., Petford, 2003; Sparks et al., 2019). Early studies suggested that magma composition and crystallinity were primary indicators of magma viscosity, as well as whether the magma could erupt, or "lock up" (e.g., Van der Molen and Paterson, 1979; Rosenberg and Handy, 2005; Petford, 2009). More recently, the primary focus has been on describing magmatic systems from the mechanical perspective of hydrogranular, dense, crystal-rich slurries, with or without exsolved volatiles (e.g., Schleicher et al., 2016; Bergantz et al., 2017; Degruyter et al., 2019; McIntire et al., 2019; Petford et al., 2020). This perspective is particularly relevant for magma mushes as it incorporates the effects of particle-particle interactions and deformation on the state of the mush, which are both welldocumented in field-based studies of magmatic structures in plutons (e.g., Paterson et al., 2018).

The Late Cretaceous Tuolumne Intrusive Complex (TIC), in the central Sierra Nevada, California is one exceptionally exposed example of a long-lived, composite, upper-crustal pluton, incrementally emplaced over $\sim 10 \mathrm{~m}$.y. at $6-10 \mathrm{~km}$ depth (Ague and Brimhall, 1988; Bateman, 1992; Coleman et al., 2004; Memeti et al., 2010; Paterson et al., 2016). The emplacement history and evolution of the TIC continues to be intensely studied and debated (e.g., Memeti et al., 2014; Paterson et al., 2016;
Bartley et al., 2018). On one hand, the TIC has been proposed to consist of sheets with ephemeral mush systems that have little interaction with each other during or after emplacement (e.g., Coleman et al., 2012; Bartley et al., 2018). In contrast, other studies have proposed that the TIC formed several long-lived (i.e., 0.5-2 m.y.) magma chambers, regions of interconnected magma mush that experienced convection and return flow (e.g., Bateman, 1992; Burgess and Miller, 2008; Solgadi and Sawyer, 2008; Memeti et al., 2010; Paterson et al., 2011, 2016). Each model has distinct implications for the origin of diverse magma compositions, the thermal history of the complex, the expected volume of eruptible magma, as well as magma rheology and the structural evolution of the complex.

The TIC contains an unusually wide range of magmatic structures; studying them can start to address issues surrounding the magmatic history of the complex. Compositionally defined magmatic structures, and specifically schlieren-bound structures, are the focus of this study (Cloos, 1936; Bateman, 1992; Reid et al., 1993; Žák et al., 2007; Solgadi and Sawyer, 2008; Paterson, 2009; Memeti et al., 2014; Paterson et al., 2018). In plutonic systems generally, the processes driving compositionally defined magmatic structure formation and consequent implications for magma rheology remain controversial, with contrasting models that rely on either physical (active) or chemical (static) mechanisms (e.g., McBirney and Noyes, 1979; Weinberg et al., 2001; Paterson, 2009; Boudreau, 2011; Hodge et al., 2012). Thus, understanding the formation and significance of magmatic structures is an important step towards understanding the physical and chemical evolution of upper-crustal magma reservoirs.

This article examines compositionally defined magmatic structures in the TIC from field, structural, and geochemical perspectives to investigate the evolution and dynamics of an upper crustal magma storage region at scales ranging from individual structures to pluton-wide dimensions. We find that schlieren-bound structures formed by physical flowsorting in an active crystal-mush environment, triggered by local flow instabilities. Dense minerals were selectively accumulated, to varying degrees, along both steeply and gently dipping boundaries. Schlieren-bound structures may form highly intricate and disorganized patterns at the outcrop scale, reflecting the complexity of crystal-melt and crystal-crystal interactions in a hydrogranular medium (e.g., Bergantz et al., 2017). Within mappable domains, the clustering of structures reflects the spatial and temporal heterogeneity of the magma mush, where fluidized (more mobile crystal mush) regions promote structure formation, and less dynamic zones are devoid of schlierenbound structures. Preservation of structures occurs within a 
"window" of favorable magmatic conditions (e.g., crystallinity, density, viscosity), which moves through time as the magmatic system cools. At the regional scale, schlieren-bound structures show weak to moderate alignment with internal unit contacts and outward younging directions that we propose are the result of internal return flow and convection of the mush. We use these patterns to estimate the maximum and minimum sizes of active magma chambers.

\section{BACKGROUND}

\section{Compositionally Defined Magmatic Structure Models}

Magmatic structures may be broadly grouped by the preferred alignment of objects (e.g., fabrics), deformation related structures (e.g., folds and faults), structures of growth, younging, or kinematics (e.g., cross-cutting boundaries, S-C structures), and structures involving internal contacts and layering (e.g., dikes and hybrid zones; Paterson et al., 2018). A fifth group includes compositionally defined magmatic structures. For example, the heterogeneous clustering of mineral populations, such as K-feldspar megacryst clusters (Vernon and Paterson, 2006; Memeti et al., 2014; Rocher et al., 2018), plagioclase clusters (Oppenheim et al., in review), and schlieren (Barrière, 1981; Reid et al., 1993).

The formation of compositionally defined magmatic structures in mafic magmatic systems has been the focus of studies for decades (e.g., reviews by Namur et al., 2015; Holness et al., 2017; O’Driscoll and VanTongeren, 2017). For example, the Skaergaard intrusion preserves spectacular rhythmic layering as well as channel-shaped trough structures (e.g., Wager and Brown, 1968; Irvine et al., 1998; Vukmanovic et al., 2018). Fewer studies in silicic magmatic systems, the focus of this study, are of great interest as they demonstrate that compositionally defined magmatic structures may form over a wide compositional and rheological range (e.g., Wiebe and Collins, 1998; Weinberg et al., 2001; Paterson, 2009; Clemens et al., 2020).

One subset of compositionally defined magmatic structures involves the formation of schlieren. Schlieren are igneous modally defined layers that may contain abundant hornblende, biotite, magnetite, apatite, titanite, and zircon, amongst other accessory minerals. They may be modally- or grain-size-graded. While observed in granitoid plutons worldwide, a few localities are noted for their rich abundance, and variety, of schlierenbound magmatic structures: the Ploumanac'h massif, Brittany (Barrière, 1981), the Tavares pluton, Brazil (Weinberg et al., 2001), the Halifax pluton, Nova Scotia (Smith, 1974; Clarke, 2003; Clarke et al., 2013), the Vinalhaven granite, Maine (Wiebe and Collins, 1998; Wiebe et al., 2007), and the TIC, California (e.g., Cloos, 1936; Bateman, 1992; Reid et al., 1993; Paterson, 2009).

Schlieren are commonly found in planar form (e.g., Bateman, 1992; Žák and Klomínský, 2007; Burgess and Miller, 2008; Pinotti et al., 2016), but also delineate curved boundaries of structures such as: channel-shaped magmatic troughs (e.g., Wahrhaftig, 1979; Barrière, 1981; Solgadi and Sawyer, 2008; Žák and Paterson, 2010; Alasino et al., 2019; see also Wager and Brown, 1968;
Vukmanovic et al., 2018 for mafic systems), stationary and migrating tubes, also called ladder dikes (e.g., Reid et al., 1993; Weinberg et al., 2001; Wiebe et al., 2007; Dietl et al., 2010; Clarke et al., 2013), meter-scale diapirs and plume heads (e.g., Weinberg et al., 2001; Paterson, 2009), and mafic ellipsoids (e.g., Memeti et al., 2014).

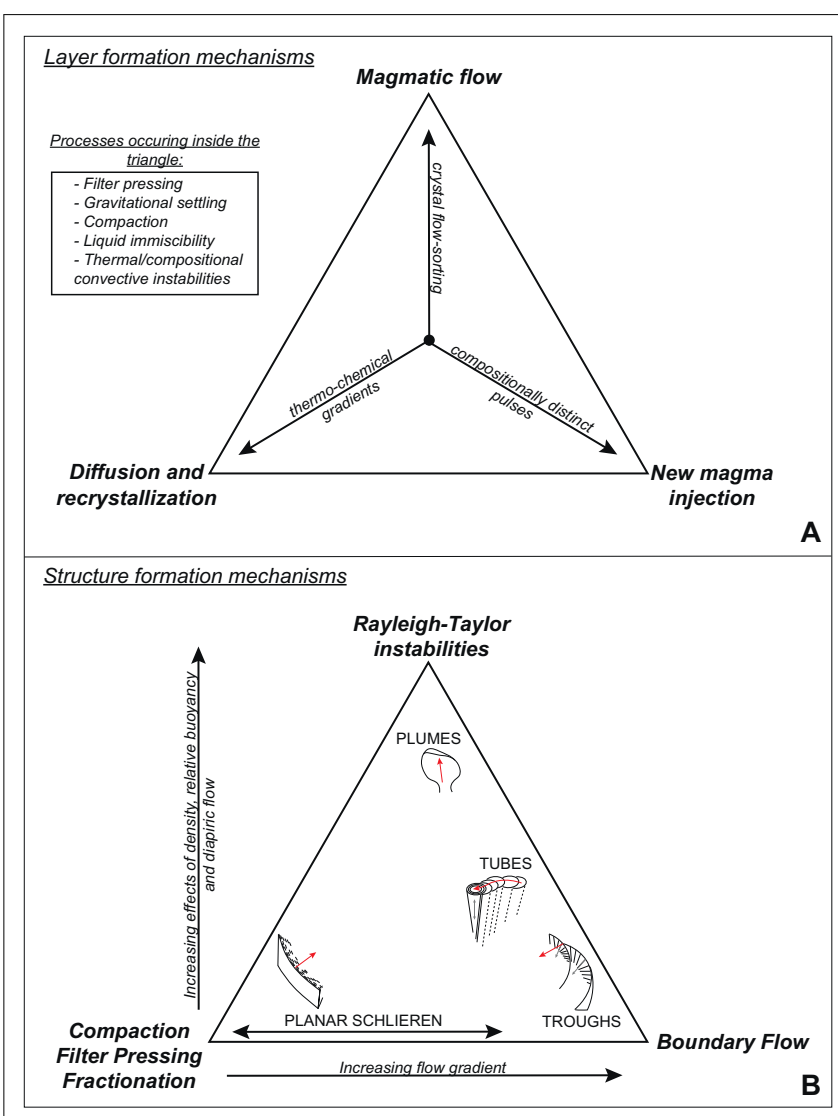

FIGURE 1 | Summary of formation mechanisms for schlieren and different magmatic structures. (A) Layer formation mechanisms. Processes listed in the box can occur in the field inside the triangle and represent combinations of end-member processes (bold). (B) Structure formation mechanisms. A summary of proposed formation mechanisms and how different schlieren-bound structures have been interpreted. Schematic diagrams show the approximate 3D geometries of each structure. Gray arrows represent interpreted motion/flow directions. Red arrows represent younging or migration directions.

In general, studies of schlieren-bound magmatic structures aim to address two related questions: (1) under what magmatic conditions and by which process(es) do schlieren form (Figure 1A) and (2) how do these processes influence, or contribute to, the variety of schlieren-bound structures of different geometries and characteristics (Figure 1B)?

Models describing schlieren formation generally fall within the range of three end-member processes, or "schools of thought" (Figure 1A; see also Solgadi and Sawyer, 2008; Barbey, 2009). The first considers schlieren as a product of incomplete mixing of new (mafic) magma injections. One example of this process 
would be the disaggregation of mafic magmatic enclaves into layers (e.g., Barbey et al., 2008; Farner et al., 2018). Related models propose that schlieren are a product of contamination and assimilation of host rock fragments (e.g., Beard et al., 2005), however, these schlieren are not considered here further in the TIC due to the rarity of host rock fragments associated with the schlieren-bound structures. The second school of thought calls upon in-situ thermochemical diffusion and recrystallization as principal mechanisms to generate modal layering in schlieren. Processes such as oscillatory nucleation and Ostwald ripening are important in these models (lower left Figure 1A; e.g., McBirney and Noyes, 1979; Glazner, 2014). The third school of thought views schlieren as resulting from magmatic flow against a more rigid boundary, in its most dynamic form by magmatic currents or avalanching, to sort crystals by size and/or density (e.g., Irvine et al., 1998; Solgadi and Sawyer, 2008; Alasino et al., 2019; Figure 1A).

Under this framework, a range of schlieren-forming processes have been proposed that involve different combinations of these three end-members (Figure 1A). These processes include thermal and compositional convective instabilities that could result from intrusion of new magma pulses or thermochemical gradients within a solidification front (Griffiths, 1986; Weinberg et al., 2001; Pons et al., 2006; Wiebe et al., 2007; Paterson, 2009; Rocher et al., 2018; Alasino et al., 2019), shear/hydrodynamic flow sorting (Cloos, 1936; Bhattacharji and Smith, 1964; Barrière, 1981; Pitcher, 1997; Clarke et al., 2013) together with compaction and filter pressing at rheologic boundaries to extract melts (Weinberg et al., 2001; Žák et al., 2007; Paterson, 2009), gravitational settling (e.g., Coats, 1936; Wager and Deer, 1939), and liquid immiscibility (e.g., Glazner et al., 2012).

Physical processes have been proposed to create the wide variety of schlieren-bound structures; structure types have been distinguished and explained by variations in magma flow geometry and intensity, magma rheology, and the importance of thermal and compositional gradients (Figure 1B) (e.g., Weinberg et al., 2001; Paterson, 2009; Wiebe et al., 2017). These variations suggest that planar schlieren could form horizontally in a largely static environment, with repeated filter pressing and/or compaction. Compaction would produce a distinct microstructural record of viscous deformation (Holness et al., 2017). However, this is not observed in Skaergaard troughs (Vukmanovic et al., 2018). Where layers are steeply dipping, graded, and deformed, magmatic flow conditions are considered to be more dynamic (Figure 1B; Paterson, 2009). For example, in this model, troughs represent magmatic erosion and boundary flow processes within a channel-shaped, basal mushy surface where minerals are deposited and flow is channelized, as shown by magmatic hornblende lineations plunging down-axis in trough basal surfaces (Solgadi and Sawyer, 2008; Paterson, 2009; Vukmanovic et al., 2018). Where relative buoyancy and density effects are significant in the magma chamber, structures such as tubes and plumes may be favored (Figure 1B; e.g., Wiebe et al., 2007; Paterson, 2009; Clarke et al., 2013). Models to describe tube formation suggest that they represent vertical magma (or volatile) pathways (e.g., Weinberg et al., 2001; Paterson, 2009; Dietl et al., 2010; Clarke et al., 2013), are a record of sinking objects (e.g., Wiebe et al., 2007; Clarke et al., 2013) or are a package of stacked trough channels (e.g., Wiebe et al., 2017). Plume heads represent examples of (now variably oriented) Rayleigh-Taylor instabilities in their dome-like heads, detached from the surrounding host (Griffiths, 1986; Paterson, 2009). The rheology of the surrounding host magma must play a role in forming and deforming structures (e.g., Wiebe and Collins, 1998; Vernon and Paterson, 2006; Hodge et al., 2012), but it is unclear if it controls the types of structures that can form.

\section{The Tuolumne Intrusive Complex}

The TIC is a $\sim 1100 \mathrm{~km}^{2}$ partially nested, composite intrusive complex, emplaced over $\sim 10$ m.y. (Calkins, 1930; Bateman and Chappell, 1979; Bateman, 1992; Coleman et al., 2004; Memeti et al., 2010; Paterson et al., 2016). From oldest to youngest, major units are: the 95-92 Ma Kuna Crest granodiorite (KC; Figure 2), the 92-90 Ma equigranular Half Dome Granodiorite (eHD; Figure 2), the 90-88 Ma porphyritic Half Dome Granodiorite (pHD; Figure 2), the 88-85 Ma Cathedral Peak Granodiorite (CP; Figure 2). Sheet-like to irregularly shaped leucogranite bodies are found throughout all units, and the largest known is the Johnson Granite Porphyry (JP; Figure 2; Kistler and Fleck, 1994; Coleman et al., 2004; Bracciali et al., 2008; Memeti et al., 2010, 2014; Paterson et al., 2016). Memeti et al. (2014) published a zircon isochron map of the TIC, using chemical abrasion-isotope dilution-thermal ionization mass spectrometry (CA-ID-TIMS) $\mathrm{U}-\mathrm{Pb}$ in zircon ages and structural observations, that illustrates the spatial relationships in zircon crystallization ages. Minor modification to this model is shown in red contours, drawn by eye following age interpretations of Memeti et al. (2010) and Paterson et al. (2016). Regions of steep age gradients, representing large age ranges over a short distance, include the western TIC margin, and the Kuna Crest lobe (Figure 4-3 in Memeti et al., 2014; Figure 2). These regions are associated with internal contacts, involving magmatic erosion and recycling along boundaries (Paterson et al., 2016). In contrast, the inner portion of the CP unit contains larger regions of similar zircon ages, depicted by shallow gradients, and indicates a general younging towards the north (Memeti et al., 2010; Figure 4-3 in Memeti et al., 2014; Figure 2).

Major and minor boundaries within the TIC are defined by a range of internal contact types (Memeti et al., 2010, 2014; Paterson et al., 2016). These include sharp and gradational contacts, and contacts defined by a change in composition and/or microstructure (Memeti et al., 2014; Paterson et al., 2016). Contacts are variable both along and across strike; for example, at Glen Aulin (GA in Figure 2), the boundary between eHD and pHD is characteristically gradational over 10$25 \mathrm{~m}$, while the younger $\mathrm{pHD}-\mathrm{CP}$ contact alternates between a gradational and sharp contact along strike at the $100 \mathrm{~m}$ scale (Paterson et al., 2016). Contacts in some cases are defined by compositionally defined magmatic structures and may have approximately contact-parallel magmatic or solid-state fabrics (Žák et al., 2007, 2009; Paterson et al., 2008). These zones are interpreted to record information about magma mingling and mixing, erosion, recycling, and preserve information about thermal or rheological magmatic conditions (Memeti et al., 2010; Paterson et al., 2016). 


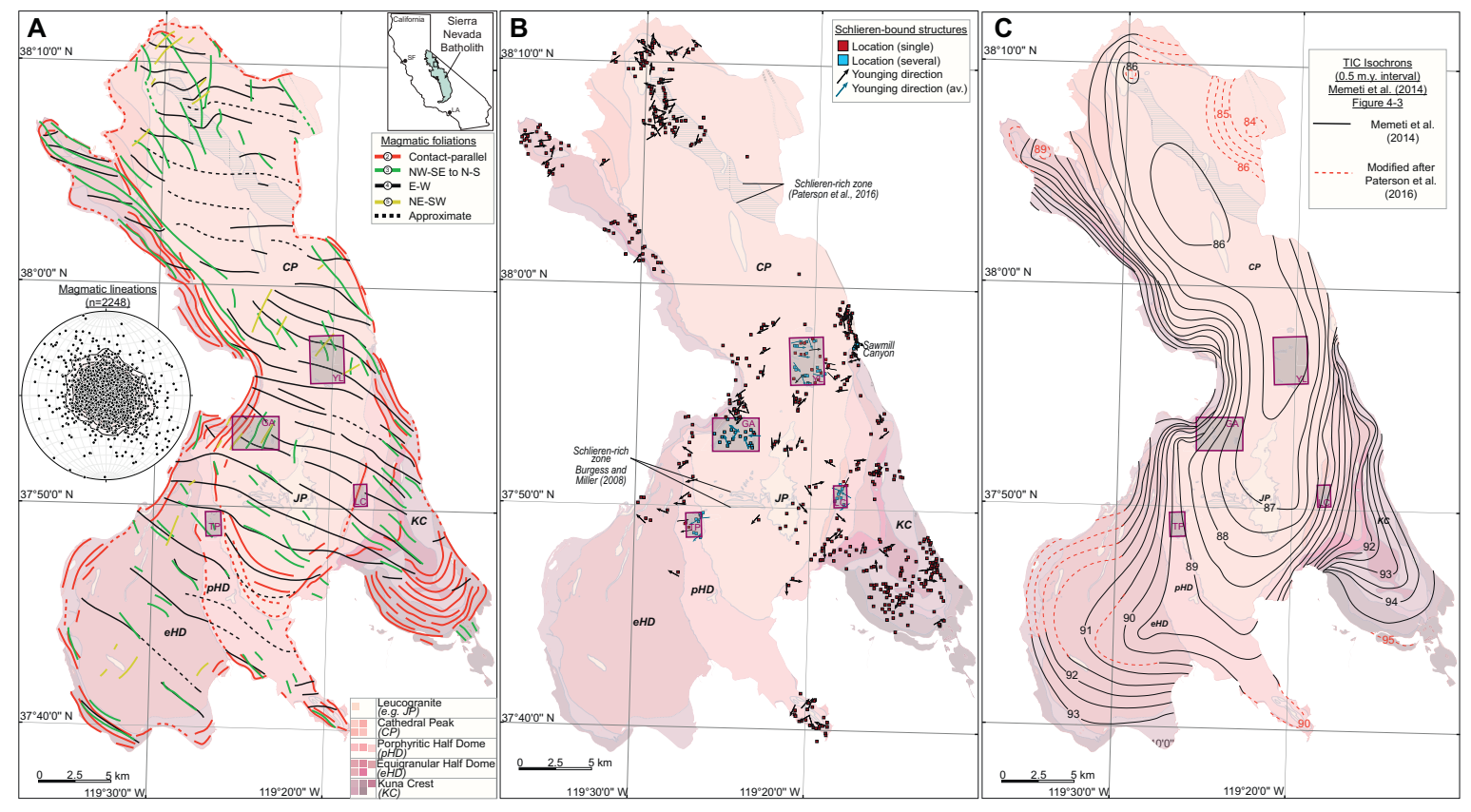

FIGURE 2 | Synthesis of magmatic structures in the Tuolumne Intrusive Complex. (A) Magmatic fabric summary. Foliation data are summarized by trend lines. Lineations are summarized on the stereonet inset. Inset map shows the location of the Tuolumne Intrusive Complex (outlined in box). (B) Map summary of schlieren-bound structural data. Points represent the locations of schlieren-bound structures. Zones of concentrated structures are highlighted in blue, and observations of younging/migration are labeled with arrows. (C) Map summary of U-Pb zircon geochronology after Figure 4-3 in Memeti et al. (2014). Isochrons shown in 0.5 m.y. intervals. Black lines represent contours on the isochron map of Memeti et al. (2014). Red dashed lines denote interpreted modified contours drawn by eye, following ages published in Memeti et al. (2010) and Paterson et al. (2016). Unit abbreviations as follows: KC, Kuna Crest granodiorite; eHD, equigranular Half Dome granodiorite; pHD, porphyritic Half Dome granodiorite; CP, Cathedral Peak granodiorite; JP, Johnson Granite Porphyry. The locations of the four mapped domains are labeled. GA = Glen Aulin; YL, Young Lakes; TP, Tenaya Peak; LC, Lyell Canyon. Data sources for map and structural data: Chesterman (1975), Bateman et al. (1988), Loetterle (2004), Burgess and Miller (2008), Paterson et al. (2008), Solgadi and Sawyer (2008), Žák et al. (2009), Memeti et al. (2010, 2014), Paterson et al. (2016), and Oppenheim et al. (in review). We acknowledge Vali Memeti, Bob Miller, and Jiri Žák for sharing field data for this synthesis.

The complex is generally more mafic in older units and more felsic in younger units; however, every unit is highly composite, and a variety of rock types occur in each unit (Bateman, 1992; Memeti et al., 2014; Paterson et al., 2016). Four lobes at the margins of the TIC are each normally zoned (Memeti et al., 2010). Kuna Crest granodiorite rocks are both the most mafic and most varied in composition, from generally equigranular, minor gabbro and diorite to tonalite, granodiorite, granite, and leucogranite. The eHD and $\mathrm{pHD}$ are granodiorite units containing euhedral $\mathrm{cm}$-size hornblende and biotite, with the addition of $<3 \mathrm{~cm} \mathrm{~K}$-feldspar phenocrysts in the pHD (Bateman and Chappell, 1979; Bateman, 1992; Memeti et al., 2014). Cathedral Peak granodiorite rocks are dominantly granodiorite to granite with K-feldspar megacrysts $2-12 \mathrm{~cm}$ forming the porphyritic texture (Bateman, 1992; Memeti et al., 2014). The most evolved, peraluminous rocks in the TIC are found in the youngest, NE corner of the CP unit (Memeti et al., 2010).

TIC rocks are metaluminous to locally peraluminous, calcalkaline compositions, spanning a wide range of $\mathrm{SiO}_{2}$ contents (48-79 wt.\%) (Bateman and Chappell, 1979; Bateman, 1992; Memeti et al., 2014). Hornblende analyses indicate that all units experienced crystal accumulation and/or melt loss to varying degrees, contributing to the wide variation in rock type (Barnes et al., 2016; Werts et al., 2020). The considerable compositional overlap between units in major and trace elements, as well as isotopes, has been attributed to a combination of fractionation and mixing processes involving multiple magma sources; the depth that these processes occur is debated (e.g., Kistler et al., 1986; Bateman, 1992; Gray et al., 2008; Coleman et al., 2012; Memeti et al., 2014; Barnes et al., 2016).

Mapping by Cloos (1936), Bateman et al. (1983), Žák and Paterson (2005), and Žák et al. (2007) revealed multiple, time-transgressive magmatic fabrics within the TIC, defined by the alignment of hornblende, biotite, plagioclase, and quartz and K-feldspar to a lesser extent. Four magmatic fabrics were distinguished: Type 1 fabric is associated with local compositionally defined structures (e.g., schlieren) and is generally discordant to, or overprinted by, additional regionally extensive fabrics. Type 2 foliations, approximately margin parallel, but in detail at an angle to internal contacts, are typically the earliest formed (Žák et al., 2007). While type 3 (NW-SEstriking) and 4 (E-W-striking) fabrics may show contradictory or ambiguous overprinting relationships to each other at a single outcrop, Žák et al. (2007) concluded that the type 4 fabric 

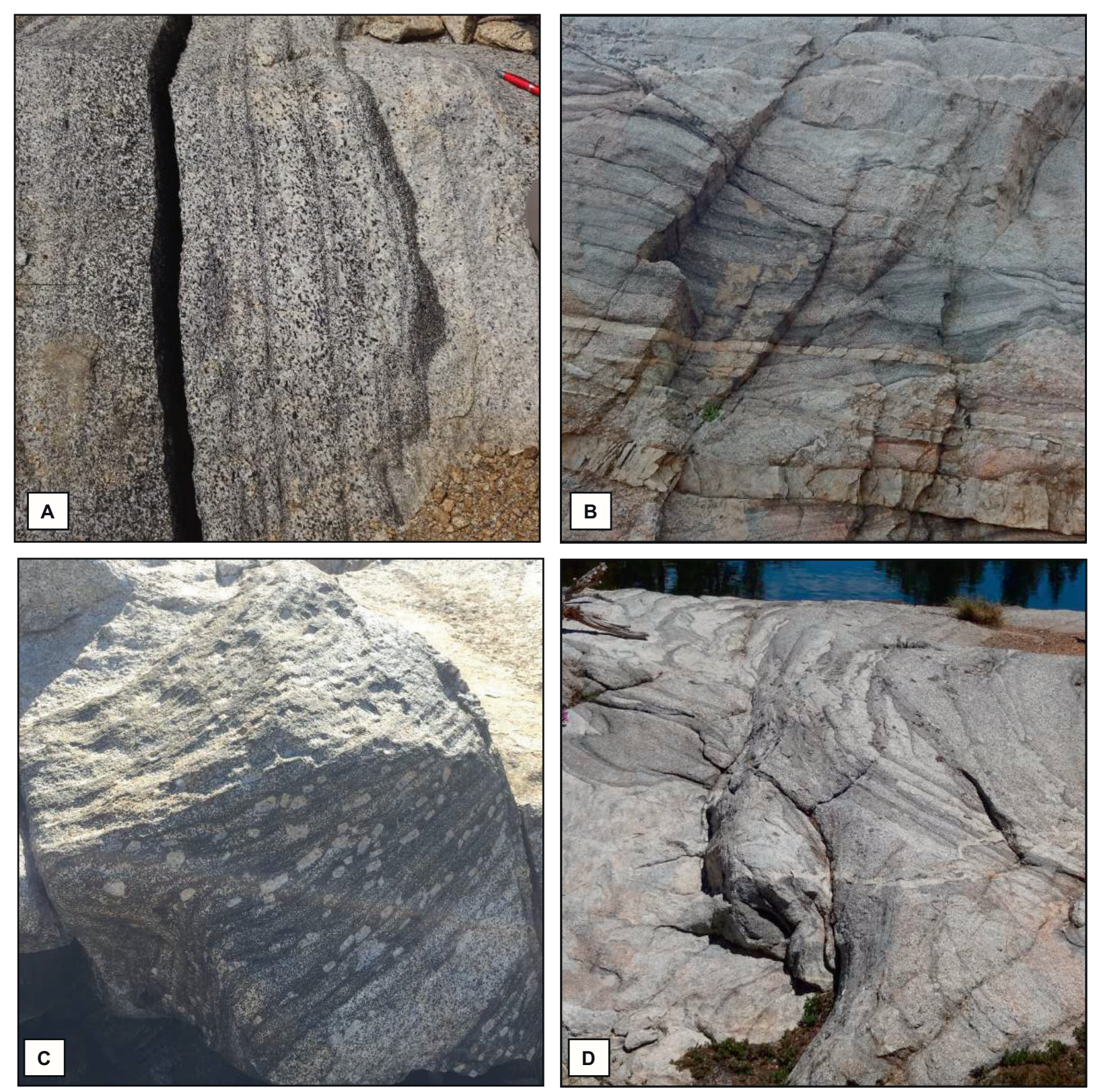

FIGURE 3 | Field photos of planar schlieren and trough structures. (A) Modally and grain-size graded schlieren layering in eHD, Sawmill Canyon area. Layers have a sharp, fine-grained base, and increase in grain size while reducing the amount of hornblende and biotite towards the right of the photo before the next layer forms. Pen for scale. (B) Erosion and redeposition of schlieren trough packages in CP at Sawmill Canyon. The package is upward-younging, and locally contains K-feldspar megacrysts. Leucogranite dikes cut the entire section. (C) Megacryst-bearing schlieren troughs showing low-angle truncation. Photo courtesy of J. McColl.

(D) Complex schlieren trough packages with interlayered felsic material that is distinct from the surrounding host. Sawmill Canyon area.

is generally younger than type 3. Magmatic lineation plunges steeply in all cases (Žák et al., 2007).

\section{Schlieren-Bound Magmatic Structures in the Tuolumne Intrusive Complex}

The earliest studies of schlieren-bound magmatic structures in the TIC by Cloos (1936), Bateman (1992), and Reid et al. (1993) documented field characteristics of planar schlieren, troughs, and tubes (referred to as ladder dikes). These included planar to concave upward schlieren geometries with horizonal to sub-vertical dips, reverse (size) graded layering, and crossbedding. Schlieren were proposed to form by either gravitational settling of crystals (e.g., Coats, 1936) or crystal flow-sorting (e.g., Cloos, 1936; Bhattacharji and Smith, 1964). Reid et al. (1993) suggested that the schlieren bounding tubes "settled from crystal slushes flowing through narrow vertical channels." Repeated events of schlieren deposition and erosion, and 

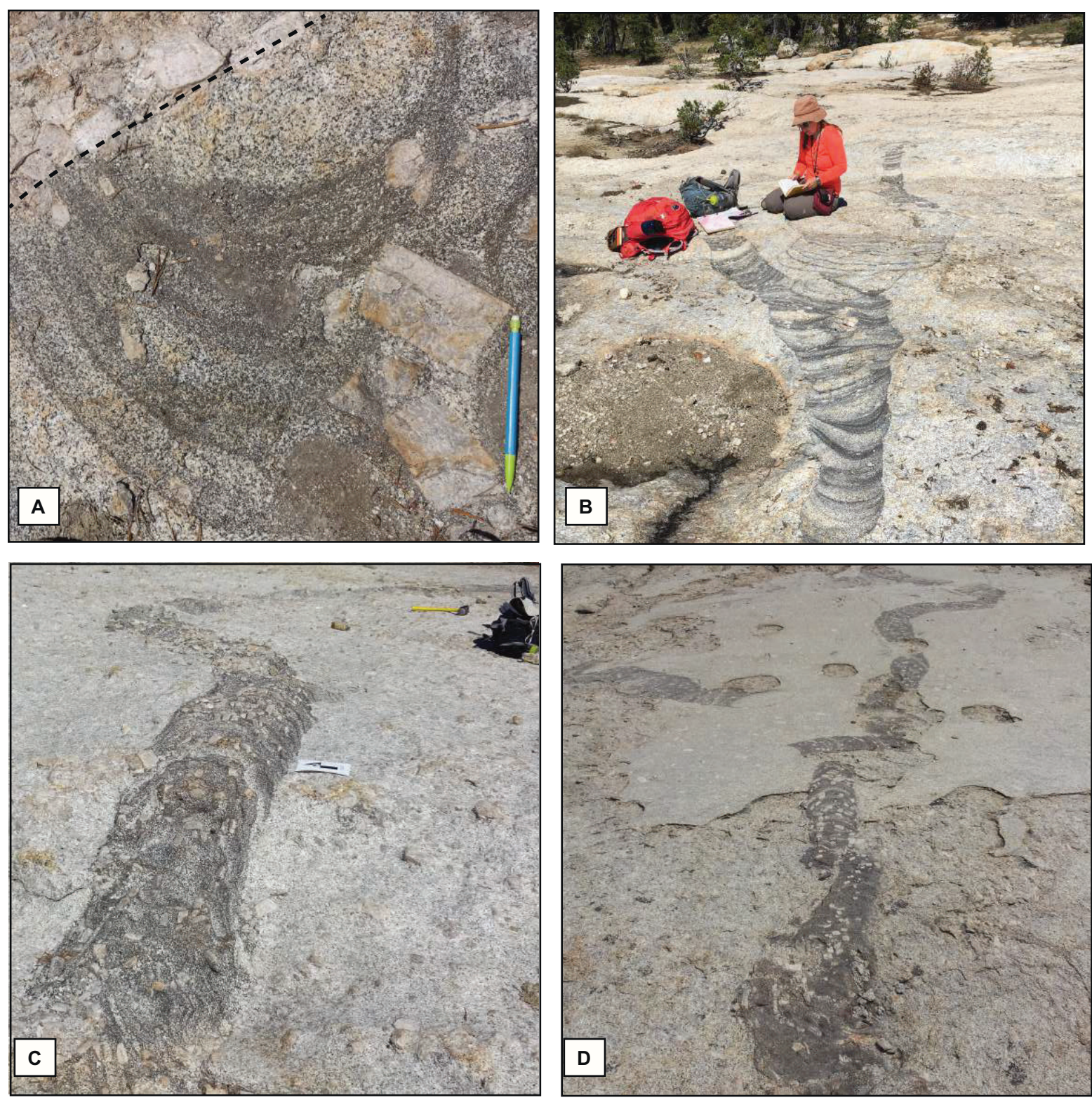

FIGURE 4 | Field photos of magmatic tubes. (A) Stationary tube truncated by host CP in the Glen Aulin area. Dashed line shows the contact where the tube is truncated by megacrystic CP. This tube contains at least 6 rings and unusually, the K-feldspar megacrysts within the structure are larger than the surrounding host megacrysts and also oriented at high angle to the schlieren rings. (B) Bifurcated migrating tube in the Glen Aulin area. This steeply dipping tube is $\sim 10 \mathrm{~m}$ in length, younging towards the field mapper. The diameter of the tube varies in size as it migrates, and in places is re-intruded by host CP. Photo from Paterson et al. (2018). (C) $6 \mathrm{~m}$ long migrating tube, migrating towards the bottom of the photo. These densely concentrated rings contain $\mathrm{K}$-feldspar megacrysts. (D) $11 \mathrm{~m}$ migrating tube and $3 \mathrm{~m}$ migrating tube, Glen Aulin area. Segments of the longer tube have been re-intruded by host CP magma and rotated. The K-feldspar megacrysts align with the mafic minerals in the schlieren rings. Migration direction is towards the bottom of the photo (see also Hodge et al., 2012 for more information on this structure).

gradients in magma flow intensity were proposed to explain field observations of the layers (Bateman, 1992; Reid et al., 1993). Bateman (1992) first observed the map-scale pattern of outward-dipping planar schlieren towards older, outer units and interpreted this pattern to result from magma tilting and shearing on the partly solid margins of the magma chamber, driven by emplacement of new magma at the core of the complex.
Reid et al. (1993) noted that migrating tubes in the TIC are spatially clustered, and that the minerals in schlieren defining tubes, while highly concentrated, matched the assemblage of the surrounding host. Whole-rock major and trace element data supported interpretations that schlieren are cumulate rocks derived from main-sequence TIC magmas, with some derived from more mafic magmas. Notably, schlieren are depleted in $\mathrm{Al}_{2} \mathrm{O}_{3}$, and other elements necessary to form plagioclase, 
relative to the main-sequence TIC rocks (Reid et al., 1993). Because of this, crystal accumulation associated with schlieren formation was not considered a viable mechanism to generate the compositional variety of main-sequence TIC rocks.

Subsequent studies investigated the interaction between structure formation and local- to regional-scale magmatic deformation. Loetterle and Bergantz (2003) interpreted deformation-related structures such as schlieren slumping to represent loading of a crystal mush at low melt fractions between 20 and 50\%. Žák and Paterson (2005) mapped sheeted zones in the TIC and found outward younging planar schlieren, troughs, and tubes that formed during and after assembly of the sheets. These structures were subsequently deformed by magmatic faults and folds and overprinted by magmatic fabrics (Žák and Paterson, 2005). Domains with the most complex structural and petrologic relationships were found at irregularly shaped contacts, such as corners (Žák and Paterson, 2005).

Paterson et al. (2008) interpreted magmatic structures within the Sawmill Canyon sheeted zone as local thermal-mechanical instabilities in crystal-rich magmas. Schlieren are enriched by 3-4-fold in the high-field-strength elements (HFSE) relative to the surrounding host, but $\mathrm{K}, \mathrm{Na}, \mathrm{Sr}$, and $\mathrm{Rb}$ remain constant, consistent with the enrichment and depletion trends identified by Reid et al. (1993). Least-squares modeling of wholerock data (Albarède, 1996) required $\sim 30 \%$ accumulation of the constituent minerals to form schlieren. Leveraging zircon saturation temperatures calculated for TIC magmas (Miller et al., 2007), the authors proposed schlieren formation to occur between $\sim 760^{\circ} \mathrm{C}$ and the solidus. The structures are locally intensely magmatically deformed, but also record the regional strain by overprinted magmatic fabric, which likely became effective when the local magma flow field waned (Paterson et al., 2008). The authors emphasized the importance of rheologic flow and stress gradients over gravitational forces alone in forming steeply dipping schlieren.

The Sawmill Canyon structures were also studied from a microstructural and chemical perspective by Solgadi and Sawyer (2008). Within planar schlieren and trough structures, they identified multiple hornblende populations corresponding to the major host rock units in the area $(\mathrm{KC}, \mathrm{HD}$, and CP units), and thus interpreted schlieren to represent crystal mixtures. Hornblende did not show intra-layer compositional gradients, and thus did not form from a gradually evolving melt composition or in-situ fractionation (Solgadi and Sawyer, 2008). All minerals within schlieren gradually were rotated away from basal, layer-parallel orientations towards the top of the layer. These observations together with field observations of erosional features led to the interpretation that dense minerals were mobilized and segregated into schlieren by high-energy "hyper-concentrated (magmatic) sedimentary gravity flows." As the flow waned, crystals were deposited, and as crystal separation became less efficient, graded layers formed. Changing flow intensities or conditions could explain different types of schlieren layers and structures.

Burgess and Miller (2008) identified a densely concentrated, heterogeneously distributed $1-2 \mathrm{~km}$ wide zone of planar schlieren and tubes near Tenaya Lake. The majority of planar schlieren are oriented at low-angles to the adjacent contact between $\mathrm{pHD}$ and CP. They viewed schlieren forming in areas of strong rheological contrasts (along boundaries), and disrupted schlieren (faulted, folded, and re-intruded) as evidence for a destabilized crystal mush. In addition to whole-rock elemental trends comparable with earlier schlieren studies (Reid et al., 1993; Paterson et al., 2008; Solgadi and Sawyer, 2008), whole-rock $\mathrm{Sm}-\mathrm{Nd}$ and $\mathrm{Rb}-\mathrm{Sr}$ isotope compositions between a schlieren sample and host sample were indistinguishable in $\varepsilon \mathrm{Nd}_{i}$, but the schlieren had slightly lower ${ }^{87} \mathrm{Sr}^{86} \mathrm{Sr}_{i}$ values than the host CP. Their interpretations focused on the mixing processes that generated the relatively narrow range of isotope compositions in the $\mathrm{CP}$ unit.

Paterson (2009) described the key characteristics of several TIC schlieren-bound structures, including the addition of plume heads, diapirs, and pipes, and outlined their structurespecific dynamic features. Paterson (2009) noted that structures were clustered in space across each unit of the TIC, with certain patterns: Troughs young outwards, potentially favoring low-stress sites, and tube structures are statistically vertically plunging, and thus may be useful paleo-vertical indicators. The implications of this study were that this group of structures together preserve a time-transgressive history of magma mobility in a crystal-rich, already-constructed magma chamber. Future, open questions concerned the spatial clustering of structures, and whether schlieren-bound structures might record tectonic information.

Žák et al. (2009) modeled whole-rock schlieren compositions in the Mammoth Peak sheeted zone to show that schlieren were enriched in major and trace elements from $\sim 150 \%$ (large-ion-lithophile elements, or LILE) to $>500 \%$ [middle rare earth elements (MREE), $\mathrm{Fe}, \mathrm{Mg}, \mathrm{Mn}$ ] over the adjacent host granitoids. Some minerals in schlieren form glomerocrysts (e.g., magnetite), separated by interstitial quartz and K-feldspar. The clots (if formed prior to structure formation) have a greater density than the individual minerals and thus may enhance the effects of gravitational settling and flow-sorting processes (Žák et al., 2009). Žák and Paterson (2010) further explored the dynamic interplay between regional tectonics and magmatic processes at magmatic internal contacts, showing that the magmatic tubes were statistically elongated parallel to the regional NW-SE magmatic foliation, indicating that the local-flow structures were experiencing the regional stress when they formed.

Hodge et al. (2012) explored the spatial clustering of tube structures at Glen Aulin, finding regular spacing between clusters of tubes of 1-10 m. In this area, tubes were statistically oriented perpendicular to the nearby CP-pHD contact. Using detailed maps and structural measurements, they proposed that tube structures were buoyant magma plumes that were oriented and deformed by rheological contrasts between the buoyant plume and the host magma. They defined regimes in which structures were most likely to be deformed (ponding or tension) and estimated a yield strength of the magma on the order of $10^{3} \mathrm{~Pa}$.

In contrast to previous studies that view schlieren-bound structures originating from physical, flow-dominated processes, Glazner et al. (2012) and Bartley et al. (2013) proposed 
a chemically driven mechanism for schlieren formation in migrating tube structures. In this model, the felsic inner core represents a conduit for late, Si-rich immiscible liquids, while the dense, Fe-rich liquid is deposited at the tube base, forming schlieren. These studies do not address the field observations of concentric magmatic fabrics in the schlieren walls of the tube, as well as processes that could produce the migrating pattern.

Memeti et al. (2014) reviewed the wide array of TIC magmatic structures in the context of regional geochronology and petrology of the main-sequence rocks. They mapped a regionally extensive planar schlieren zone in the north of the $\mathrm{CP}$ unit (Figure 2). U-Pb in zircon CA-ID-TIMS dates from zircons in schlieren and surrounding host overlapped, and thus were interpreted to be locally derived. Paterson et al. (2016) expanded these datasets and outlined several lines of evidence for magmatic erosion and recycling in the TIC main sequence rocks, that included schlieren-bound structures. Extrapolating from the known occurrence and approximate density of structures, they estimated that the TIC contains $>9000$ schlieren-bound magmatic structures with local erosional features.

Wiebe et al. (2017) proposed a model for the formation of migrating tube structures involving progressive downward flow and stacking of schlieren-bounded channels (akin to trough channels). They suggest that tubes migrate outwards (towards older units) when new magma pulses are intruded in the center of the complex (e.g., Bateman, 1992).

Bartley et al. (2018) interpreted schlieren layers at Tenaya Lake, which grade towards older units in the west, as one part of "kilometer-scale lithologic cycles" where regional E-W extension makes space for the emplacement of N-S striking dikes. In this model, the schlieren (representing early crystallizing components) concentrate in the lower part of the dike to form modal, graded layers. This study does not address the spatially variable orientations of schlieren, deformation of schlieren, more complex geometries observed in the same area as planar, graded schlieren (e.g., tubes-Burgess and Miller, 2008), as well as the lack of graded layering in other parts of the Tenaya Lake area (e.g., the host equigranular Half Dome unit).

Building on previous studies of schlieren-bound magmatic structures in the TIC, this study will focus on characterizing and quantifying observations of planar schlieren, troughs, tubes, and plumes at multiple spatial scales.

\section{MATERIALS AND METHODS}

\section{Field Data}

\section{Regional Compilations}

Ongoing regional compilations of TIC datasets are summarized here in order to provide context to schlieren-bound structure data. Existing regional mapping (>1:24,000 scale) and new $1: 10,000$ scale maps of the TIC, including information about the nature of contacts from previous studies (Žák and Paterson, 2005; Paterson et al., 2008, 2016; Žák et al., 2009; Memeti et al., 2010, 2014), were compiled and digitized using ESRI ArcGIS 10.6.1 (for a list of map sources, see Figure 2). The compilation of TIC fabric data is the result of $\sim 50$ years of field mapping by the USGS (Chesterman, 1975; Bateman et al., 1983) and others (Žák and Paterson, 2005; Žák et al., 2007, 2009; Burgess and Miller, 2008; Paterson et al., 2008; Memeti et al., 2010; Aldiss, 2017; McColl, 2017; this study). Fabric data from the USGS quadrangle maps (Chesterman, 1975; Bateman et al., 1983) were digitized by Graham (2012) as part of the Geologic Resources Inventory Project for Yosemite National Park and Devils Postpile National Monument. (2006-2012) compositionally defined magmatic structures, such as K-feldspar megacryst clusters, are reported widely in the TIC, however, they do not form part of the digital database. Schlieren-bound magmatic structure data were digitized from the same sources as the fabric data, and assigned locations, orientations and defining characteristics (e.g., structure type), where available. In legacy data (pre-2009), the schlieren-structure type was not always specified (e.g., planar schlieren, trough, tube, plume). In these cases, strike and dip measurements were assigned as planar schlieren by default.

\section{Mapping Domains}

Mapping in four domains at $1: 5,000$ to $1: 10,000$ scale was performed over four field seasons (see Figure 2 for domain locations). Domains were selected in a symmetrical pattern around the center of the southern CP region in locations that were variably proximal to contacts with the older $\mathrm{pHD}$ unit (e.g., domains are adjacent to, traversed across, or distanced from, the major unit contact) to encompass a range of magmatic conditions. Domains were mapped in order to provide information on the distribution of magmatic structures across areas $2-12 \mathrm{~km}^{2}$ in size. Mapping focused on characterizing the location, type, and orientation of schlierenbound structures within each domain, and documenting their relationships to lithology, magmatic fabrics, and contacts. Structures studied include planar schlieren, troughs, tubes (stationary and migrating) and plumes in each domain. Less emphasis was placed on mafic ellipsoids, K-feldspar clusters and K-feldspar pipes; the location of these structures was noted in the field.

\section{Grid Mapping}

Individual structures or outcrops were selected for grid mapping at 1:10-1:100 scale to highlight key field relationships and as a tool to unravel complicated structure. Each grid square was drawn out with a tape measure and string. Measurements were taken of magmatic fabrics and all schlieren-bound structures in each square. Photographs aided in digitizing the map.

\section{Taking Structural Measurements and Determining Younging/Migration Directions}

Measurements of the strike, dip and intensity of the magmatic fabric(s) were made at approximately regular intervals across domains. When recording information about schlieren-bound structures specifically, a protocol was implemented as follows: (1) record structure type and approximate dimensions; (2) measure strike and dip of planar features (e.g., planar schlieren strike and dip); (3) measure trend and plunge of linear features in the structure (e.g., trough or tube axis); (4) measure 

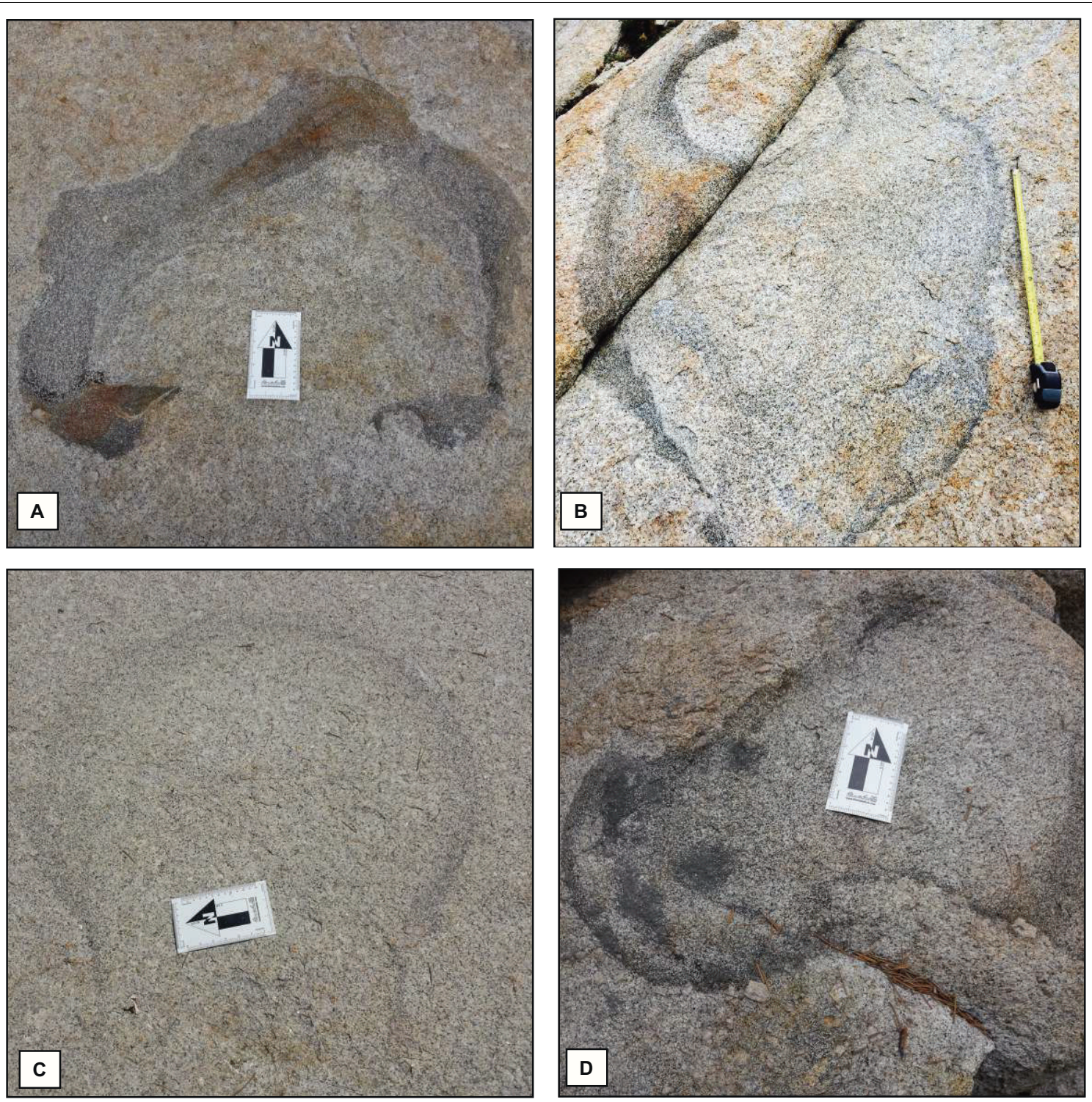

FIGURE 5 | Field photos of plumes. (A) Plume with a $\sim 0.5 \mathrm{~m}$ diameter and thick schlieren head, Glen Aulin area. The thickness of the schlieren varies around the margins of the plume, is sharpest at the contact with host CP, and more diffuse towards the interior. (B) $\sim 1 \mathrm{~m}$ wide plume head, Young Lakes area. As in panel (A), the schlieren is sharpest at the contact with host CP and is diffuse towards the interior. The plume is re-intruded by host CP. (C) Diffuse plume with tail preserved, Lyell Canyon area. This diffuse type of schlieren is common in the central regions of the CP unit (see also Pothole Dome area; Paterson, 2009). (D) Plume with well-defined head and elongate tail. The interior of this plume has a clear compositional difference with the surrounding host CP.

younging or migration directions (see below and Figure 1B); and (5) note additional relative timing indicators if observed, such as overprinting relationships of fabrics, or relationships between structures.

Planar schlieren younging directions are measured if they are reverse graded; the younging azimuth is towards coarser grained, less modally concentrated compositions, perpendicular to the strike of the layer (Figures 1B, 3A). Troughs show evidence of layer erosion and truncation of older troughs. These cross-cutting relationships define a relative younging direction that is measured perpendicular to the trough axis (Figures 1B, 3B-D). A strike and dip measurement can also be taken at this point to constrain $3 \mathrm{D}$ geometry. In stationary tubes, usually the younging is inward, and so a migration direction is not measured (Figure 4A). Sharp erosional contacts between crescentshaped schlieren rings define the migration direction of a (migrating) tube structure (Figures 1B, 4B-D). To measure plume head migration, azimuthal younging is measured in the direction perpendicular, and towards the convex side of the plume head (Figures 1B, 5A-D). Measurements are made in $3 \mathrm{D}$ where possible, but working on glacially polished surfaces resulted in some measurements in 2D (e.g., azimuthal younging/migration directions). 


\section{Statistical Analysis of Structural Measurements From Domains}

Statistical analysis of structural measurements (strike, dip, younging, or migration directions) was performed for each type of structure (foliation, planar schlieren and troughs, tubes, and plumes) in each domain. Structural data was separated by unit before analysis. Stereonets and rose diagrams were created using Stereonet 10 software (Cardozo and Allmendinger, 2013), and mean vectors and cylindrical best fits of the data within the program were used to estimate average orientations.

Angular difference was calculated as [foliation strike schlieren strike] (planar schlieren and troughs only) at each field station. The angular difference was converted to a $0^{\circ}-90^{\circ}$ scale (i.e., ignoring dip direction). In cases where no fabric measurement was taken, the fabric strike from the adjacent station was used. For stations with two or more fabrics, the angular difference was calculated for each foliation measurement at that station. The same applies for multiple schlieren strike measurements at one station. Foliation measurements were assigned to a Type $(2,3$, or 4$)$ based on their orientation, and following the protocol used in the regional scale map.

\section{Sample Collection and Analysis}

Samples were collected from each of the main TIC units, from a range of schlieren-bound structure types (sample locations provided in Supplementary Material). The largest group consists of planar schlieren and troughs, with a smaller subset of tube and plume samples. In many cases, multiple samples were collected from a single structure, or outcrop, and divided into "schlieren," "felsic," and "adjacent host" components. Samples were used for petrographic analysis and whole-rock geochemistry.

\section{Petrography}

Seven representative samples were selected for petrographic description and mineral mode estimation: two samples each from the pHD and $\mathrm{KC}$ units, and three samples from the $\mathrm{CP}$ unit (samples listed in Table 1). In each unit, one schlieren sample from a trough and an adjacent host sample were studied. In the CP unit, one additional schlieren sample was studied from a migrating tube structure adjacent to the sampled trough. Thin section images were traced and scanned into ImageJ software (Schindelin et al., 2012) where they were subsequently processed using the Color Threshold tool to isolate individual phases. We then used ImageJ to calculate the proportion of mineral phases in each sample. Quartz and feldspar proportions were estimated by difference (subtracted the mafic phases) and then estimated under an optical microscope.

\section{Whole Rock Geochemistry}

A subset of 19 samples, consisting of 9 schlieren, 5 felsic components, and 5 host samples, were analyzed by ICP-MS at Activation Laboratories, or by XRF and ICP-MS at the University of Washington, GeoAnalytical Laboratory for major, trace, and rare-earth element (REE) concentrations (samples are labeled by method in Table 2). Kuna Crest granodiorite major, trace, and REE sample data and materials were provided by V. Memeti. Six of these samples of a trough and adjacent host, each from the CP,

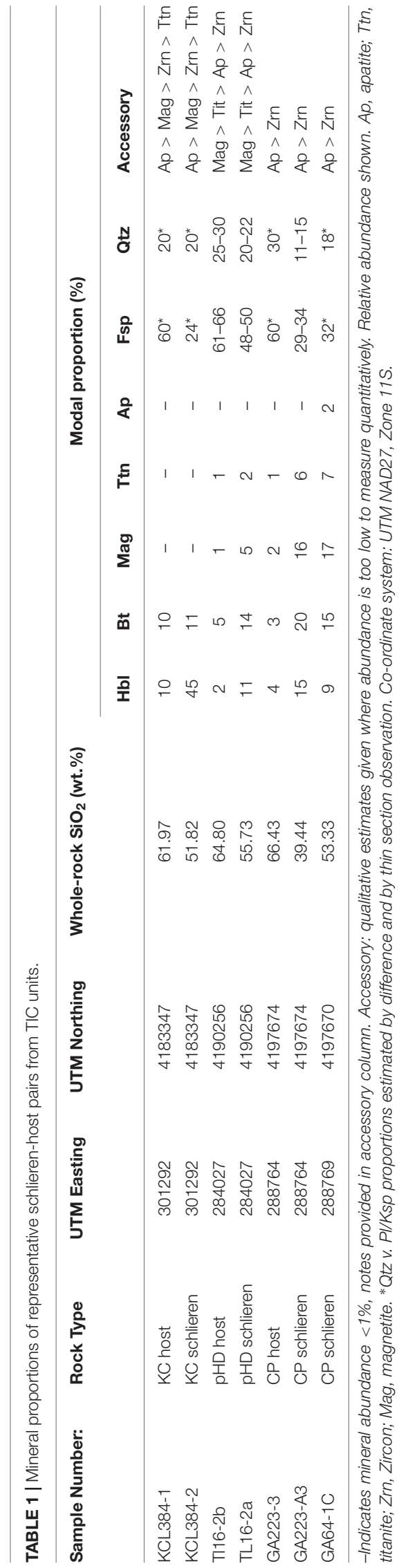


TABLE 2 | Whole-rock geochemistry for representative schlieren, host, and felsic samples.

\begin{tabular}{|c|c|c|c|c|c|c|c|c|c|}
\hline \multirow[b]{2}{*}{ Sample number } & \multicolumn{3}{|c|}{ Kuna Crest granodiorite } & \multicolumn{2}{|c|}{$\begin{array}{l}\text { Porphyritic Half Dome } \\
\text { granodiorite }\end{array}$} & \multicolumn{4}{|c|}{ Cathedral Peak granodiorite } \\
\hline & KCL384- $1^{*}$ & KCL384-2* & $\mathrm{KCL}-386^{\star}$ & TL16-2b & TL16-2a & GA223-3 & GA223-A3 & GA64-1c & GA64-2 \\
\hline Sample type & host & Schlieren & Felsic layer & Host & Schlieren & Host & Schlieren & Schlieren & Felsic layer \\
\hline UTM easting & 0301292 & 0301292 & 0301409 & 0283945 & 0283945 & 0288682 & 0288682 & 0288687 & 0288687 \\
\hline UTM northing & 4183347 & 4183347 & 4183151 & 4190456 & 4190456 & $4 \mathrm{E}+06$ & 4197874 & 4197870 & 4197870 \\
\hline \multicolumn{10}{|c|}{ Major oxides (wt \%) } \\
\hline $\mathrm{SiO}_{2}$ & 61.97 & 51.82 & 68.53 & 64.80 & 55.73 & 66.43 & 39.44 & 53.33 & 69.26 \\
\hline $\mathrm{TiO}_{2}$ & 0.78 & 1.18 & 0.30 & 0.67 & 1.59 & 0.62 & 3.68 & 1.95 & 0.37 \\
\hline $\mathrm{Al}_{2} \mathrm{O}_{3}$ & 16.28 & 9.54 & 17.38 & 15.67 & 13.68 & 16.33 & 10.32 & 13.66 & 15.75 \\
\hline $\mathrm{FeO}_{t}$ & 5.72 & 11.38 & 1.56 & 4.83 & 12.57 & 4.32 & 24.84 & 16.33 & 2.71 \\
\hline $\mathrm{Fe}_{2} \mathrm{O}_{3}$ & - & - & - & - & - & - & - & - & - \\
\hline $\mathrm{MnO}$ & 0.10 & 0.35 & 0.02 & 0.08 & 0.20 & 0.08 & 0.37 & 0.22 & 0.06 \\
\hline $\mathrm{MgO}$ & 2.63 & 9.45 & 0.63 & 1.43 & 2.61 & 1.15 & 5.13 & 2.37 & 0.71 \\
\hline $\mathrm{CaO}$ & 5.34 & 8.86 & 4.16 & 3.67 & 4.04 & 3.95 & 5.97 & 4.18 & 3.09 \\
\hline $\mathrm{Na}_{2} \mathrm{O}$ & 3.44 & 1.70 & 3.91 & 3.97 & 2.67 & 4.76 & 2.03 & 3.56 & 4.44 \\
\hline $\mathrm{K}_{2} \mathrm{O}$ & 2.78 & 2.30 & 3.35 & 3.04 & 5.20 & 2.39 & 2.81 & 2.65 & 2.71 \\
\hline $\mathrm{P}_{2} \mathrm{O}_{5}$ & 0.19 & 0.71 & 0.10 & 0.21 & 0.53 & 0.23 & 1.12 & 0.54 & 0.18 \\
\hline Total & 99.22 & 97.30 & 99.94 & 98.83 & 99.41 & 100.56 & 96.07 & 98.82 & 99.72 \\
\hline \multicolumn{10}{|c|}{ Trace elements (ppm) } \\
\hline Cs & 6.0 & 8.3 & 4.5 & 7.5 & 4.3 & 3.3 & 10.8 & 5.6 & 3.0 \\
\hline $\mathrm{Rb}$ & 114 & 94 & 104 & 174 & 118 & 90 & 205 & 136 & 99 \\
\hline $\mathrm{Sr}$ & 522 & 113 & 570 & 452 & 583 & 712 & 248 & 543 & 729 \\
\hline $\mathrm{Ba}$ & 654 & 256 & 844 & 1918 & 436 & 381 & 363 & 644 & 594 \\
\hline La & 40.3 & 44.5 & 19.1 & 115.0 & 37.9 & 39.8 & 204.0 & 109.0 & 23.0 \\
\hline $\mathrm{Ce}$ & 72.3 & 105.2 & 35.3 & 205.0 & 65.6 & 78.0 & 454.0 & 231.0 & 41.4 \\
\hline $\operatorname{Pr}$ & 7.4 & 14.7 & 3.9 & 22.1 & 6.8 & 8.5 & 52.4 & 26.4 & 4.5 \\
\hline $\mathrm{Nd}$ & 26.6 & 68.6 & 14.5 & 82.2 & 25.2 & 29.8 & 192.0 & 96.7 & 16.5 \\
\hline $\mathrm{Sm}$ & 5.0 & 20.3 & 2.9 & 13.4 & 4.2 & 5.0 & 31.3 & 15.5 & 2.3 \\
\hline $\mathrm{Eu}$ & 1.3 & 2.2 & 0.8 & 2.9 & 1.0 & 1.2 & 6.5 & 3.3 & 0.6 \\
\hline $\mathrm{Gd}$ & 3.9 & 20.9 & 2.2 & 8.7 & 2.9 & 3.4 & 20.1 & 9.9 & 1.5 \\
\hline $\mathrm{Tb}$ & 0.6 & 3.6 & 0.3 & 1.2 & 0.4 & 0.4 & 2.6 & 1.2 & 0.2 \\
\hline Dy & 3.1 & 22.5 & 1.8 & 5.9 & 1.8 & 2.1 & 13.2 & 6.3 & 0.9 \\
\hline $\mathrm{Ho}$ & 0.6 & 4.5 & 0.3 & 1.0 & 0.3 & 0.4 & 2.3 & 1.1 & 0.2 \\
\hline $\mathrm{Er}$ & 1.6 & 12.7 & 0.9 & 2.8 & 0.9 & 1.1 & 6.5 & 3.1 & 0.5 \\
\hline $\mathrm{Tm}$ & 0.2 & 1.8 & 0.1 & 0.4 & 0.1 & 0.2 & 0.9 & 0.4 & 0.1 \\
\hline $\mathrm{Yb}$ & 1.6 & 10.9 & 0.8 & 2.7 & 0.8 & 1.0 & 6.2 & 2.9 & 0.5 \\
\hline Lu & 0.3 & 1.6 & 0.1 & 0.4 & 0.1 & 0.1 & 1.0 & 0.5 & 0.1 \\
\hline U & 7.4 & 6.3 & 4.4 & 16.1 & 6.2 & 3.5 & 15.8 & 9.0 & 1.8 \\
\hline Th & 29.8 & 25.4 & 9.4 & 85.5 & 23.3 & 15.4 & 42.1 & 29.7 & 5.9 \\
\hline Y & 17 & 128 & 10 & 32 & 10 & 12 & 72 & 34 & 5 \\
\hline $\mathrm{Nb}$ & 9 & 18 & 5 & 21 & 6 & 11 & 60 & 31 & 6 \\
\hline $\mathrm{Zr}$ & 131 & 266 & 94 & 556 & 157 & 212 & 1313 & 941 & 116 \\
\hline $\mathrm{Hf}$ & 4.0 & 8.5 & 2.9 & 14.2 & 3.9 & 5.6 & 17.6 & 23.2 & 3.3 \\
\hline $\mathrm{Ta}$ & 0.9 & 1.3 & 0.7 & 2.3 & 0.7 & 1.1 & 5.1 & 2.6 & 0.6 \\
\hline Co & N.A. & N.A. & N.A. & 18 & 9 & 7 & 36 & 21 & 5 \\
\hline $\mathrm{Cr}$ & 13 & 62 & 5 & B.D.L & 20 & B.D.L & 20 & B.D.L. & B.D.L. \\
\hline $\mathrm{Pb}$ & 13 & 7 & 18 & 18 & 17 & 15 & 8 & 12 & 16 \\
\hline V & 130 & 304 & 35 & 237 & 78 & 72 & 517 & 358 & 43 \\
\hline $\mathrm{Zn}$ & 77 & 158 & 28 & 190 & 80 & 90 & 440 & 280 & 70 \\
\hline \multicolumn{10}{|l|}{ Isotope ratios } \\
\hline${ }^{87} \mathrm{Sr}^{86} \mathrm{Sr}_{i}$ & 0.705991 & 0.706224 & N.A. & 0.706517 & 0.706656 & 0.706639 & N.A. & 0.706607 & N.A. \\
\hline std error (\%) & 0.0007 & 0.0012 & N.A. & 0.0011 & 0.0011 & 0.0011 & N.A. & 0.0008 & N.A. \\
\hline$\varepsilon \mathrm{Nd}_{i}$ & -2.21 & -0.63 & N.A. & -4.58 & -4.48 & -5.42 & N.A. & -5.58 & N.A. \\
\hline std error (\%) & 0.0016 & 0.0009 & N.A. & 0.0012 & 0.0006 & 0.001 & N.A. & 0.0006 & N.A. \\
\hline
\end{tabular}

UTM projection is NAD27 Zone 11S. N.A., not analyzed; B.D.L., below detection limit. Full dataset $(n=19)$ included in the Supplementary Material. *Major, trace, and rare earth elements for KCL samples from Memeti (2009). Isotopic data from this study. 
$\mathrm{pHD}$, and $\mathrm{KC}$ units (the same samples analyzed for mineralogy), were selected for isotope analysis. Four additional samples were selected from the Pothole Dome area of schlieren and host (not paired). Samples selected for $\mathrm{Sr}$, and $\mathrm{Nd}$ isotope analyses were analyzed at the University of Arizona. Full laboratory conditions and methods for isotope analyses are described in Otamendi et al. (2009). Element and isotope data from schlieren, felsic components, and nearby host samples in the TIC were compiled from the literature to supplement our dataset (Data sources: Loetterle, 2004; Burgess and Miller, 2008; Paterson et al., 2008; Solgadi and Sawyer, 2008; Memeti, 2009; Žák et al., 2009; Memeti et al., 2014).

\section{RESULTS}

\section{Regional Syntheses Magmatic Foliations and Lineations}

The 6485 magmatic foliation measurements and 1933 lineation measurements, covering $>70 \%$ of the intrusive complex, are summarized in Figure 2A. Building on the findings of Žák et al. (2007), we mapped the distribution of Type 2-4 foliations and identified one additional N-NE striking foliation (Type 5; Figure 2A). Many domains contain multiple magmatic foliations. Magmatic lineations are steeply plunging; $80 \%$ of measurements plunge $\geq 60^{\circ}$ (Figure 2A).

\section{Compositionally Defined Magmatic Structures}

Compositionally defined magmatic structures, specifically heterogeneous crystal clusters, are found in all TIC units (Paterson, 2009). K-feldspar megacryst clusters are especially common in the CP unit, even in regions of sparse to absent schlieren (e.g., Paterson et al., 2005; Vernon and Paterson, 2006). K-feldspar megacryst clusters are found both inside and outside mapped domains, in zones of concentrated schlieren-bound structures as well as in zones with sparse schlierenbound structures (see below). They form a wide range of shapes from irregular, to pipes and sheets (Paterson, 2009; Memeti et al., 2014).

\section{Schlieren-Bound Magmatic Structures}

The compilation identified $>1500$ schlieren-bound magmatic structures (planar schlieren, troughs, tubes, and plumes). Schlieren-bound structures are also widely distributed and appear to be either sparsely or densely clustered (Paterson, 2009; Figure 2B). In addition, the types of structures vary between units. Planar schlieren and troughs, tubes, and plumes are found in all major TIC units, are less common in the $\mathrm{KC}$ unit and rare in late leucogranites. Tubes (both stationary and migrating) and plumes are abundant in the CP unit, and found less commonly in the $\mathrm{pHD}$, eHD, and KC units (Paterson, 2009).

Younging indicators suggest that schlieren orientations largely young or migrate outwards, towards older contacts $(\sim 70 \%$ of the younging dataset; $n=470$ ) (see also Bateman, 1992; Burgess and Miller, 2008; Paterson et al., 2008; Solgadi and Sawyer, 2008; Paterson, 2009; Žák et al., 2009). They often migrate or young at high angles to nearby contacts (Hodge et al., 2012;
Wiebe et al., 2017). However, a smaller population ( 30\% of the dataset; $n=202$ ) show inward younging or contact-parallel orientations, in part reflecting some of the heterogeneity found across smaller spatial scales (see section "Outcrop-Scale Patterns").

\section{Summary}

Compositionally defined magmatic structures, including schlieren-bound magmatic structures, are widespread in the TIC and found in all units spanning the entire duration of the complex (i.e., they are times transgressive). Schlieren-bound structures are not evenly distributed in the TIC; instead they are broadly clustered in packages on the order of $5-15 \mathrm{~km}^{2}$ in size, irrespective of unit type, distance to nearest contacts, or contact orientation. They are found across both sharp and gradational contact zones. Relative younging directions of tubes and troughs are generally outward towards contacts. Fabric type spatially varies throughout the TIC, defining several domains with multiple, different fabrics preserved. Schlieren-bound magmatic structures are not associated with any particular regional fabric configuration at the regional scale.

\section{Domain-Scale Structure Patterns}

In each of the four study areas, schlieren-bound magmatic structures are abundant (Figure 2B, blue squares). Planar schlieren and troughs represent $\sim 60 \%$ of the structures reported in the four domains. Stationary and migrating tubes represent $22 \%$ of the structures in the four study regions and plumes make up $18 \%$ of the dataset. For each domain, we describe: (1) rock types, ages, and contact relationships; (2) magmatic foliation and lineation patterns; (3) planar schlieren and trough orientations and their relationship to fabrics; (4) tube and plume structure patterns; and (5) structure clustering.

\section{Glen Aulin Domain}

The Glen Aulin domain is situated at the western margin of the $\mathrm{CP}$ unit, crossing the contacts with $\mathrm{pHD}$ and $\mathrm{eHD}$ units (Figures 2, 6). The CP unit at Glen Aulin is characterized by hornblende biotite granodiorite in the west and becomes increasingly granitic eastwards towards Pothole Dome, as hornblende and biotite decrease in abundance. Hornblende in the eastern part of the domain is replaced by biotite, except in schlieren where it is sometimes preserved. K-feldspar megacrysts range in size from 3 to $10 \mathrm{~cm}$ and generally increase in size to the east. K-feldspar clusters and leucogranite dikes are widely found. Contacts between the $\mathrm{CP}$ and $\mathrm{pHD}$ units, and $\mathrm{pHD}$ and $\mathrm{eHD}$ units both strike NE-SW (azimuth: 033) in the north, and bend to an E-W (azimuth: 090) orientation at the western margin of the study area. The contact between the CP and pHD transitions from a sharp to gradational contact southwards along strike. The nearest $\mathrm{U}-\mathrm{Pb}$ in zircon ages range from $88.1 \pm 0.2 \mathrm{Ma}$ in the $\mathrm{CP}$ unit to $89.79 \pm 0.15 \mathrm{Ma}$ in the pHD (Coleman et al., 2004; Paterson et al., 2016). There are steep age gradients across the contacts in the isochron map (Memeti et al., 2014; Figure 2C).

Regional E-W striking (Type 4) and local NE-SW striking (Type 2) approximately margin-parallel magmatic foliations are dominant, and the regional NW-SE fabric (Type 3) is locally and weakly expressed in the north of the domain 


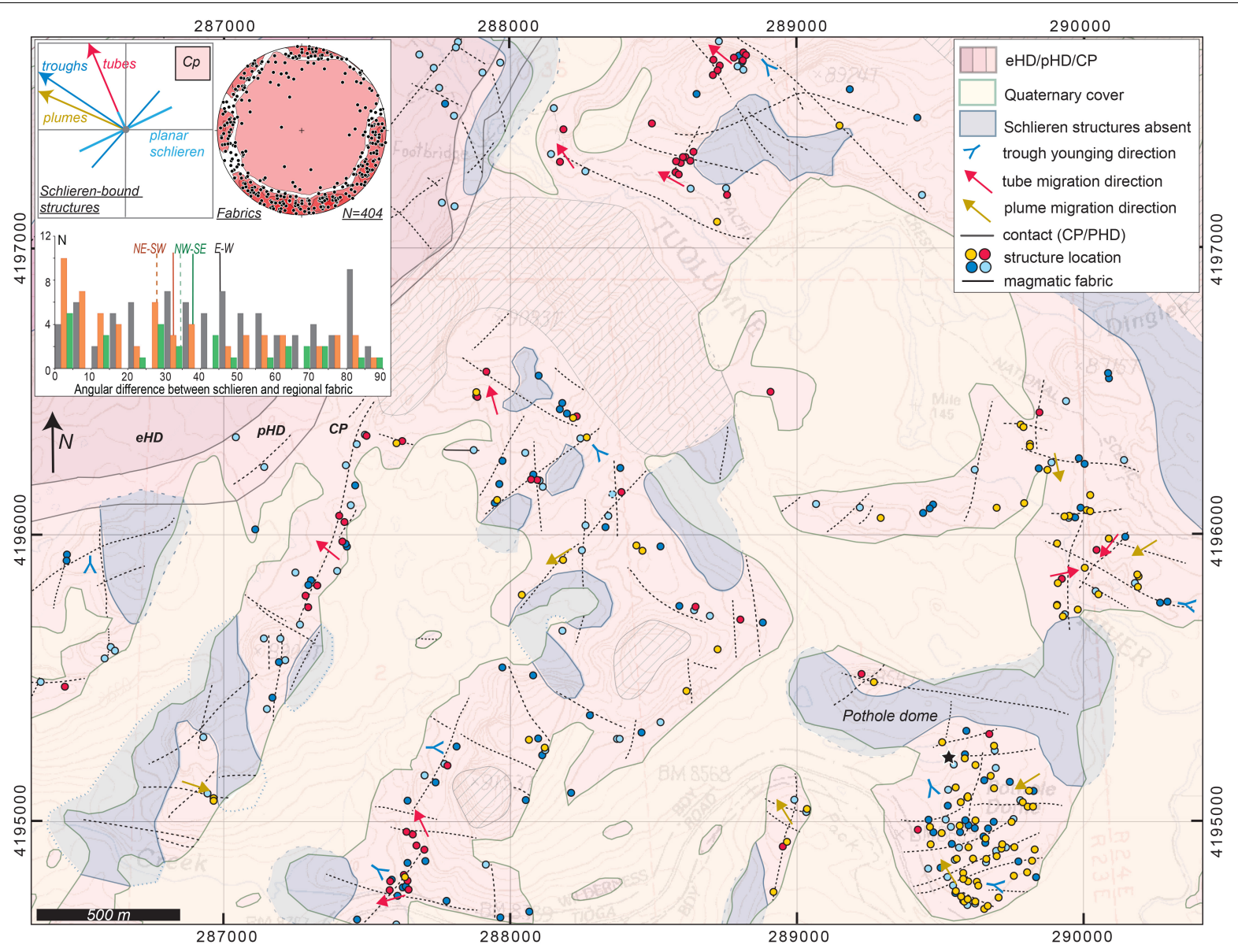

FIGURE 6 | Magmatic structures field data summary of the Glen Aulin area, NW quadrant. Bold lines mark major unit contacts. Hatching indicates unmapped areas. The trend of steeply dipping $\left(70^{\circ}-90^{\circ}\right)$ magmatic foliations is shown by dashed lines. Magmatic lineations are steeply plunging, regardless of the strike of the foliation. The locations of different schlieren-bound structures are shown by colored dots (light blue-planar schlieren; dark blue-trough; red; tube; yellow; plume). Y or arrow symbols are oriented in the direction of measured migration/younging. Inset box shows the domain-scale magmatic foliation summary on a stereonet, and a summary of average younging/migration orientations shown with arrows. For Glen Aulin and Young Lakes domains, angular difference measurements between the foliations and schlieren are shown as a histogram in the inset box, color-coded by fabric type. eHD-Equigranular Half Dome granodiorite. pHD-Porphyritic Half Dome granodiorite; CP-Cathedral Peak granodiorite; Co-ordinate system used: UTM NAD27 zone 11S.

(Figure 6). Lineations plunge steeply, with a best fit of $83 \rightarrow 235$ (plunge $\rightarrow$ trend; $n=18$ ).

Planar schlieren and troughs are observed in all orientations and range from shallow to sub-vertical dips. In the CP unit, the cylindrical best fit orientation is $212 / 78(n=87)$ for planar schlieren and $221 / 76(n=75)$ for troughs, although there is a wide scatter. Trough younging (perpendicular to trough strike), similarly is varied in orientation. The largest population of troughs in the CP unit young toward the NW, perpendicular to, and towards, the CP-pHD contact at an average azimuth of $304 \pm 24^{\circ}$ (Figure 6; $2 \sigma$ uncertainty). Troughs in the southwestern part of the CP unit, where the contact strikes E$\mathrm{W}$, have a younging direction to the north, perpendicular to the adjacent contact. pHD and eHD planar schlieren $(n=38)$ and troughs $(n=8)$ trend $\mathrm{N}-\mathrm{S}$ to NE-SW, dip to the west, and young on average towards 333, perpendicular and towards older contacts of eHD and $\mathrm{KC}$, respectively. There is no clear pattern between the orientations of the regional Type 3 and 4 foliations and schlieren orientations (Figure 6 histogram). However, schlieren orientations and the contact-parallel foliations (Type 2) are more similar, as shown by the number of schlieren with a low angular difference to the foliation.

The average azimuthal orientation of tube migration in the $\mathrm{CP}$ unit is $339 \pm 23^{\circ}(n=113)$, perpendicular and towards the contact with the $\mathrm{pHD}$, a result consistent with previous studies of TIC tubes in this area (Figure 6) (e.g., Hodge et al., 2012; Wiebe et al., 2017). pHD or eHD tubes are less commonly found north of Glen Aulin. Plume heads are abundant in the central and eastern parts of the study area, within the CP unit $(n=131)$. Most observations of plumes are on horizontal to shallowly dipping planes, and in 2D they have variable migration directions, with a mean azimuth towards $293 \pm 17^{\circ}$ (Figure 6). No plumes were identified in the $\mathrm{pHD}$ or $\mathrm{eHD}$.

Consistent with regional patterns, schlieren-bound structures at Glen Aulin are non-uniformly distributed throughout the map area (Figure 6). Schlieren-bound structures are concentrated 
in zones that range in size between 0.3 and $1.1 \mathrm{~km}^{2}$. These clusters are separated by zones where schlieren-bound structures are rare to absent, ranging in size from 0.02 to $0.2 \mathrm{~km}^{2}$. Both zones contain magmatic fabrics, and other compositionally defined structures such as K-feldspar megacryst clusters. To a first order, structures are weakly clustered by type, with plumes most abundant in the eastern part of the domain (e.g., Pothole Dome), and tubes most abundant in the western part. Planar schlieren and troughs are, in contrast, evenly distributed within structure-rich zones.

\section{Young Lakes Domain}

The Young Lakes domain is situated in the east-central part of the CP unit (Figures 2, 7). The dominant rock type is biotite granodiorite, with rare hornblende (pseudomorphed by biotite). K-feldspar megacrysts are between 3 and $6 \mathrm{~cm}$ in size. Mafic enclaves and $\mathrm{K}$-feldspar clusters are common, and rare leucogranite dikes are observed. Young Lakes is located 2-3 km west of the nearest contact, which is the gradational internal contact of the $\mathrm{CP}$ unit with the $\mathrm{pHD}$ and $\mathrm{eHD}$ units at Sawmill Canyon, striking NW-SE (azimuth: 300). This contact transitions to a sharp contact with the eHD southwards along strike (Paterson et al., 2008). The nearest $\mathrm{U}-\mathrm{Pb}$ in zircon age is $88.53 \pm 0.12 \mathrm{Ma}$ from Sawmill Canyon (Paterson et al., 2016). On the isochron map of Memeti et al. (2014), the domain is characterized by a shallow age gradient of broadly similar ages (Figure 2C).

Both Type 3 and 4 foliations are found at Young Lakes and appear to be equally dominant (Figure 7). A weaker NE-SW striking foliation (Type 5) is also identified locally. Lineations are steeply plunging (see Figure 3 in Paterson et al., 2008).

Planar schlieren $(n=13)$ and troughs $(n=117)$ have a strong preferred orientation, striking NE-SW and dipping SE, with cylindrical best fit orientations of $009 / 50$ and $013 / 41$ for planar schlieren and troughs, respectively. Troughs young predominantly towards the ESE (mean azimuth: $102 \pm 17^{\circ}$ ), and broadly perpendicular to, the CP-pHD contact at Sawmill Canyon (Figure 7$)$. A smaller population $(\sim 27 \%)$ young in other orientations. The angular difference between the Type 3 and 4 foliations and schlieren orientations is high (median between $45^{\circ}$ and $60^{\circ}$ ) and each foliation type has a distinct angular difference distribution (Figure 7 histogram). Migrating and stationary tubes $(n=2)$ as well as plumes $(n=4)$ are rare at Young Lakes and do not show any preferred orientation.

Structural diversity is relatively low at Young Lakes, making it difficult to estimate clustering by structure type. However, planar schlieren and troughs are clustered in space. Zones where schlieren are rare to absent range in size from 0.07 to $0.6 \mathrm{~km}^{2}$. These domains are smaller than the extent of zones where schlieren-bound structures are abundant $\left(0.6-1 \mathrm{~km}^{2}\right)$. Within the structure-rich clusters, structures appear more sparsely distributed than in Glen Aulin.

\section{Tenaya Peak Domain}

The Tenaya Peak domain is situated in a narrow N-S trending belt of the pHD unit (Figures 2, 8A). The pHD unit is a biotite-hornblende granodiorite with hornblende phenocrysts and biotite books 3-8 $\mathrm{mm}$ in size. K-feldspar megacrysts are $2-3 \mathrm{~cm}$ in size, increasing in size towards the CP unit (see also Bateman, 1992; Memeti et al., 2014). The mapped domain crosses the N-S trending sharp contact of the CP-pHD in the east (azimuth: 350-000; Figure 8A) and is $\sim 200 \mathrm{~m}$ from the $\mathrm{N}-\mathrm{S}$ trending gradational contact of the pHD-eHD in the west. The eastern part of the domain, in the CP unit, was previously mapped and studied by Burgess and Miller (2008). Ages range from $87.3 \pm 0.7 \mathrm{Ma}$ to $89.79 \pm 0.15$ across the contact (Burgess and Miller, 2008; Paterson et al., 2016), represented by a smoothly varying age gradient on the zircon isochron map (Memeti et al., 2014; Figure 2C).

The E-W Type 4 foliation is dominant over the NW-SE Type 3 foliation (Figure 8A). A N-S to NE-SW striking foliation (Type 2 ) is locally well-defined in the pHD unit, but weak-to-absent in other areas. Burgess and Miller (2008) report steeply plunging lineations between $70^{\circ}$ and $90^{\circ}$.

Planar schlieren and troughs in the pHD unit, on average, strike parallel to the contact (165/40; $n=26$ schlieren, $147 / 44$; $n=35$ troughs; Figure $\mathbf{8 A}$ ), although there is a wide range in orientation, with strikes between 021 and 358. Trough younging orientation is variable, with a weak preference towards the west (mean vector: $245 \pm 50^{\circ}$ ). Including measurements by Burgess and Miller (2008), troughs in the CP unit $(n=7)$ vary in orientation between NW-SE striking to E-W striking. Two troughs measured in the adjacent CP unit young westward, and one trough youngs towards the east. The small number of foliation and planar schlieren/trough measurements from this domain precludes statistical analysis of angular difference. Qualitatively, the cylindrical best fit orientations for planar schlieren and troughs aligns with the orientations for Type 2 and Type 3 foliations.

Migrating tubes in the $\mathrm{pHD}$ are concentrated at the eastern margin of the $\mathrm{pHD}$, adjacent to the contact with the CP. A small number of measurements $(n=13)$ show a preference for westward migration (mean vector: $266 \pm 26^{\circ}$; Figure 8A), perpendicular to the nearby $\mathrm{eHD}$ contact. In the $\mathrm{CP}$ unit, including measurements by Burgess and Miller (2008), tubes are also westward-younging ( $n=9$; not shown). Thirteen plumes mapped across the pHD have a widely variable orientation, with a mean vector of $284 \pm 99^{\circ}$ (Figure 8A). Plumes were not found at the western margin of the $\mathrm{CP}$ unit.

Within this domain, the structures are not strongly clustered by type. However, tubes seem to be most abundant close to the pHD-CP contact. Areas ranging in size from 0.1 to $0.4 \mathrm{~km}^{2}$ do not contain schlieren-bound structures. Domains that contain abundant structures are $\sim 0.5-1 \mathrm{~km}^{2}$ in area.

\section{Lyell Canyon Domain}

The Lyell Canyon domain is situated in a wide gradational zone at the southeastern margin of the $\mathrm{CP}$ unit, bordering the pHD unit to the east (Figures 2, 8B) (Oppenheim et al., in review). The $\mathrm{pHD}$ unit here is a porphyritic granodiorite with biotite > hornblende, and locally contains biotite books and $\mathrm{K}$-feldspar megacrysts $(2-3 \mathrm{~cm}$ in size). In the transitional CP unit, the K-feldspar megacrysts increase in size and number. The gradational contact strikes NE-SW (azimuth: 015). The 


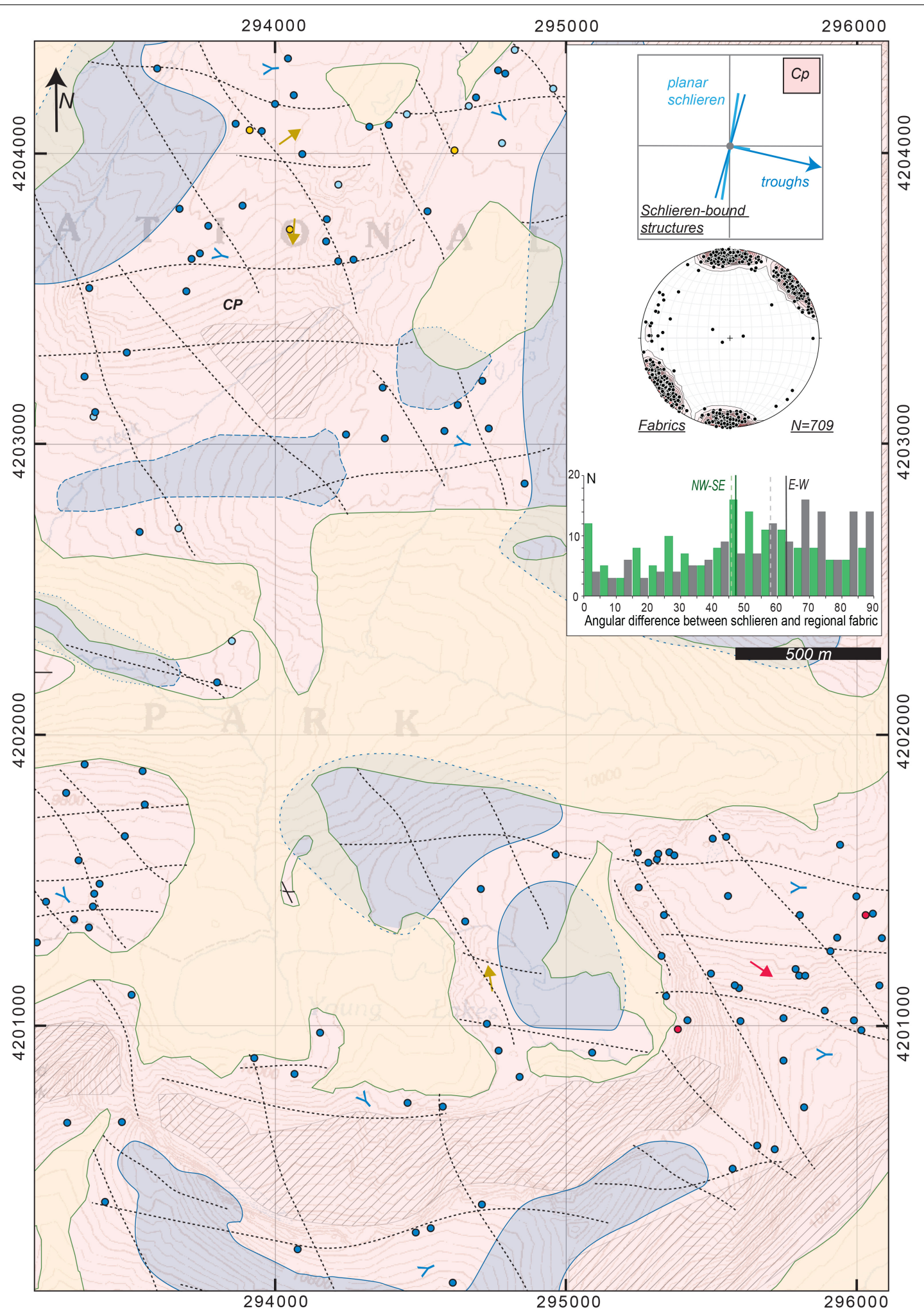

FIGURE 7 | Magmatic structures field data summary of the Young Lakes area, NE quadrant. Bold lines mark major unit contacts. Hatching indicates unmapped areas. The trend of steeply dipping $\left(70^{\circ}-90^{\circ}\right)$ magmatic foliations is shown by dashed lines. Magmatic lineations are steeply plunging, regardless of the strike of the foliation. The locations of different schlieren-bound structures are shown by colored dots (see key in Figure 6). Y or arrow symbols are oriented in the direction of measured migration/younging. Inset box shows the domain-scale magmatic foliation summary on a stereonet, and a summary of average younging/migration orientations shown with arrows. For Glen Aulin and Young Lakes domains, angular difference measurements between the foliations and schlieren are shown as a histogram in the inset box, color-coded by fabric type. CP-Cathedral Peak granodiorite. Co-ordinate system used: UTM NAD27 zone 11 S. 

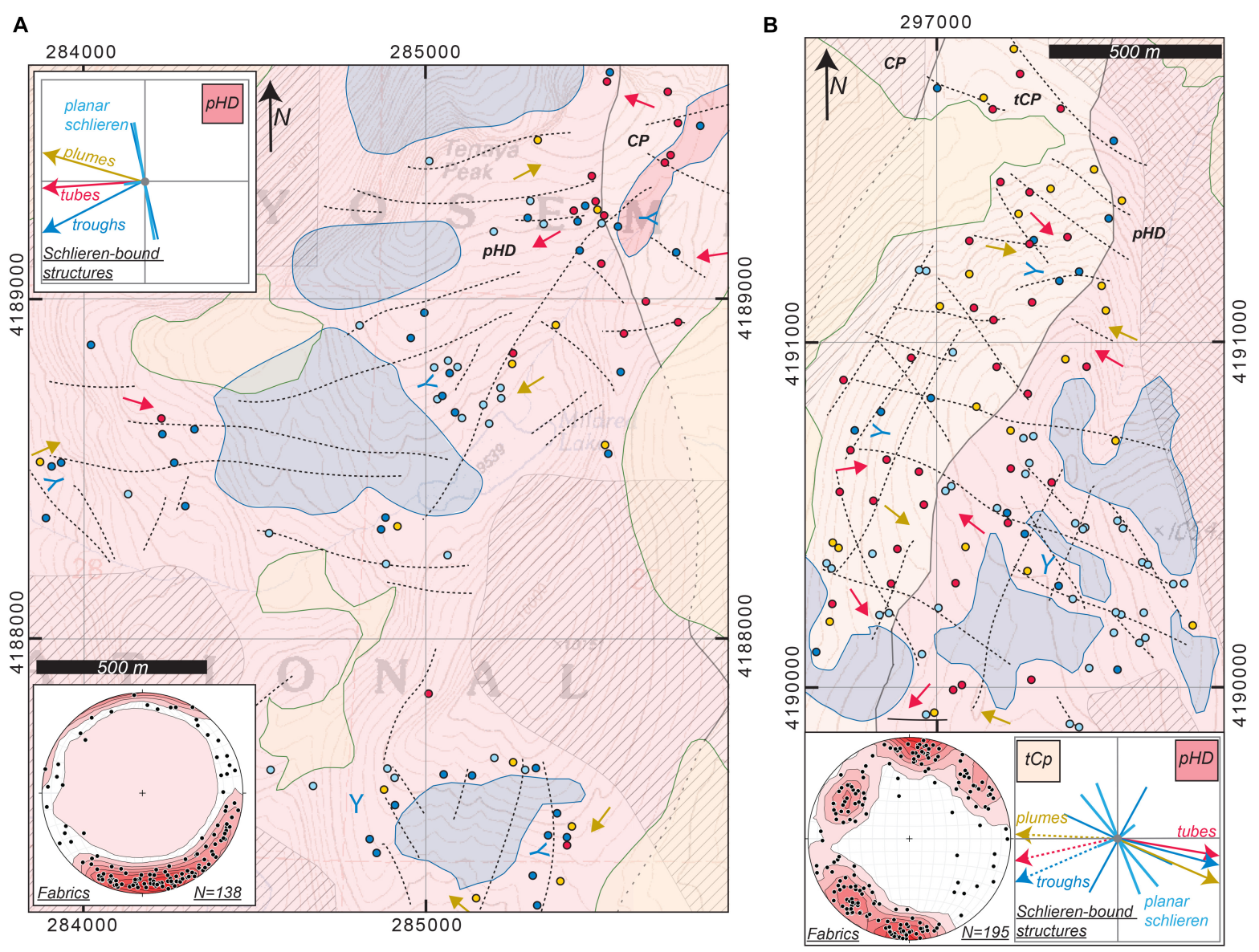

FIGURE 8 | Magmatic structures field data summary of the Tenaya Peak and Lyell Canyon areas. Bold lines mark major unit contacts. Hatching indicates unmapped areas. The trend of steeply dipping $\left(70^{\circ}-90^{\circ}\right)$ magmatic foliations is shown by dashed lines. Magmatic lineations are steeply plunging, regardless of the strike of the foliation. The locations of different schlieren-bound structures are shown by colored dots (see key in Figure 6). Y or arrow symbols are oriented in the direction of measured migration/younging. Inset box shows the domain-scale magmatic foliation summary on a stereonet, and a summary of average younging/migration orientations shown with arrows. pHD-Porphyritic Half Dome granodiorite; CP-Cathedral Peak granodiorite; tCP-Transitional Cathedral Peak granodiorite. (A) Tenaya Peak, SW quadrant (after Aldiss, 2017). (B) Lyell Canyon, SE quadrant (after McColl, 2017). Co-ordinate system used: UTM NAD27 zone 11 S.

gradational contact between the transitional $\mathrm{CP}$ and main $\mathrm{CP}$ unit is found at the western edge of the mapped domain and also strikes NE-SW. There are no age estimates for this section of the CP unit. The interpolation on the isochron map of Memeti et al. (2014) suggests that this region has broadly similar ages (a shallow age gradient) of about $87 \mathrm{Ma}$ (Figure 2C).

Regional Type 3 and 4 foliations are observed in equal intensity and cross-cut the CP-pHD contact (Figure 8B). A broadly contact-parallel, NE-SW striking foliation (Type 2) is also found in both units. Lineations were not recorded in this domain.

The Lyell Canyon domain is the smallest of the four mapped domains, and the number of structures observed is also the smallest. Thus, less emphasis is placed on statistically average orientations (for comparison to other domains, average orientations are given in inset summary diagram Figure 8B). A small number of planar schlieren and troughs in the CP unit $(n=16)$ vary widely in orientation, but the largest group are NW to NE striking. A small number of graded schlieren measurements ( $n=5$ ) indicate younging eastwards towards the pHD unit and troughs also young towards the contact, between 060 and 160. In the pHD unit, planar schlieren and troughs are both striking NW $(n=37)$ : 337/61 $(n=30)$ and $294 / 79(n=7)$, respectively. Planar schlieren grading in the pHD unit indicates younging westwards $(n=9)$, with a smaller number younging to the NE $(n=2)$. Trough azimuthal younging directions are between 180 and 330, opposite to structures in the CP unit. Angular relationships between foliations and schlieren orientations were not calculated due to the limited size of the dataset.

Tubes and plumes are found across the contact in both units. In the CP unit, tubes $(n=24)$ and plumes $(n=11)$ migrate eastwards, with plumes showing a wider scatter in orientation. In the pHD unit, migration directions are reversed, as tubes $(n=12)$ and plumes $(n=10)$ migrate westwards (Figure 8B).

Domains where structures are rare to absent are $0.1-0.3 \mathrm{~km}^{2}$ in area, similar to the other study areas, but spatially restricted to the southern parts of the domain. The rest of the domain 
has abundant structures, approximately evenly spaced. With a larger dataset covering a broader area, clustering by type could be evaluated.

\section{Summary}

Domain-scale mapping revealed structure clustering on the order of $0.3-1 \mathrm{~km}^{2}$ in size, separated by zones of sparse to absent schlieren-bound structures. Both zones are characterized by magmatic fabrics and K-feldspar megacryst clusters. Structurerich and structure-poor domains form highly irregular shapes, with no apparent preferred orientation in map view. The clusters show no clear spatial relationship to nearby contacts or magmatic fabric orientations. In a subset of domains (Glen Aulin and Tenaya Peak) plume and tube structures are weakly grouped by type. In contrast, planar schlieren and troughs appear in all clusters of the four domains. Planar schlieren and troughs are weakly aligned with contact-parallel magmatic fabrics at Glen Aulin, and younging or migration directions of all schlierenbound structure types in the CP unit is, on average, outward younging, perpendicular to contact orientations (with overall a wide range in orientations). There is additional complexity to resolve in the $\mathrm{pHD}$ unit.

\section{Outcrop-Scale Patterns Magmatic Structure Patterns}

Grid mapping of several outcrops illustrates several features of schlieren-bound structures: (1) Schlieren-bound structures include a component of schlieren, but also include components that are more felsic, or slightly different composition, than the surrounding host (e.g., layers between schlieren bases of troughs, tube centers, Figures 3B, 4A; herein called "felsic components"); (2) Schlieren-bound structures may be deformed, evidenced by magmatic faulting and folding (Figures 3A,D, 4D, 9A), and structures broken and re-intruded by the surrounding host pluton (Figures 4B-D, 9A-C, see also Hodge et al., 2012); (3) While structures are typically classified as tubes, troughs, and plumes (or others, not part of this study), outcrops less commonly show structures that represent transitions, or combinations, of structures (Figure 9B); (4) K-feldspar megacrysts, where observed in schlieren-bound structures, are often strongly aligned with local schlieren-parallel foliation or sorted by size (Figures 9A-C). This is not common in the surrounding host, where K-feldspar megacrysts are clustered or weakly aligned in a magmatic fabric (e.g., Paterson, 2009).

Local schlieren-parallel foliations (Type 1) in schlierenbound structures are discordant to magmatic foliations in the surrounding host (Type 2-5). The schlieren-parallel foliation in the mafic (schlieren) component of structures is rarely overprinted by other magmatic foliations. However, minerals defining fabrics in the felsic components of schlieren-bound structures (e.g., hornblende and biotite) are discordant to schlieren-parallel foliations, and rotated to Type 2, 3, 4, or 5 orientations. In addition, the presence of schlieren-bound structures at an outcrop does not modify the orientation of the magmatic foliations in the host (Figures 9A,B).

\section{Effects of Magmatic Deformation and Rotation}

Field evidence described above in each of the mapped domains indicates that some structures were magmatically deformed (i.e., translated, rotated, and distorted), and no longer record their original orientations. This deformation can also produce multiple younging directions within a single outcrop (Figure 9A). Even in outcrops where structures appear undeformed, there may be multiple schlieren-bound structures with varying orientations and several, opposing younging indicators (Figures 4B, 9B). Thus, the effects of rotation are not easily quantified and generate scatter in the structural data.

However, even with this scatter, the observation that multiple types of structures show similar outward-younging trends at regional and domain-scales indicates that the most prominent younging direction, or orientation, measured in the outcrop is meaningful. There is no systematic rotation of the structures in the dataset in space (e.g., changing strikes and dips towards contact zones). In addition, schlieren foliations (type 1) are discordant to, and thus not rotated by, strain producing the host magmatic fabric (types 2-5), suggesting they are in a primary orientation (see above). The possibility of rotated structures underscores the importance of using large datasets at the domain- or regional-scales when interpreting patterns in orientation or younging.

\section{Schlieren Petrography}

Schlieren in the TIC contain between 2 and 8 times more hornblende, biotite, magnetite, apatite, titanite, and zircon than the surrounding plutonic material (e.g., Wahrhaftig, 1979; Reid et al., 1993; Table 1). The relative modal proportions of these minerals in the schlieren structures varies with the mineralogy of the host unit. Within the TIC, the ratio of biotite to hornblende increases towards the interior of the complex (e.g., Bateman and Chappell, 1979; Memeti et al., 2014). This trend is mirrored in the schlieren found in different TIC units (Table 1). The proportion of quartz to feldspar also increases from the $\mathrm{KC}$ to the $\mathrm{CP}$ in both schlieren and host samples.

The abundance of magnetite, titanite and apatite increases from the outer KC unit to the interior CP unit in both host and schlieren samples, yet the relative proportions of these minerals are highly unit-dependent (Table 1). For example, both the Kuna Crest host and schlieren are generally titanite-poor, relative to younger units. In contrast, the Cathedral Peak unit is richer in titanite $(\sim 1 \%$; Table 1$)$, which is also pronounced in the schlieren ( 7\%; Table 1). Magnetite forms crystal clusters in all schlieren samples, which also includes titanite clusters in the CP schlieren. Zircon is sometimes observed in thin section but is generally too small to measure quantitatively. Previous workers have also identified allanite in select samples (e.g., Reid et al., 1993; Paterson, 2009). These changes towards the TIC interior coincide with an increase in the grain size of the accessory minerals, and in all studied samples, the grain size of accessory minerals is, on average, larger in the schlieren than in the host.

In thin section, schlieren-bound magmatic structures record the same type of microstructures found in the surrounding host and are dominantly magmatic in origin. For example, 

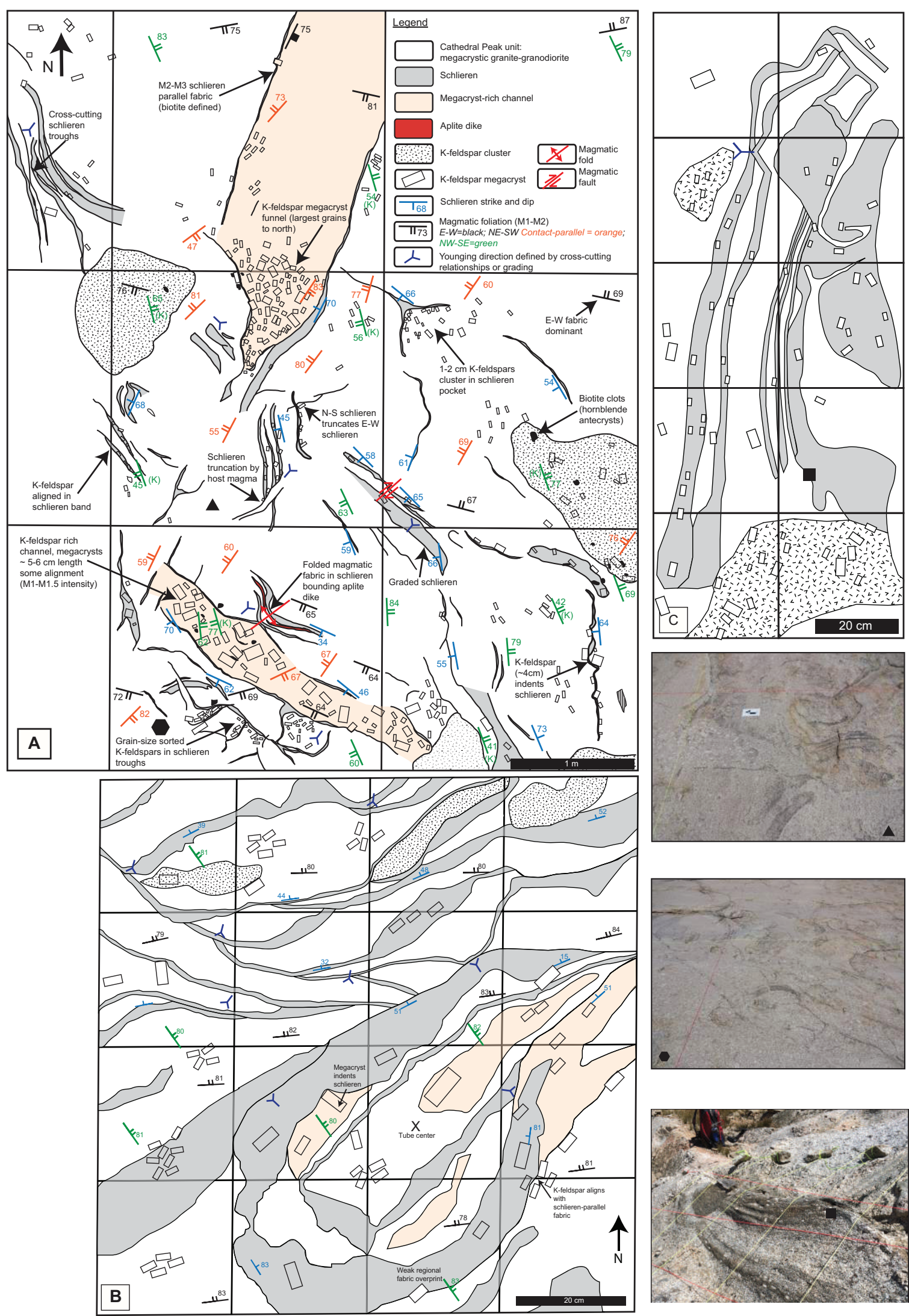

FIGURE 9 | Continued 
FIGURE 9 | Outcrop-scale grid maps showing complex schlieren-bound structures. (A) Pothole Dome, Glen Aulin area (NW quadrant). Schlieren are sharply truncated, or re-intruded, by Cathedral Peak magma, and are locally folded. The Cathedral Peak unit contains K-feldspar megacrysts from $\sim 4$ to 6 cm in size at Pothole Dome. At this outcrop, K-feldspar megacrysts are densely clustered (stippled pattern) and are sorted by grain size into funnel- or channel-shaped structures bounded by schlieren. K-feldspars are included in schlieren, and where observed, they are aligned with schlieren-parallel fabric defined by hornblende and biotite. This is an example where there are multiple younging directions preserved at one outcrop. The regional fabric is locally distorted into-schlieren-parallel orientations, although a clear regional E-W orientation and contact-parallel NE-SW orientation is still dominant. (B) Young Lakes area (NE quadrant). The northern section of the map shows a package of $\mathrm{cm}$ wide schlieren troughs, with a consistent younging direction to the NNE. K-feldspar megacrysts (3-8 cm) are abundant within schileren layers and align in a schileren-parallel orientation. Within some layers (yellow) the schlieren are generally more megacryst-rich. The trough package is truncated by an elliptical-shaped tube structure which is stationary (youngest rings are in the center of the tube). K-feldspar megacrysts in the tube are aligned parallel to schlieren. K-feldspar defined fabric within the CP is weakly defined, except in and around schlieren-bound magmatic structures. (C) Young Lakes area (NE quadrant). Folded schlieren troughs with 3D relief younging to the east. The northern portion of the structure has slumped with a small $\sim 10 \mathrm{~cm}$ displacement to create an apparent sinistral offset. Schlieren include K-feldspar megacrysts that are variably aligned. The most well defined foliation in thin elongate layers, and weak foliation in irregularly shaped schlieren.

interstitial quartz is pinned by phenocrystic feldspar, biotite, and hornblende. Crystal clots of feldspar, magnetite, and titanite are common in all studied examples. Crystal-plastic deformation is limited to undulose extinction in quartz, and rare cases of deformation twinning in feldspar.

\section{Whole-Rock Geochemistry Major, minor, and trace elements}

TIC schlieren have a wide range in $\mathrm{SiO}_{2}$ contents (40-70 wt.\%; Figures 10A-D), encompassing much of the variation in $\mathrm{SiO}_{2}$ found in the main TIC units (48-79 wt.\% $\mathrm{SiO}_{2}$ ), except at the high-silica end $>70$ wt. $\% \mathrm{SiO}_{2}$. As described in earlier studies (Reid et al., 1993; Paterson et al., 2008; Solgadi and Sawyer, 2008; Žák et al., 2009), for many elements TIC schlieren samples plot at a high angle to the main TIC trend in $\mathrm{SiO}_{2}$-element space. Schlieren are enriched in $\mathrm{TiO}_{2}, \mathrm{MnO}$, and $\mathrm{P}_{2} \mathrm{O}_{5}$, relative to the host TIC for a given $\mathrm{SiO}_{2}$ contents and have a variable $\mathrm{FeO}_{t}$ contents at $\mathrm{SiO}_{2}<62$ wt.\% (Figure 10B). Schlieren are depleted in $\mathrm{Al}_{2} \mathrm{O}_{3}$ (Figure 10A) and $\mathrm{CaO}$ relative to the surrounding host, and $\mathrm{Na}_{2} \mathrm{O}$ ranges from depleted to overlapping with the host at higher $\mathrm{SiO}_{2}$ content. $\mathrm{K}_{2} \mathrm{O}$ is enriched in schlieren relative to the host at low $\mathrm{SiO}_{2}$ and then compositionally overlaps with the host at $\mathrm{SiO}_{2}>60$ wt.\%. Felsic components of schlieren-bound structures compositionally overlap with the surrounding TIC rocks. $\mathrm{SiO}_{2}$ contents of the felsic component are between 57 and 78 wt.\%, falling at the felsic end of schlieren compositions and in some cases matching compositions of TIC leucogranite samples (Figure 10). The intersection of linear trends formed by the schlieren samples and felsic or host samples is consistently between 65 and 70 wt.\% $\mathrm{SiO}_{2}$.

Some large-ion-lithophile-elements such as $\mathrm{Rb}, \mathrm{Cs}$, and $\mathrm{Eu}$ are enriched in the schlieren relative to the host for a given $\mathrm{SiO}_{2}$ content, while $\mathrm{Sr}$ (Figure 10C) and $\mathrm{Ba}$ are depleted (Table 2). Most high-field-strength-elements, such as $\mathrm{Y}, \mathrm{Nb}$, and $\mathrm{Zr}$ (Figure 10D) are enriched relative to the host (Table 2). $\mathrm{Pb}$ and Sc contents in both schlieren and host are approximately equal (Table 2), forming one trend line.

\section{Rare earth elements}

The main TIC units have classic arc-type REE slopes, with $\mathrm{La}_{N} / \mathrm{Yb}_{N}$ values between 2 and 44 . The REE patterns vary between units, with the CP samples showing the most fractionated patterns. TIC schlieren generally have REE patterns parallel to the host unit they are situated in, with the exception of schlieren samples in the Kuna Crest granodiorite (Figure 11A). A key feature that distinguishes schlieren from the main TIC units is that the schlieren have REE abundances up to 10 times greater than the surrounding host. Felsic components also have REE patterns parallel to those of the host but display lower REE contents (as much as 10 times lower than the host) (Figures 11A-C). A felsic component sample from the Half Dome units shows a slight positive Eu anomaly, which is not found in the sample of the adjacent host (Figure 11B).

\section{Sr and $\mathrm{Nd}$ isotopes}

The TIC has a large range initial ${ }^{143} \mathrm{Nd} /{ }^{144} \mathrm{Nd}\left(\varepsilon \mathrm{Nd}_{i}\right.$ notation used) between -2.0 and -9.5 and initial ${ }^{87} \mathrm{Sr} /{ }^{86} \mathrm{Sr}$ values ( $\mathrm{Sr}_{i}$ notation used), between 0.7055 and 0.7077 , with the $\mathrm{CP}$ unit and late leucogranite samples producing the most evolved compositions (Kistler et al., 1986; Memeti et al., 2014; Figure 11D). Within one unit, the isotopes vary up to 5 epsilon units $\left(\varepsilon \mathrm{Nd}_{i}\right)$, with smaller variations in $\mathrm{Sr}_{i}$ (Figure 11D; Memeti et al., 2014). Schlieren and host pairs are isotopically similar, corresponding well with the isotopic composition of the unit they are found in. However, the schlieren and host pairs are not identical. Differences in $\varepsilon \mathrm{Nd}_{i}$ between paired schlieren and host samples are $<1$ epsilon unit, and in $\mathrm{pHD}$ and $\mathrm{CP}$ samples this difference is minimized to within 0.2 epsilon units. The schlieren samples in all but one example have higher $\mathrm{Sr}_{i}$ ratios than their adjacent host (Figure 11D). These differences are greater than the $2 \sigma$ analytical uncertainty (0.0006-0.0025\%, smaller than the size of the symbols in Figure 11D).

\section{Relative Timing Indicators}

The zircon isochron map of Memeti et al. (2014) provides the only absolute timing constraint on schlieren-bound structure formation; notably, schlieren-bound structures span the entire 10 m.y. history of the complex (Figure 2C). At the scale of a single schlieren trough, Memeti et al. (2014) also found identical ages between zircons contained in the schlieren and zircons in the surrounding host.

Several examples have been found where intrusive contacts sharply truncate schlieren-bound structures (e.g., Figure 4A) indicating that these schlieren-bound structures formed prior to arrival of a new magma pulse. Examples have also been found where materials of one unit slumped off a contact into the adjacent unit to form a compositionally defined magmatic structure, requiring that they formed immediately 

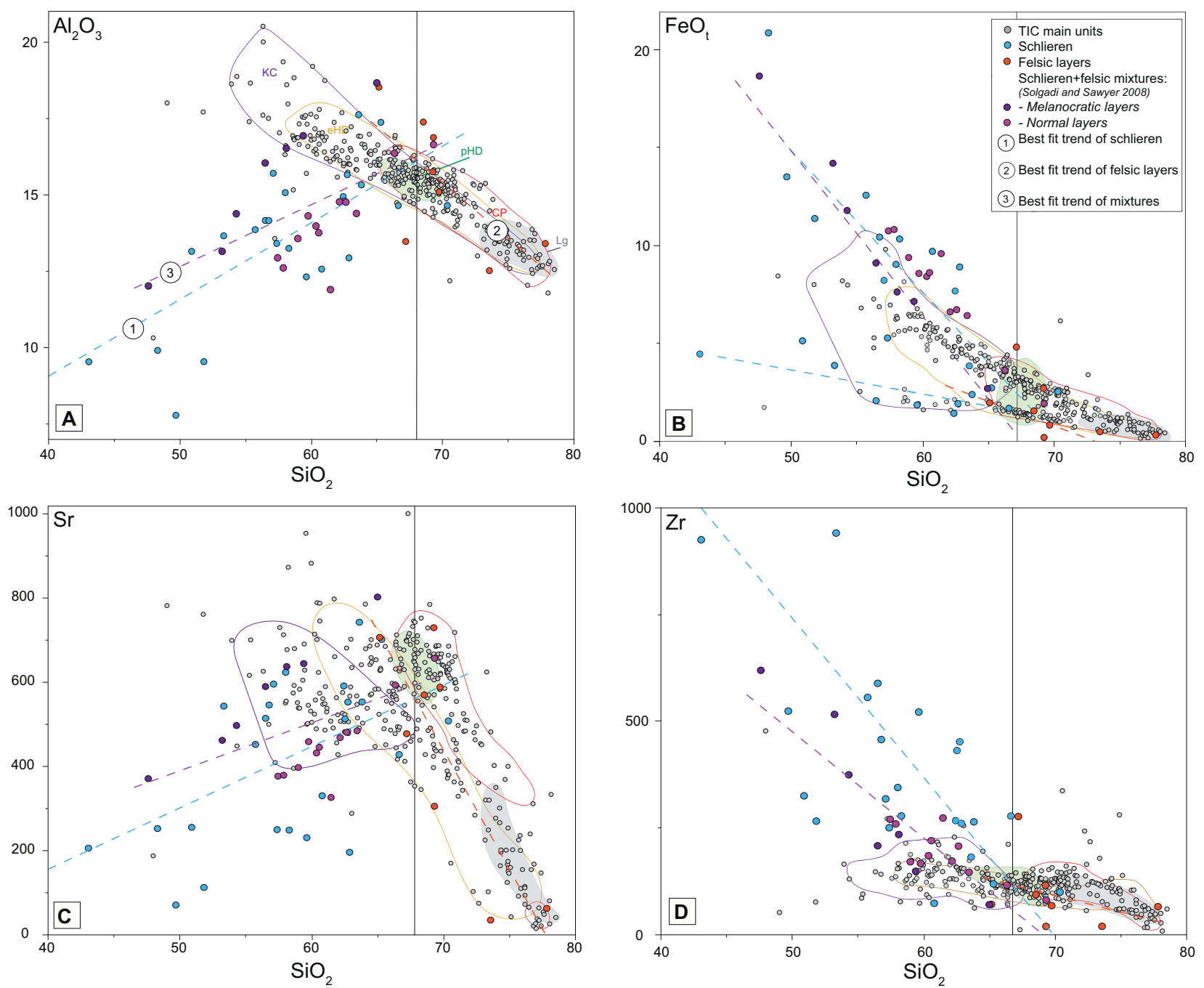

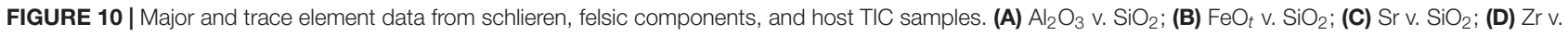
$\mathrm{SiO}_{2}$. Data sources: Bateman and Chappell (1979), Peck and Van Kooten (1983), Kistler et al. (1986), Bateman et al. (1988), Loetterle (2004), Burgess and Miller (2008), Gray et al. (2008), Paterson et al. (2008), Solgadi and Sawyer (2008), Economos et al. (2009), Memeti (2009), Žák et al. (2009), Coleman et al. (2012), and new data (Table 2).

after juxtaposition of two magma pulses (Paterson et al., 2008). Elsewhere, schlieren-bound structures seem to cluster along internal contacts indicating the contact already existed (e.g., Žák and Paterson, 2005). Together with the temporal history established from zircon ages, these observations indicate that compositionally defined magmatic structures formed from many repeated events both prior to, during, and after juxtaposition of magma pulses, over the entire $10 \mathrm{~m}$.y. history of the TIC.

The relative timing between different types of schlierenbound structures (i.e., planar schlieren, troughs, tubes, and plumes) is not clear. This is because different schlieren-bound structures are generally spaced $\sim 1-10 \mathrm{~m}$ apart and do not cross-cut each other (see also Hodge et al., 2012), except in rare cases (Figure 9B). Often, transitional-type structures are observed, for example, trough structures that grade into tubes, or bifurcating tubes (Figure 4B), where a local relative timing relationship can be determined (e.g., Paterson, 2009). Overprinting relationships between type 1 magmatic fabrics in schlieren-bound structures and fabric types 2-5, described above, suggest that schlieren-bound structures and magmatic fabric types 2-5 formed synchronously.

In addition, schlieren major and trace element compositions consistently intersect TIC host compositions between 65 and 70 wt.\% $\mathrm{SiO}_{2}$. We used these intersections to estimate the bulk composition of a TIC magma that we could model under fixed pressure and varying temperature conditions. Werts et al. (2020) and Barnes et al. (2020), using the thermometer of Putirka (2016), calculated hornblende crystallization temperatures ranging from $>800$ to $\sim 650^{\circ} \mathrm{C}$ across all TIC units. As hornblende is abundant in all schlieren studied, the temperature range $800-700^{\circ} \mathrm{C}$ was considered relevant to schlieren formation to a first order. Further, a study of apatite in TIC rocks (also abundant in 

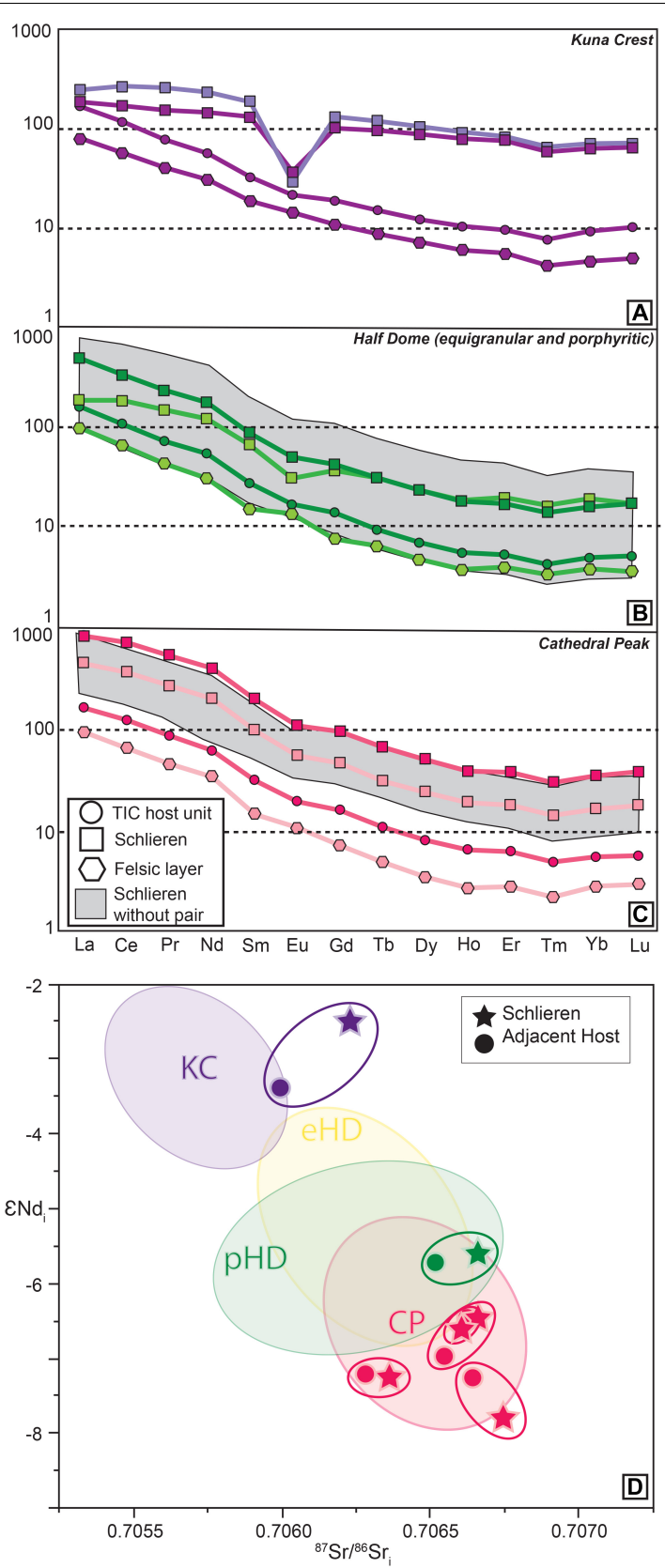

FIGURE 11 | (A-C) Rare Earth Element patterns in TIC host, schlieren and felsic components. Plots are divided up by major unit. (A) Kuna Crest granodiorite [sample data from Memeti (2009)]. (B) Half Dome granodiorite units. eHD and pHD have been combined to maximize data coverage. (C) Cathedral Peak granodiorite. Matching colors indicate that the samples were collected from the same outcrop, at adjacent layers. Normalized after Sun and McDonough (1989). (D) Whole rock isotopes ${ }^{87} \mathrm{Sr} /{ }^{86} \mathrm{Sr}_{i} \mathrm{~V} . \varepsilon \mathrm{Nd}_{j}$. TIC samples are color-coded by unit. They define a broad isotopic range. Schlieren-host pairs collected at the same outcrop are circled. Fields defined by host rock samples as shown in Memeti et al. (2014). Standard errors are smaller than the size of the symbols and provided in Table 2. Data sources: Bateman and Chappell (1979), Peck and Van Kooten (1983), Kistler et al. (1986), Bateman et al. (1988), Loetterle (2004), Burgess and Miller (2008), Gray et al. (2008), Paterson et al. (2008), Solgadi and Sawyer (2008), Economos et al. (2009), Memeti (2009), Žák et al. (2009), Coleman et al. (2012), and new data (Table 2). schlieren) suggested that at apatite saturation $\left(\sim 900^{\circ} \mathrm{C}\right)$ magma crystallinity was 9\% (Piccoli and Candela, 1994), which we use as a minimum crystallinity here. The modeled compositions included 4 wt.\% $\mathrm{H}_{2} \mathrm{O}$ in the melt due to the presence of hornblende (Naney, 1983; Fox and Miller, 1990). This represents a minimum estimate on water contents in the system. The presence of miarolitic cavities and vugs in the TIC indicate that volatiles were exsolved during magma crystallization and cooling, however the relative timing of volatile exsolution and schlieren-formation is not yet clear and is a target for future study (Bateman, 1992; Memeti et al., 2014). At higher $\mathrm{H}_{2} \mathrm{O}$ contents, effective viscosity decreases. Thus, the effective viscosity estimates below can be considered broadly as maximum values for each modeled composition.

Using the estimated bulk composition from schlieren-host TIC intersections (Table 3), with 4 wt.\% $\mathrm{H}_{2} \mathrm{O}$ and 65 wt.\% $\mathrm{SiO}_{2}$, we calculated effective viscosities of the bulk composition containing between $10 \%$ and $90 \%$ crystals from 800 to $700^{\circ} \mathrm{C}$ using the method of Murase et al. (1985; equation 3). This method incorporates the major element composition, $\mathrm{H}_{2} \mathrm{O}$ contents, and the volume fraction and mean size of spherical crystals. Although a simplification of the natural system, it provides an initial estimate of effective viscosity that provides a basis for future study. At this bulk composition at $800^{\circ} \mathrm{C}$, effective viscosity increases from $10^{6.9}$ to $10^{9.3} \mathrm{~Pa}$ s with increasing crystal contents

TABLE 3 | Viscosity summary.

\begin{tabular}{lccc}
\hline & \multicolumn{2}{c}{ Starting compositions } \\
\hline Model number & 1 & & 2 \\
\cline { 2 - 3 } Model type & Bulk & Hornblende & $\begin{array}{c}\text { Amphibole } \\
\text { uncertainties from } \\
\text { Zhang et al. (2017) }\end{array}$
\end{tabular}

\begin{tabular}{lcccc}
\hline Major oxides (wt \%) & & & & \\
$\mathrm{SiO}_{2}$ & 65.00 & 76.97 & 3.7 & \\
$\mathrm{TiO}_{2}$ & 0.50 & 0.20 & 0.62 & \\
$\mathrm{Al}_{2} \mathrm{O}_{3}$ & 16.00 & 13.62 & 0.93 & \\
$\mathrm{FeO}_{t}$ & 3.00 & 0.99 & 1.67 & \\
$\mathrm{MnO}$ & 0.50 & - & - & \\
$\mathrm{MgO}$ & 2.00 & 0.22 & 0.96 & \\
$\mathrm{CaO}$ & 3.00 & 1.82 & 1.31 & \\
$\mathrm{Na}_{2} \mathrm{O}$ & 3.80 & 3.50 & - & \\
$\mathrm{K}_{2} \mathrm{O}$ & 4.00 & 3.12 & 0.57 & \\
$\mathrm{P}_{2} \mathrm{O}_{5}$ & 0.15 & - & - & \\
$\mathrm{H} \mathrm{O}_{2} \mathrm{O}$ & 4.00 & 4.00 & - & \\
$\mathrm{Total}$ & 101.95 & 104.44 & - & \\
\hline & & Log effective viscosity (Pa s) & \\
\hline Temperature ( $\left.{ }^{\circ} \mathrm{C}\right)$ & 800 & 700 & 800 & 700 \\
Crystal contents (\%) & & & & \\
10 & 6.87 & 7.90 & 8.14 & 9.34 \\
25 & 7.66 & 8.69 & 8.93 & 10.1 \\
50 & 8.43 & 9.47 & 9.71 & 10.90 \\
75 & 8.98 & 10 & 10.26 & 11.5 \\
90 & 9.25 & 10.3 & 10.53 & 11.7
\end{tabular}


and reaches a maximum of $10^{10.3}$ at $700^{\circ} \mathrm{C}$ (Table 3). Werts et al. (2020) demonstrated that the bulk composition of many TIC samples is generally more mafic than the composition of melts in equilibrium with hornblende due to crystal accumulation. We compared our bulk-rock results to a model using a calculated melt composition in equilibrium with $\mathrm{CP}$ hornblende, containing 4 wt. $\% \mathrm{H}_{2} \mathrm{O}$ and 76 wt.\% $\mathrm{SiO}_{2}$ (equations $3,5,7,9,11,13$, and 14 and associated uncertainties from Zhang et al., 2017). This model resulted in calculated effective viscosities ranging between $10^{8.2}$ and $10^{10.5} \mathrm{~Pa}$ at $800^{\circ} \mathrm{C}$, with a maximum of $10^{11.8} \mathrm{~Pa}$ s at $700^{\circ} \mathrm{C}$.

\section{DISCUSSION}

Our field and geochemical results allow us to analyze schlierenbound magmatic structure formation across several spatial scales. First, outcrop-scale observations and sample compositions are discussed, forming the basis for physical and chemical models of schlieren formation. Kilometer-scale domainal clustering and 10 's km scale regional patterns are then discussed to characterize the scale and mobility of the magma mush system(s).

\section{Outcrop Scale}

\section{Evaluating Models to Form Schlieren}

New (mafic) magma injection

Models concluding that schlieren form from distinct, mafic magma batches (e.g., from a similar source as mafic magmatic enclaves) cannot describe the origin of most TIC schlieren (Figure 1A). The varied geometries and field patterns of schlieren from outcrop to regional scales are difficult to explain by injection of mafic magma batches alone. In addition, mineralogy and whole-rock geochemistry suggests that schlieren are sourced from the surrounding host magma, rather than an "exotic" mafic magma. Schlieren mineral assemblages reflect, to a first order, the assemblage of the surrounding host, with different modal abundances (Table 1, see also Reid et al., 1993; Alasino et al., 2019). Parallel REE patterns further suggest that the mixture of REE-bearing minerals in schlieren is matched in the host and indicates a common magma source, distinct from enclaves (Reid et al., 1993), which is supported by the similarity in host and schlieren isotope compositions (Figure 11D). The unique bulk-rock compositions of schlieren, together with modal assemblages, indicate that they are cumulates (Figure $\mathbf{1 0}$ and Table 1, see below). Thus, their present bulk compositions are not representative of the more evolved parental magma from which they were derived. One interpretation of this parental magma composition is that it falls between 65 and 70 wt. $\% \mathrm{SiO}_{2}$, where the best fit line of schlieren compositions intersects the main TIC trend. Another, determined from calculated melts in equilibrium with TIC hornblende compositions, suggests a range from 67 to 79 wt.\% $\mathrm{SiO}_{2}$ (Werts et al., 2020).

\section{Diffusion and re-crystallization}

Thermochemical diffusion and recrystallization end-member models are also not supported by our combined structural and geochemical datasets (Figure 1A). Field patterns of schlieren, including cross-cutting relationships, are not explained by this model. Solgadi and Sawyer (2008) demonstrated, using hornblende Mg-number, that schlieren lacked any compositional gradients from base to top, which either a thermal or chemical gradient should impose. In-situ mineral analyses of samples across all TIC units reveal complex zoning patterns, which suggests that thermochemical diffusion did not re-equilibrate the mineral compositions (Memeti et al., 2014; Barnes et al., 2016; Werts et al., 2020). In a liquid immiscibility model, a form of chemical diffusion (e.g., Glazner et al., 2012; Bartley et al., 2019), isotope compositions should be identical between schlieren and host, and the felsic component to the mafic schlieren should be enriched in alkalis, Rb, Cs, Sr, and Ba (Ryerson and Hess, 1978; Hurai et al., 1998), neither of which are observed in TIC samples. Instead, the felsic component has a similar composition to the host. Mixing schlieren and felsic components together as demonstrated by analyses of Solgadi and Sawyer (2008) and shown on Figure 10 produces a compositional array parallel to schlieren trends, distinct from the host. Furthermore, if mafic schlieren represented the Fe-rich liquid of an immiscible pair, the density of the schlieren should be considerably greater than the host and would be expected to separate from felsic components and the host, rather than be interlayered with them.

\section{Magmatic flow}

Our proposed model to explain field and geochemical datasets involves hydrodynamic flow-sorting of crystals in a mush to produce schlieren layering (Figure 12C). TIC schlieren contain dense minerals and reduced abundance of low-density feldspar. An exception includes schlieren containing K-feldspar megacrysts, which are a part of some (but not all) schlierenbound structures (e.g., Figures 3C, 4A,C,D). Their considerably greater size compared to other minerals may contribute to their inclusion. Together with evidence of common mode and size grading of schlieren layers, these observations are consistent with mineral accumulation that depends on the density, size, and shape of individual crystals (e.g., Bhattacharji and Smith, 1964; Kawabata et al., 2013). Further, outcrop scale cross-cutting relationships, truncation of structures by the host magma, and consistent patterns of outward-younging orientations within and across domains that span a range of crystallization ages requires physical, magmatic erosion and flow processes to operate synchronously and repeatedly. Schlieren form an array of major and trace element compositions at high-angle to the main TIC trend, which are interpreted here to represent the varying degrees of crystal accumulation of hornblende, biotite, apatite, titanite and zircon that dominate schlieren compositions. As a suitable complementary felsic fractionate is not observed (see above), we interpret that any melts resulting from schlieren accumulation were mixed back in with surrounding host magma, to form the felsic components of schlieren-bound structures (see also Alasino et al., 2019).

Small shifts towards radiogenic $\mathrm{Sr}_{i}$ in schlieren, and variable differences in $\varepsilon \mathrm{Nd}_{i}$ between schlieren and host are also compatible with a flow-sorting crystal accumulation model. Measurable isotopic shifts at the scale of the schlieren and adjacent host could be caused by: (1) crystal-melt fractionation from an isotopically hybrid magma (e.g., Beard, 2008); 


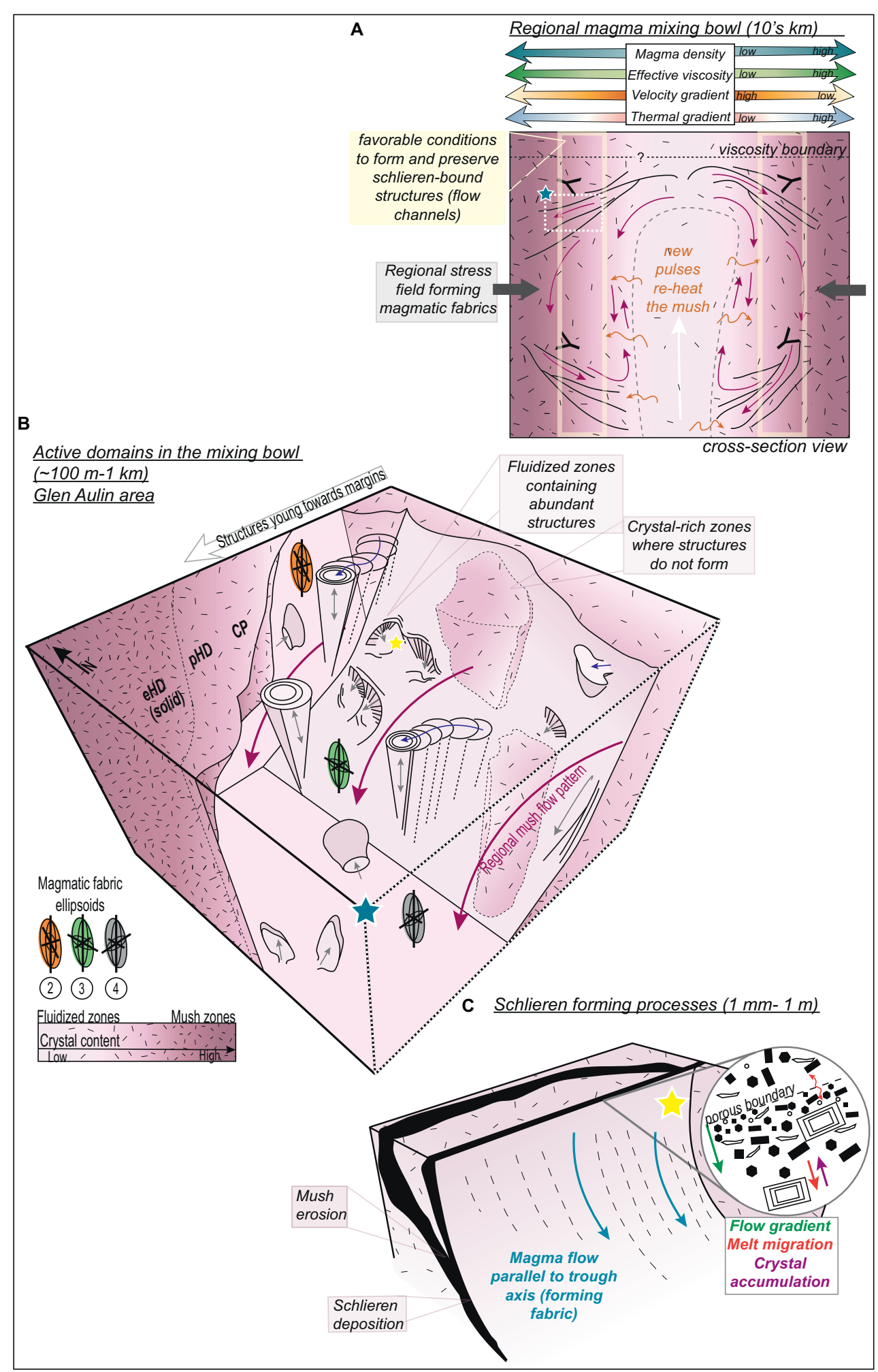

FIGURE 12 | Summary of multi-scale dynamic processes operating in mobile magma mushes. (A) Mixing bowl scale. Return flow of the mush is triggered by intruding pulses in the center of the complex. Thermal/mechanical gradients aid convection. (B) Domain scale activity summarized as a 3D diagram. Structures form in fluidized zones that are more melt-rich due to local changes in pore-pressure, viscosity, and stress, while crystal rich zones represent zones that are absent of schlieren-bound structures. They still contain melt as they contain magmatic fabrics, dikes and other structure. (C) Structure-scale processes demonstrated for a magmatic trough. Flow sorting, filter pressing, crystal accumulation and melt escape are all important processes at the mm-cm scale. Flow along the trough channel produces a lineation in hornblende. 
(2) selective crystal accumulation of Rb-bearing minerals, or Sm-bearing minerals; or (3) alteration of minerals by late magmatic fluids (e.g., Li et al., 2018; Alasino et al., 2019). Diffusion or metasomatism by late magmatic fluids should leach mobile elements, such as Rb, from samples, leading to low $\mathrm{Rb} / \mathrm{Sr}$. However, the relationship between pairs of related samples is not the same for all samples studied or compiled; in most cases (five samples out of six), $\mathrm{Sr}_{i}$ is more radiogenic in schlieren, but $\varepsilon \mathrm{Nd}_{i}$ is variable. In addition, the preservation of textural and compositional zoning in Rb-bearing phases such as K-feldspar, and $\mathrm{Sm}$ and Nd-bearing phases such as hornblende (and apatite) demonstrates that diffusion of fast- and slow-diffusing elements was limited in the TIC (Memeti et al., 2014; Barnes et al., 2016; Werts et al., 2020). Thus, isotopic differences between schlieren and host are interpreted as primary magmatic features of the samples resulting from processes (1) and (2), rather than secondary features (3).

As the TIC is isotopically heterogeneous (Kistler et al., 1986; Gray et al., 2008; Memeti et al., 2014), models that fractionate crystals from a hybrid magma and create further heterogeneity, as illustrated by Beard (2008) are considered likely to explain schlieren-host isotopes in combination with field data and mineral assemblages. Furthermore, selective fractionation and accumulation of minerals could amplify the difference in isotope composition between schlieren and the surrounding host (e.g., Kendall et al., 1995; Blum and Erel, 1997). Rubidiumbearing minerals such as biotite, abundant in the CP schlieren, could result in high $\mathrm{Sr}_{i}$ ratios, while accumulation of Smbearing minerals such as apatite and hornblende could result in high ${ }^{143} \mathrm{Nd} /{ }^{144} \mathrm{Nd}_{i}$ and thus more primitive $\varepsilon \mathrm{Nd}_{i}$ values. An example of the latter is the $\mathrm{KC}$ schlieren sample, which contains $\sim 40 \%$ hornblende.

\section{The Significance of Forming Schlieren Between 65 and 79 wt. $\% \mathrm{SiO}_{2}$}

TIC host magmas were already mixed before schlieren formation based on whole-rock isotope trends (Memeti et al., 2014). The flow-sorting model requires that most, if not all, of the highly concentrated minerals (biotite, hornblende, magnetite, titanite, apatite, and zircon) were saturated in the host magma before schlieren minerals were separated and requires sharp rheological boundaries to exist in the mush. Melt presence is required to deform schlieren-bound structures by magmatic faulting and folding, for the felsic component of schlieren accumulation to mix back in with the host magma, and also to form magmatic fabrics (discussed below). The structure must have formed in a sufficiently strong magma to erode and sometimes break structures without losing definition in individual layers and also to form sub-vertically dipping schlieren (e.g., Bergantz, 2000; Weinberg et al., 2001; Paterson, 2009; Alasino et al., 2019). Each of these observations suggest that the magma was chemically evolved and crystal-rich during schlieren formation.

The intersection of major and trace element best-fit trends of schlieren with TIC host and felsic component samples lies consistently between 65 and 70 wt. $\% \mathrm{SiO}_{2}$. One possibility is that this represents the bulk composition of the parental magma when the schlieren and felsic components were formed. However calculated melt compositions from hornblende, using the Zhang et al. (2017) chemometer range between 67 and 79 wt.\% $\mathrm{SiO}_{2}$ within the TIC, highlighting the effects of crystal accumulation (Barnes et al., 2020; Werts et al., 2020). In the CP unit, with the calibrated uncertainties on the amphibole calculations (listed in Table 3), these melts are rhyolitic (Werts et al., 2020). Further, these two independent approaches to estimate melt compositions overlap within the smaller range of $67-70 \mathrm{wt} . \% \mathrm{SiO}_{2}$. In both examples we can place initial constraints on magmatic conditions during schlieren formation, specifically the magma viscosity. Given the rhyolite composition of the melt, the largest effects can be expected from changing temperature $\left(800-700^{\circ} \mathrm{C}\right)$, crystal content, and $\mathrm{H}_{2} \mathrm{O}$ content, which here is considered a minimum. During the temperature interval of $800-700^{\circ} \mathrm{C}$, when schlieren likely formed, calculated effective viscosities increased from $\sim 10^{7}$ to $10^{11} \mathrm{~Pa} \mathrm{~s}$ as crystal content increased in both starting compositions, with considerable overlap between models, and the calculated melt compositions providing the highest values.

Although these values appear on the high end to facilitate magmatic flow, previous studies have demonstrated that small variations in pore pressure or strain rate may manifest as large variations in magma viscosity, without substantially reducing temperature or crystallinity of the magma to generate local rheologic boundaries (e.g., Weinberg et al., 2001; Bergantz et al., 2017; Sparks et al., 2019). Numerical modeling of hydrogranular crystal networks suggest that, at the crystal scale, particle-particlemelt interactions and forces such as melt lubrication, crystal clustering, jamming, and the migration of particle force chains all can aid or inhibit movement of crystals and fluids under magmatic conditions and thus instantaneously and dramatically modify mush rheology to promote or inhibit magmatic flow (Bergantz et al., 2017; Carrara et al., 2019; McIntire et al., 2019). Thus, bulk or effective viscosity does not fully describe the mobility or the dynamics of the system. Future studies exploring parameters such as volatile content (including separate fluid phases), estimating strain rates, crystal properties (e.g., size, shape, density), and the porosity and pore pressure of the system could help to constrain the dynamics of the system during schlieren formation. These processes that locally and transiently reduce viscosity may also enhance melt migration out of the schlieren and into the surrounding host mush; potential mechanisms include filter-pressing or porous flow (e.g., Weinberg et al., 2001). Similar magmatic flow models were previously proposed in granitoid systems by Weinberg et al. (2001), Paterson (2009), and Alasino et al. (2019), who invoked deformation-assisted mineral-melt separation to form schlieren structures in the Tavares pluton, the TIC, and the Sonora Pass Intrusive Suite, respectively.

\section{Evaluating Models to Form Different Schlieren-Bound Structures}

The results of this study support a range of physical processes to form different schlieren-bound structures, as described by Weinberg et al. (2001) and Paterson (2009). These include boundary flow, filter pressing, and Rayleigh-Taylor instabilities. Combinations of these processes might operate to create transitional-type structures described in section "Relative Timing 
Indicators" (e.g., troughs grading into tubes). Instabilities triggering fluidization of the mush and structure formation may be driven by sinking of dense objects or magma mushes (e.g., Wiebe et al., 2007), or the rise of buoyant objects (e.g., exsolved volatiles, extracted melts: Clarke, 2003; Dietl et al., 2010), both of which have been proposed to form individual tube structures. In addition, the intrusion of new magma pulses into the chamber may promote thermal, chemical and mechanical instability (e.g., Pons et al., 2006). This behavior has been suggested to drive crystal avalanches (forming troughs; Solgadi and Sawyer, 2008; Alasino et al., 2019), as well as local rising of magmas (forming tubes or plumes; Paterson, 2009).

The diversity in the types of observed magmatic structures within most map domains (GA, TP, and LC) indicates that at a single outcrop ( $\sim 10-20 \mathrm{~m}$ scale), local flow fields were complex enough to form geometrically distinct troughs, tubes and plumes. For example, at several localities at Glen Aulin there may be both vertical magma flow through tube structures, and moderately down-dipping flow in troughs. This raises the question if different structures may require or favor different magmatic conditions, or driving mechanisms, to form (e.g., Figure 1B). In contrast, within the Young Lakes area, tubes and plumes are sparse and planar schlieren and troughs are dominant, which could suggest the magmatic flow field was distinct, and perhaps more uniform.

There is a weak spatial control on the types of structures that form. At Glen Aulin, plumes are generally concentrated in the east, and tubes are concentrated in the west. The eastern edge of the domain is the youngest edge of the domain, formed across a steep age gradient (Memeti et al., 2014 isochron plot), which suggests that this could result from a temporal shift in physical flow mechanisms, in addition to a spatial shift.

\section{Domain Scale \\ Magma Chamber Domains Are Spatially Heterogeneous as a Result of Flow Instabilities}

TIC schlieren-bound structures are spatially clustered between large $\left(\sim 0.1-0.5 \mathrm{~km}^{2}\right)$ zones where structures are sparse to absent. As described above (section "The Significance of Forming Schlieren Between 65 and 79 wt.\% $\mathrm{SiO}_{2}$ "), schlieren are likely recording events within an evolved, crystal-rich mush, at temperatures between 800 and $700^{\circ} \mathrm{C}$, thus they represent a view into later stage magma flow and evolution within a chamber. The difference between the structure-rich and structure-poor zones could reflect: (1) zones which were "fluidized," more meltrich and therefore more mobile mush, producing abundant structures, separated by mushy zones that were unable to flow as dynamically and therefore lack schlieren-bound structures (a form of partitioning); (2) structures were uniformly present throughout the chamber and were subsequently erased by later mixing and homogenization; and (3) structure rich domains represent zones of sharp flow velocity gradients that could have increased mobility due to positive feedbacks as structures started forming; or 4) structure rich zones represent channels of porous flow. All scenarios imply that magma dynamics were spatially heterogeneous at the $1-10 \mathrm{~km}$ scale. It appears more difficult to completely erase the evidence of schlieren-bound structures, because that would require thorough mixing at high crystal contents. Field observations show that schlieren-bound structures can deform semi-rigidly (by faulting and folding and re-intrusion) or mingle with the host magma, suggesting it may be mechanically challenging to fully erase the schlieren once they form. This is supported by the weak to absent overprinting of local type 1 fabrics by regional type $2-5$ fabrics in schlieren, but more pervasive overprinting in the felsic parts of the structures.

Spatial clustering of schlieren-bound structures is documented in other plutons. In the Vinalhaven intrusive complex, schlieren-bound structures (mostly tubes) "occur widely but sparsely," wherever sinking enclaves could sufficiently shear the surrounding crystal mush (Wiebe et al., 2007). The pluton was strongly vertically stratified, controlling the path of the enclave (Wiebe et al., 2007). Clarke et al. (2013) suggested that tube structures were preferentially found near the pluton margins in the Halifax pluton, Nova Scotia, a result also found in K-feldspar pipes associated with schlieren by Rocher et al. (2018) in the San Blas intrusive complex, Argentina. Clarke et al. (2013) further posited that the cause of structures clustering within the contact zone could be attributed to "restricted zones of permeability," which could represent the fluidized zones described here.

\section{Processes triggering domain-scale flow instabilities}

The occurrence of domain-scale magmatic structure patterns suggests that broader-scale dynamic instabilities were present in TIC mushes, and not restricted to the outcrop-scale where individual structures formed. Several processes may have operated in the TIC. The intrusion of new pulses, or upwards migration of volatiles, could lead to mobilization and convection of the mush (e.g., Bachmann and Bergantz, 2006; Burgisser and Bergantz, 2011; Pinotti et al., 2016; Figure 12A). In computational models, the heterogeneous distribution of particle force chains maps transient high and low stress zones in the mush, that has implications for pore-pressure variability, and overall mush porosity (e.g., Estep and Dufek, 2012; Bergantz et al., 2017). Focused porous flow could also create zones of increased permeability that promote flow instability (Kelemen et al., 1995; Paterson et al., 2012). In other cases (e.g., Sawmill Canyon) structure-rich domains may be spatially restricted to magma sheets or cracks (e.g., Clarke and Clarke, 1998; Paterson et al., 2008). Pluton roofs and internal contacts may generate vertical domain-scale instabilities. Roof instability can lead to sinking of crystalline mush, which could then be further segregated by density (e.g., "crystal-rich drips"; Bergantz and Ni, 1999; Rocher et al., 2018; Carrara et al., 2019). We infer that the present-day exposed levels of the TIC are representative of the upper levels of the magma body, close to the roof. Evidence includes local exposures of roof flaps and an approximately uniform elevation plane of highest (plutonic) peaks across the TIC (e.g., Bateman, 1992; Cruden et al., 2017). Sub-vertical, internal contacts are ideal locations for solidification fronts, leading to mush collapse and avalanching along steeply dipping walls (e.g., Marsh, 1996; Bergantz, 2000; Rocher et al., 2018; Alasino et al., 2019). 
Domain-scale solidification fronts may play a larger role in the Glen Aulin area, relative to the Young Lakes or Lyell Canyon areas, as major unit contacts are closely spaced, with potentially greater thermal, chemical, and rheologic gradients across them. While all of these processes likely were active during the evolution of the TIC, the lack of similarity in domain size, shape and orientation, together with our outcrop- and regional-scale structural patterns favor forming domains by spatial heterogeneity in particle-particle interactions, driven by new pulses.

\section{Planar Schlieren and Troughs Weakly Align With Nearby Contacts Due to Boundary Conditions}

In the Glen Aulin domain, there is a weak preference for planar schlieren and trough orientations in a NESW direction that aligns with the well-defined Type 2 foliation, and with the adjacent contacts of the Cathedral Peak unit with the older Half Dome units. This is also qualitatively suggested in $\mathrm{N}-\mathrm{S}$ striking contact-parallel schlieren at Tenaya Peak, although this interpretation is complicated by a similarly oriented Type 3 foliation. In contrast, this relationship is not apparent in the Young Lakes domain, where the nearest contact (2-3 km away) is NW-SE striking, yet planar schlieren and troughs are oriented at high angle to the NW-SE foliation, and instead show a preference for NE-SW striking orientations.

The relationship between schlieren orientations and the contact is ambiguous at Lyell Canyon, potentially because the contact is a wide, gradational zone between units that hybridized (Žák and Paterson, 2005; Paterson et al., 2011, 2016; Oppenheim et al., in review). At Glen Aulin, the contacts between eHD (probably near-solidus) and the pHD and CP (active magma mushes of varying crystallinity, Figure 12B) are proximal across a 100-200 m wide zone. Thermal and chemical gradients could be significant in driving flow gradients, and perhaps play a larger role in defining the orientations of the structures at Glen Aulin than in the other domains (Figure 12B). As domains devoid of structures are interspersed with domains concentrated in structures across zones both near and far from contacts, we suggest that nearby contacts are not controlling the formation of schlieren, but potentially play an indirect role in their orientation at the schlieren-bound structure scale.

\section{Crystal Clustering Is Widespread and Independent of Domains}

The observation that K-feldspar megacryst clusters are found widely in the TIC, even in areas of sparse to absent schlieren complicates the story of heterogeneous, isolated, schlieren-rich domains (e.g., Paterson et al., 2005). In some cases they are associated with schlieren, but they also represent a similarly local (meter-scale), selective mineral sorting and accumulation process that does not seem to be as spatially restricted. The K-feldspar megacryst clusters could be mechanically sorted (Paterson et al., 2005; Vernon and Paterson, 2006; Paterson, 2009), possibly representing "logjams" in a less-dynamic flow field, brought together in a cluster due to their large size (Weinberg et al., 2001).

\section{Regional Scale}

\section{Outward-Younging Patterns Reflect Re-mobilization of the Mush by New Pulses}

At the regional scale, the TIC is defined by four compositionally distinct units, which are bounded by a wide variety of external and internal contacts. Multiple magmatic fabrics are found in each of the units, and cross several of these internal contacts. Compositionally defined magmatic structures occur across all TIC units. Schlieren-bound structures are clustered, with a dominant pattern of structure migration or younging outwards, towards internal contacts with older units. The regional patterns listed above may provide insight into viable emplacement models for the TIC, including dike emplacement, sill/laccolith emplacement, or a combination of sheet and diapir emplacement. Emplacement models are described below, specifically focusing on what these models predict for schlierenbound structure patterns at regional scales and how our regionalscale results (contacts, fabrics, schlieren-bound structures) compare. A broader overview of TIC emplacement is provided in section "Implications for Emplacement Models and the Minimum Sizes of Magma Chambers."

\section{Incremental growth models for the TIC}

Some studies have proposed that the TIC was emplaced by a series of stacked sills, or laccoliths that were subsequently folded and eroded to produce the nested map pattern of major units (Bartley et al., 2006; Coleman et al., 2012). Individual sills freeze before younger sheets or sills are intruded, and so deeper source regions are responsible for observed compositional/textural heterogeneity in a closed system. In this model, outwardyounging patterns of schlieren-bound magmatic structures represent an artifact of the folding of individual sills, assuming that the structures were initially horizontal (layer-parallel) and upward younging, as suggested by Bartley et al. (2018). The model also predicts that schlieren-bound structure dips should systematically shift from the center of the TIC to the margin, with initially vertical and upward-younging orientations in the center, towards rotated, horizontal, and outward-younging orientations at the margins. This model cannot explain why schlierenbound structures are clustered. We have found no evidence for systematically changing structural dip across transects of the TIC, in any of the mapped structures. Further, magmatic fabrics show no evidence for being axial planar to a TIC-scale fold, nor is there a systematic change in dip, as magmatic lineations are largely sub-vertical throughout the TIC. The observation that fabrics can overprint unit contacts (e.g., Žák et al., 2007), and that mixing occurred between units (Chambers et al., 2020) precludes the idea that older units were completely solidified before emplacement of new batches.

A similar model proposes that the pulses are vertical dikes instead of sills, which also freeze before subsequent dikes are emplaced (Bartley et al., 2018). In this case, older dikes are displaced outwards by younger, producing a strict temporal sequence. This model is also problematic for the TIC, as it shares several of the same issues as the sill model above, with some additions: Firstly, sheeted contacts are restricted to locally mapped zones (Paterson et al., 2008; Žák et al., 2009; 
Memeti et al., 2010). Secondly, the schlieren-bound structures have a wide range of types, and do not show any preferential orientations that would be consistent with flow along dike walls. The observations of magmatic deformation, erosion, and flow of crystals with mixed mineral populations is also inconsistent with a dike model (e.g., Solgadi and Sawyer, 2008).

A third model suggests that the TIC grew initially by sheets, which amalgamated into larger magma bodies and facilitated the emplacement of diapirs (e.g., Memeti et al., 2010; Paterson et al., 2011). In this model, schlieren-bound structures form from magmatic flow as a response, at the regional scale, to the intrusion of new magma batches. Older and younger batches can interact within the magma chamber to generate emplacement-level, open system magma mixing. This model explains observations of internal contacts that vary along and across strike as regions of differential magmatic erosion and recycling, and the regional extents of multiple magmatic fabrics as a record of regionally extensive melt-present regions (Paterson et al., 2016). Below we discuss our schlieren-bound structure results in the context of this model:

\section{Return flow model}

Outward younging directions in the Cathedral Peak unit are consistent with a model where new pulses, intruded at the center of the complex, drives displacement of the mush and causes it to flow outwards and downwards (see also Bateman, 1992; Paterson et al., 2016; Wiebe et al., 2017; Figure 12A). Physical gradients (e.g., flow velocity, viscosity, density) and thermal gradients help drive convection of the mush, as well as define the regions in which structure formation and preservation are favorable (Figure 12A). At the margins of the mush, cooler, more crystalline portions sink, and flow downwards. The intruding hotter pulses re-heat the mush to create melt-rich regions, as well as draw lower levels of the mush pile to higher levels of the chamber (Figure 12A). This region of mobile mush is referred to as the mixing bowl, after Bergantz et al. (2015, 2017). We propose that movement of the mush occurred within a vertically extensive magma mush body, accommodated by downward flow that creates space for new magma batches (Figure 12A). This is supported by sub-vertical external and internal contacts, a steep magmatic lineation, moderate to steeply dipping schlieren and vertical tube axes (Oliver, 1977; Paterson, 2009; Paterson et al., 2011). The return flow model implies that towards the base of the magma body, the structures should start to young inwards, influenced by the downward flow of the mush and the intruding pulses (Figure 12A). Inward younging structural patterns are reported in other plutons in the central Sierra Nevada (e.g., Alasino et al., 2019), however, this model would optimally be tested in a tilted pluton, where multiple levels are exposed.

\section{Alternative models}

There are likely multiple causes of younging, or migration directions measured in schlieren-bound structures. Flow in magma sheets related to cracking of the magma mush is one mechanism that could create a broader-scale younging direction (Paterson et al., 2008; Žák et al., 2009). This process is likely to have dominated where sheeted zones are documented.
Other scenarios that could cause structures to migrate and young outwards, such as regional extension, a thin, laterally spreading mush, or a static, inwardly cooling mush, are not supported by our datasets. In the former, the regional dextraltranspressive tectonic setting recorded in the surrounding host rock, as well as rapid crustal thickening, regional inward magmatic focusing patterns, and steep magmatic lineations in the TIC, all preclude any extensional emplacement model (e.g., Žák and Paterson, 2005; Cao et al., 2015, 2016b; Ardill et al., 2018; Hartman et al., 2018). We note that extension could occur locally in the return flow model. In a static, cooling mush, where cooling at the margins outpaces intrusion by new pulses, the structures are predicted to young inwards, not outwards, due to collapse of the newly solidifying mush at the margins.

\section{Significance of return flow: mapping mixing bowls}

As the outward younging pattern is found in each of the TIC units, this process occurred repeatedly over the 10 m.y. lifespan of the TIC. In addition, the outward-younging structures across four mapped domains of the CP unit are consistent with the possibility that it was as a single large mixing bowl (see below section "Implications for Emplacement Models and the Minimum Sizes of Magma Chambers"; Figure 12). In contrast, inward-younging structures in the eastern porphyritic Half Dome unit observed in the Lyell Canyon area represent an exception to the outward-younging pattern found elsewhere in the $\mathrm{CP}$ and pHD. Although the dataset is limited in size, one possibility is that the pHD mixing bowls were smaller than the $\mathrm{CP}$ mixing bowl, and that the Lyell Canyon structures and the Tenaya Peak structures record events from two different pHD mixing bowls. Although much of the $\mathrm{pHD}$ unit has been removed by the $\mathrm{CP}$, mapping larger areas containing $\mathrm{pHD}$ structures can test this hypothesis.

\section{External Processes Are Not a Significant Control on Schlieren-Bound Structure Orientation}

Tectonism has been proposed to cause magma mush instability on the timescales of seconds to minutes (e.g., earthquakes; Davis et al., 2007), and at the m.y. time-scale can form fabrics and extract melts (e.g, Paterson et al., 1998; Garibaldi et al., 2018; Bachmann and Huber, 2019). Regional tectonism during emplacement of the TIC was dextral transpressive, with metavolcanic and metasedimentary host-rock fabric orientations consistent with the regional NW-SE magmatic foliation found in TIC domains (e.g., Žák et al., 2007; Cao et al., 2015; Hartman et al., 2018). At the scale of the intrusive complex, regional E-W magmatic foliations and vertical lineation are pervasive. Schlieren do not show a clear angular relationship to either regional foliation orientations within any of the mapped domains. This supports the conclusion that strain caused by local magmatic flow, forming schlierenbound structures, dominated over regional-scale strains that formed fabrics, and suggest this is due to higher strain rates in structures formed by magmatic flow (Žák et al., 2007; Paterson et al., 2008). Magmatic fabrics are timetransgressive throughout the $10 \mathrm{~m} . \mathrm{y}$. lifespan of the TIC, indicating that the regional strain fields were long-lived 
(Žák et al., 2007). Schlieren-bound structures, found in all TIC units, are thus also a time transgressive record of internal magmatic processes.

\section{Timing of Schlieren-Bound Structure Formation}

Examination of the field and geochemical datasets indicate that schlieren-bound structure formation occurred in a crystalrich mush, where crystal frameworks were important to form, deform, and also preserve schlieren-bound structures. In the broader context of the TIC, schlieren-bound structures formed pre, syn, and post formation of major unit contacts, and after crystallization of minerals contained in abundance in the schlieren-bound structure (e.g., zircon; Memeti et al., 2014; hornblende, biotite). Schlieren formation was widespread, occurring repeatedly over the $10 \mathrm{~m}$.y. lifespan of the TIC.

Magmatic erosion, re-deposition and deformation occurred in a magma that had a yield strength (see also Hodge et al., 2012). Since these processes occurred in quick succession at a single outcrop, it suggests that there were complex interactions between crystallinity and effective viscosity, particle-particle interactions, pore-pressure, and crystal lubrication effects (Weinberg et al., 2001; Paterson, 2009; Bergantz et al., 2017; Carrara et al., 2019). Discordance between local schlieren-defined fabric and the regional fabrics and the overprinting relationships within felsic components indicates that the strain fields forming regional fabrics and local schlieren fabrics were active at the same time, but at different rates. The schlieren fabric likely formed at faster strain rates than the regional fabrics, producing discordance. When the rate of magmatic flow and deposition slowed, the regional fabric was able to re-orient minerals in melt-rich felsic components, producing the overprinting relationships (e.g., Paterson et al., 2008).

Mineralogically, quartz abundance varies little in abundance between schlieren and host samples, which, together with petrographic textures, suggests that it was the main mineral to crystallize late in the magmatic history (after schlieren formation) from trapped, interstitial melts that were evolved. The bulk rock compositions and equilibrium melt compositions suggest that schlieren formed from an evolved magma mush, containing 65-79 wt.\% $\mathrm{SiO}_{2}$.

\section{Implications for Emplacement Models and the Minimum Sizes of Magma Chambers}

The TIC is a composite magmatic complex, containing gabbro to leucogranite with granodiorite and granite the most abundant rock types. The complex spans a $10 \mathrm{~m}$.y. zircon crystallization history, with four major units bounded by sharp to gradational contacts that internally range from homogenous (at outcrop scale) plutons to sheeted zones (Žák et al., 2009; Memeti et al., 2010). To explain these observations, different incremental emplacement models have been proposed, and are outlined above (section "Incremental growth models for the TIC"). Regionally extensive magmatic fabrics (e.g., Figure 1A), recycling of older units into younger, compositional evidence for widespread magma mixing and recycling in bulk rocks and in minerals, geochronologic studies, and thermal models all suggest that TIC magma chambers (interconnected melt regions) in the Cathedral Peak unit, and in each of the older units, were volumetrically extensive $\left(\sim 1000 \mathrm{~km}^{3}\right)$ and long-lived (up to 1.5 m.y.) (e.g., Matzel et al., 2005, 2006; Žák et al., 2007; Solgadi and Sawyer, 2008; Memeti et al., 2010, 2014; Paterson et al., 2011, 2016; Barnes et al., 2016). Together with the above-listed evidence, outcropscale flow features, domain-scale clustering and regional-scale outward-younging schlieren-bound structure patterns presented here require a magma emplacement model where incrementally emplaced new magma pulses can interact with older pulses dynamically by magmatic flow, transferring mass and energy to the larger-scale interconnected-melt region, or magma mush. This has been proposed to occur by the interaction of dike- or diapir-shaped pulses that amalgamate in time and space to form long-lived, dynamic magma bodies (e.g., Miller and Paterson, 2001; Memeti et al., 2010; Cao et al., 2016a).

The multi-scale observations of magmatic structures also allow us to place additional constraints on the minimum sizes of likely magma chambers that existed in the Cathedral Peak unit. As the younging patterns in each study area of the CP unit are all consistently outward (Figure 12A), then the southern portion of the $\mathrm{CP}$ unit, encompassing all four domains, represents the minimum size of one mixing bowl, or magma chamber, in the return flow model described earlier. This results in an area of about $150-175 \mathrm{~km}^{2}$, or a volume between 750 and $1750 \mathrm{~km}^{3}$ (using the vertical extents estimated by Karlstrom et al., 2017). The zircon isochron map of Memeti et al. (2014) suggests that this mixing bowl formed across $\sim 1.5$ m.y. At shorter timescales, the domainal fluidized zones could each represent their own active magma chambers, capable of magma mixing, mingling and fractionation. Their sizes, between approximately $0.5-2 \mathrm{~km}^{2}$ in area (vertical extents unknown), suggest they could be locally important for producing structural and compositional diversity in plutons, but are unlikely to explain the outcrop-scale to mapscale homogeneous appearance of the well-mixed CP unit.

\section{Implications for the Behavior of Magma Mush Systems}

The above observations indicate crystal-rich mushes, even in upper crustal magma chambers, can be highly dynamic environments. Numerical modeling of mushy plutonic systems has demonstrated the potential for complex crystal-melt and crystal-crystal interactions that schlieren may represent just one (visible) example of (e.g., Bergantz et al., 2017). The "mixing bowl" model of Bergantz et al. (2015) and Schleicher et al. (2016) displays a number of features that match field-based structural observations in the TIC. These include magmatic faulting, slumping, and folding of schlieren, and erosion of earlier formed layers. In addition, the spatial heterogeneity of the deforming mush, with locally "active" and "static" areas in the model is consistent with our interpretation of the spatial clustering of magmatic structures. Finally, the outward younging patterns predicted by the upper parts of the model concur with our field dataset. The widespread distribution of the 
structures across the TIC suggest that dynamic hypersolidus conditions, as exemplified by the "mixing bowl" model, existed in different units and areas of the TIC repeatedly throughout its entire $\sim 10$ m.y. lifespan. The schlieren-bound structures represent sites of compositional differentiation occurring at the emplacement level, and sites of local magmatic recycling (e.g., Paterson et al., 2016).

No clear relationship yet exists between the orientation of regional magmatic fabrics (Types 3-5) and schlieren-bound structure orientations (Type 1). This suggests that internal magmatic processes dominate in the formation and orientation of schlieren-bound structures. Garibaldi et al. (2018) proposed that magmatic fabrics and magmatic structures (e.g., miarolitic cavities) in the Huemul pluton record evidence for a crystalrich mush mobilizing interstitial rhyolitic melts by tectonic filter pressing. Other studies have also considered tectonism as a mechanism to mobilize crystal-mushes and re-orient earlier-formed magmatic structures, including fabrics (e.g., Žák and Paterson, 2010; Alasino et al., 2019). To reconcile these findings in the context of schlieren-bound structures in the TIC, we suggest that the strain rates producing regional fabrics (of which some may be tectonic) are slower, but longer-lived than strain rates producing local schlieren-bound structure fabrics.

Despite large variations in composition, size and emplacement depth, schlieren-bound structures are ubiquitous in plutons, although less well developed in many. Some notable localities include the Tavares pluton, Brazil (Weinberg et al., 2001), the Skaergaard intrusion, Greenland (Wager and Brown, 1968; Holness et al., 2017), and the Coastal Maine batholith (Wiebe and Collins, 1998), which, in addition to the TIC, contain a high abundance and diversity of schlieren-bound structures. It suggests that the physical flow-sorting mechanisms proposed here are an intrinsic feature of magma mushes, and are not primarily dependent on magma compositions, pressure, or temperature.

\section{Future Directions}

Further quantifying the physical and chemical magma properties at the time schlieren-bound structures formed is an important step in reconstructing magma mush dynamics. In addition, exploring why some plutons are rich in schlieren-bound structures, while others are poorer, may provide definition on the most important magma properties or mechanisms to form schlieren-bound structures. Ongoing and future studies must explore these themes at multiple scales.

At the mineral scale, this includes determining which minerals grew in-situ within a structure, and which were physically sorted into schlieren. Studies have proposed that some structures may represent volatile pathways (Paterson, 2009; Clarke et al., 2013). The role of any exsolved fluid or gas that aids or impedes the formation and preservation of structures remains unclear and would benefit from quantitative structural and compositional analysis. Recent studies indicate that magmatic deformation of mushes leaves a microstructural signature (Holness et al., 2017; Holness, 2018), which could be illuminating in terms of schlieren formation. For example, do the minerals in schlieren show evidence of crystal-plastic deformation indicating that they were compacted (e.g., Holness, 2018), or is crystal-repacking a suitable alternative (Bachmann and Huber, 2019)? What was the porosity of the schlieren cumulate when melts were extracted, and did they experience secondary grain-boundary adjustments (e.g., Holness, 2018)? Is there a microstructural record of regional-scale deformation in schlieren-bound structures, and can we quantify the strain rates forming schlieren fabrics and regional fabrics?

At the outcrop scale, the diversity of structures in the TIC suggests that different magmatic conditions and/or mechanisms operate within a magma mush at any one time or place. Future directions could investigate the mechanical and fluid-dynamical relationships between different types of structures, as well as quantitatively considering the role of the surrounding magma and its physical and chemical properties in determining which type of structure forms.

Across the entire TIC, constraining the different mechanisms of fabric formation is needed to place a regional context to the internal magmatic schlieren-forming process. Additional statistical analysis of the regional compilation could resolve why schlieren-bound structures are clustered at this scale, and whether certain structures dominate certain clusters (e.g., by comparing the structures that are the target structures nearest neighbor), and resolve the distinction between the distribution of compositionally defined magmatic structures like K-feldspar megacryst structures, and schlieren-bound structures.

\section{CONCLUSION}

Schlieren layers are locally sourced from nearby magmas and provide evidence for local magma flow, mineral-melt separation, and compositional differentiation. Although the diversity of schlieren-bound structures in the TIC suggests there are multiple mechanisms of formation, schlieren are a common link between them. Thus, schlieren-forming processes such as hydrogranular flow-sorting, melt migration and crystal accumulation are considered both widespread and significant in magma mush systems.

Analysis of magmatic structure orientations from outcrop, domainal, and regional scales suggests that magma mushes are highly dynamic environments across multiple length scales, and field observations are remarkably similar to hydrogranular behavior described by the "mixing bowl" models (Bergantz et al., 2015, 2017; Schleicher et al., 2016). Domainal clustering of structures indicates that mush fluidization is spatially and temporally heterogeneous.

Outward-younging patterns are likely driven by regionalscale convection and return flow of the magma mush, driven by the intrusion of new pulses at the center of the magma mush chamber. This pattern, recorded in all types of schlierenbound structures studied here, can provide clues to the extent of magma mixing bowls, and the sizes of active domains within them. Schlieren-bound structure orientations are sensitive to some boundary types, such as local rheological boundaries and nearby internal contacts, but not to regional stress fields. Thus, 
the interplay of internal and external forces operating within magma chambers remains an exciting avenue of future research.

\section{DATA AVAILABILITY STATEMENT}

The datasets generated for this study are available on request to the corresponding author.

\section{AUTHOR CONTRIBUTIONS}

KA and SP designed the research. KA compiled data and wrote the first draft of the manuscript. KA, SP, JS, and PA analyzed the data. KA, SP, and PA wrote sections of the manuscript. KA, JS, JK, and SC drafted the figures. All authors performed the research in the field and lab to collect the data. All authors have contributed to the article and approved all submitted versions.

\section{FUNDING}

We acknowledge support from National Science Foundation grants EAR-1624847 and EAR-1019636 awarded to SP, and a GSA Graduate Student Research Grant Lipman Research

\section{REFERENCES}

Ague, J. J., and Brimhall, G. H. (1988). Magmatic arc asymmetry and distribution of anomalous plutonic belts in the batholiths of California: effects of assimilation, crustal thickness, and depth of crystallization. Geol. Soc. Am. Bull. 100, 912-927. doi: 10.1130/0016-76061988100<0912:MAAADO<2.3.CO;2

Alasino, P. H., Ardill, K., Stanback, J., Paterson, S. R., Galindo, C., and Leopold, M. (2019). Magmatically folded and faulted schlieren zones formed by magma avalanching in the Sonora Pass Intrusive Suite. Sierra Nevada, California. Geosphere 15, 1677-1702. doi: 10.1130/GES02070.1

Albarède, F. (1996). Introduction to Geochemical Modeling. Cambridge: Cambridge University Press.

Aldiss, G. P. F. B. (2017). The geology of Iron Mountain and Tenaya Peak areas, Sierra National Forest and Yosemite National Park, Sierra Nevada, California. Durham: Durham University.

Annen, C., Blundy, J. D., Leuthold, J., and Sparks, R. S. J. (2015). Construction and evolution of igneous bodies: towards an integrated perspective of crustal magmatism. Lithos 230, 206-221. doi: 10.1016/j.lithos.2015.05.008

Ardill, K., Paterson, S., and Memeti, V. (2018). Spatiotemporal magmatic focusing in upper-mid crustal plutons of the Sierra Nevada arc. Earth Planet. Sci. Lett. 498, 88-100. doi: 10.1016/j.epsl.2018.06.023

Bachmann, O., and Bergantz, G. W. (2004). On the origin of crystal-poor rhyolites: extracted from batholithic crystal mushes. J. Petrol. 45, 1565-1582. doi: 10.1093/ petrology/egh019

Bachmann, O., and Bergantz, G. W. (2006). Gas percolation in upper-crustal silicic crystal mushes as a mechanism for upward heat advection and rejuvenation of near-solidus magma bodies. J. Volcanol. Geother. Res. 149, 85-102. doi: 10.1016/j.jvolgeores.2005.06.002

Bachmann, O., and Huber, C. (2016). Silicic magma reservoirs in the Earth's crust. Am. Mineral. 101, 2377-2404. doi: 10.2138/am-2016-5675

Bachmann, O., and Huber, C. (2019). The inner workings of crustal distillation columns; the physical mechanisms and rates controlling phase separation in silicic magma reservoirs. J. Petrol. 60, 3-18. doi: 10.1093/petrology/egy103

Barbey, P. (2009). Layering and schlieren in granitoids: a record of interactions between magma emplacement, crystallization and deformation in growing plutons (The André Dumont medallist lecture). Geol. Bel. 12, 109-133.
Award to KA that funded valuable fieldwork and bulk-rock geochemical analyses.

\section{ACKNOWLEDGMENTS}

We thank V. Memeti for providing samples of the KC schlieren and host and for providing field data from the Tuolumne Intrusive Complex with contributions from R. Miller and J. Žák. We also thank G. Aldiss, L. Ardill, M. Cuevas, J. McColl, K. O' Rourke, and L. Teruya for assistance in fieldwork, and Yosemite National Park rangers for their continued support. D. De La Cruz is thanked for assistance in organizing the TIC field data. We thank C. Barnes for the helpful comments during manuscript preparation. We also thank S. Erdmann and G. Bergantz for their constructive reviews that improved the manuscript, as well as G. Shellnutt for editorial handling.

\section{SUPPLEMENTARY MATERIAL}

The Supplementary Material for this article can be found online at: https://www.frontiersin.org/articles/10.3389/feart. 2020.00190/full\#supplementary-material

Barbey, P., Gasquet, D., Pin, C., and Bourgeix, A. L. (2008). Igneous banding, schlieren and mafic enclaves in calc-alkaline granites: the Budduso pluton (Sardinia). Lithos 104, 147-163. doi: 10.1016/j.lithos.2007.12.004

Barnes, C. G., Memeti, V., and Coint, N. (2016). Deciphering magmatic processes in calc-alkaline plutons using trace element zoning in hornblende. Am. Mineral. 101, 328-342. doi: 10.2138/am-2016-5383

Barnes, C. G., Werts, K., Memeti, V., and Ardill, K. (2020). Most granitoid rocks are cumulates: deductions from hornblende compositions and zircon saturation. J. Petrol. 60, 2227-2240. doi: 10.1093/petrology/egaa008

Barrière, M. (1981). On curved laminae, graded layers, convection currents and dynamic crystal sorting in the Ploumanac'h (Brittany) subalkaline granite. Contribut. Mineral. Petrol. 77, 214-224. doi: 10.1007/BF00373537

Bartley, J. M., Coleman, D. S., and Glazner, A. F. (2006). Incremental pluton emplacement by magmatic crack-seal. Earth Environ. Sci. Trans. R. Soc. Edinburgh 97, 383-396. doi: 10.1017/S0263593300001528

Bartley, J. M., Glazner, A. F., and Coleman, D. S. (2018). Dike intrusion and deformation during growth of the Half Dome pluton, Yosemite National Park, California. Geosphere 14, 1283-1297. doi: 10.1130/GES01458.1

Bartley, J. M., Glazner, A. F., Coleman, D. S., and Law, B. (2013). Geometry and emplacement of ladder dikes in the Cathedral Peak granodiorite, Yosemite National Park. Geol. Soc. Am. Abst. Progr. 45:13.

Bartley, J. M., Glazner, A. F., and Law, B. (2019). Ladder structures in the Cathedral Peak granodiorite, Yosemite: two-phase flow in fingered dikes? Geol. Soc. Am. Abst. Progr. 51, doi: 10.1130/abs/2019AM-338571

Bateman, P. C. (1992). "Plutonism in the central part of the Sierra Nevada batholith, California," in USGS Professional Paper 1483, (Reston, VI: USGS), doi: $10.3133 / \mathrm{pp} 1483$

Bateman, P. C., and Chappell, B. W. (1979). Crystallization, fractionation, and solidification of the Tuolumne intrusive series, Yosemite National Park, California. Geol. Soc. Am. Bull. 90, 465-482.

Bateman, P. C., Chappell, B. W., Kistler, R. W., Peck, D. L., and Busacca, A. (1988). Tuolumne Meadows quadrangle, California - analytic data. US Geol. Surv. Bull. 1819:43. doi: 10.3133/b1819

Bateman, P. C., Kistler, R. W., Peck, D. L., and Busacca, A. (1983). Geologic map of the Tuolumne Meadows quadrangle, Yosemite National Park, California (No. 1570). California: Yosemite National Park, doi: 10.3133/gq1570 
Beard, J. S. (2008). Crystal-melt separation and the development of isotopic heterogeneities in hybrid magmas. J. Petrol. 49, 1027-1041. doi: 10.1093/ petrology/egn 015

Beard, J. S., Ragland, P. C., and Crawford, M. L. (2005). Reactive bulk assimilation: a model for crust-mantle mixing in silicic magmas. Geology 33, 681-684. doi: 10.1130/G21470AR.1

Bergantz, G. W. (2000). On the dynamics of magma mixing by reintrusion: implications for pluton assembly processes. J. Struct. Geol. 22, 1297-1309. doi: 10.1016/S0191-8141(00)00053-5

Bergantz, G. W., and Ni, J. (1999). A numerical study of sedimentation by dripping instabilities in viscous fluids. Int. J. Multiphase Flow 25, 307-320. doi: 10.1016/ S0301-9322(98)00050-0

Bergantz, G. W., Schleicher, J. M., and Burgisser, A. (2015). Open-system dynamics and mixing in magma mushes. Nat. Geosci. 8, 793-796. doi: 10.1038/ngeo2534

Bergantz, G. W., Schleicher, J. M., and Burgisser, A. (2017). On the kinematics and dynamics of crystal-rich systems. J. Geophys. Res. 122, 6131-6159. doi: 10.1002/2017JB014218

Bhattacharji, S., and Smith, C. H. (1964). Flowage differentiation. Science 145, 150-153. doi: 10.1126/science.145.3628.150

Blum, J. D., and Erel, Y. (1997). Rb-Sr isotope systematics of a granitic soil chronosequence: the importance of biotite weathering. Geochim. Cosmochim. Acta 61, 3193-3204. doi: 10.1016/S0016-7037(97)00148-8

Boudreau, A. (2011). The evolution of texture and layering in layered intrusions. Int. Geol. Rev. 53, 330-353. doi: 10.1080/00206814.2010.496163

Bracciali, L., Paterson, S. R., Memeti, V., Rocchi, S., Matzel, J., and Mundil, R. (2008). "Build-up of the Tuolumne Batholith, California: the Johnson Granite Porphyry," in Proceedings of the LASI III Conference Abstracts, Malaysia, 17-18.

Burgess, S. D., and Miller, J. S. (2008). Construction, solidification and internal differentiation of a large felsic arc pluton: Cathedral Peak granodiorite, Sierra Nevada Batholith. Geol. Soc. Lond. Spec. Publ. 304, 203-233. doi: 10.1144/ SP304.11

Burgisser, A., and Bergantz, G. W. (2011). A rapid mechanism to remobilize and homogenize highly crystalline magma bodies. Nature 471, 212-215. doi: 10. 1038/nature09799

Calkins, F. C. (1930). "The granitic rocks of the Yosemite region, in Matthes," in Geologic history of the Yosemite Valley: USGS Professional Paper 160, ed. E. Francois (Reston, VI: USGS), 120-129. doi: 10.3133/pp160

Cao, W., Kaus, B. J., and Paterson, S. (2016a). Intrusion of granitic magma into the continental crust facilitated by magma pulsing and dike-diapir interactions: numerical simulations. Tectonics 35, 1575-1594. doi: 10.1002/2015TC00 4076

Cao, W., Paterson, S., Saleeby, J., and Zalunardo, S. (2016b). Bulk arc strain, crustal thickening, magma emplacement, and mass balances in the Mesozoic Sierra Nevada arc. J. Struct. Geol. 84, 14-30. doi: 10.1016/j.jsg.2015.11.002

Cao, W., Paterson, S., Memeti, V., Mundil, R., Anderson, J. L., and Schmidt, K. (2015). Tracking paleodeformation fields in the Mesozoic central Sierra Nevada arc: implications for intra-arc cyclic deformation and arc tempos. Lithosphere 7, 296-320. doi: 10.1130/L389.1

Cardozo, N., and Allmendinger, R. W. (2013). Spherical projections with OSXStereonet. Comput. Geosci. 51, 193-205. doi: 10.1016/j.cageo.2012.07.021

Carrara, A., Burgisser, A., and Bergantz, G. W. (2019). Lubrication effects on magmatic mush dynamics. J. Volcanol. Geother. Res. 380, 19-30. doi: 10.1016/j. jvolgeores.2019.05.008

Cashman, K. V., Sparks, R. S. J., and Blundy, J. D. (2017). Vertically extensive and unstable magmatic systems: a unified view of igneous processes. Science 355:eaag3055. doi: 10.1126/science.aag3055

Chambers, M., Memeti, V., Eddy, M. P., and Schoene, B. (2020). Half a million years of magmatic history recorded in a K-feldspar megacryst of the Tuolumne Intrusive Complex. California, USA. Geology 48, 400-404. doi: 10.1130/G46 873.1

Chesterman, C. W. (1975). Geology of the Matterhorn Peak 15-minute Quadrangle, Mono and Tuolumne Counties, California. California Division of Mines and Geology, Map Sheet 22, scale 1:48,000.

Clarke, D. B. (2003). Exploded Xenoliths, layered Granodiorites, and Chaotic Schlieren associated with the eastern contact of the South Mountain Batholith. Wolfville: Atlantic Geoscience Society.
Clarke, D. B., and Clarke, G. K. C. (1998). Layered granodiorites at Chebutco Head, South Mountain batholith, Nova Scotia. J. Struct. Geol. 20, 1305-1324. doi: 10.1016/s0191-8141(98)00067-4

Clarke, D. B., Grujic, D., McCuish, K. L., Sykes, J. C., and Tweedale, F. M. (2013). Ring schlieren: description and interpretation of field relations in the Halifax Pluton, South Mountain Batholith, Nova Scotia. J. Struct. Geol. 51, 193-205. doi: 10.1016/j.jsg.2013.01.009

Clemens, J. D., Stevens, G., le Roux, S., and Wallis, G. L. (2020). Mafic schlieren, crystal accumulation and differentiation in granitic magmas: an integrated case study. Contrib. Mineral Petrol. 175:51. doi: 10.1007/s00410-020-01689-x

Cloos, E. (1936). Der Sierra Nevada Pluton in Californien. Neues Jahrbuch für Mineralogie. Geol. Paleontol. 76, 355-450.

Coats, R. R. (1936). Primary banding in basic plutonic rocks. J. Geol. 44, 407-419. doi: $10.1086 / 624432$

Coleman, D. S., Bartley, J. M., Glazner, A. F., and Pardue, M. J. (2012). Is chemical zonation in plutonic rocks driven by changes in source magma composition or shallow-crustal differentiation? Geosphere 8, 1568-1587. doi: 10.1130/GES00798.1

Coleman, D. S., Gray, W., and Glazner, A. F. (2004). Rethinking the emplacement and evolution of zoned plutons: geochronologic evidence for incremental assembly of the Tuolumne Intrusive Suite. California. Geology 32, 433-436. doi: $10.1130 / \mathrm{G} 20220.1$

Cruden, A. R., McCaffrey, K. J. W., and Bunger, A. P. (2017). "Geometric Scaling of Tabular Igneous Intrusions: Implications for Emplacement and Growth," in Physical Geology of Shallow Magmatic Systems. Advances in Volcanology (An Official Book Series of the International Association of Volcanology and Chemistry of the Earth's Interior), eds C. Breitkreuz and S. Rocchi (Cham: Springer).

Davis, M., Koenders, M. A., and Petford, N. (2007). Vibro-agitation of chambered magma. J. Volcanol. Geother. Res. 167, 24-36. doi: 10.1016/j.jvolgeores.2007. 07.012

Degruyter, W., Parmigiani, A., Huber, C., and Bachmann, O. (2019). How do volatiles escape their shallow magmatic hearth?. Philos. Trans. R. Soc. A 377:20180017. doi: 10.1098/rsta.2018.0017

Dietl, C., De Wall, H., and Finger, F. (2010). Tube-like schlieren structures in the Fürstenstein Intrusive Complex (Bavarian Forest, Germany): evidence for melt segregation and magma flow at intraplutonic contacts. Lithos 116, 321-339. doi: 10.1016/j.lithos.2009.11.011

Economos, R. C., Memeti, V., Paterson, S. R., Miller, J. S., Erdmann, S., and Žák, J. (2009). Causes of compositional diversity in a lobe of the Half Dome granodiorite, Tuolumne Batholith, Central Sierra Nevada, California. Earth Environ. Sci. Trans. R. Soc. Edinburgh 100, 173-183. doi: 10.1017/ S1755691009016065

Estep, J., and Dufek, J. (2012). Substrate effects from force chain dynamics in dense granular flows. J. Geophys. Res. 117:F01028. doi: 10.1029/2011JF00 2125

Farner, M. J., Lee, C. T. A., and Mikus, M. L. (2018). Geochemical signals of maficfelsic mixing: case study of enclave swarms in the Bernasconi Hills pluton, California. GSA Bull. 130, 649-660. doi: 10.1130/B31760.1

Fox, L. K., and Miller, D. M. (1990). "Jurassic granitoids and related rocks of the southern Bristol Mountains, southern Providence Moutnains, and Colton Hills, Mojave Desert, California," in The Nature and Origin of Cordilleran Magmatism, Vol. 174, ed. J. L. Anderson (Washington, DC: GSA Memoirs), 111. doi: 10.1130/MEM174-p111

Garibaldi, N., Tikoff, B., Schaen, A. J., and Singer, B. S. (2018). Interpreting granitic fabrics in terms of rhyolitic melt segregation, accumulation, and escape via tectonic filter pressing in the Huemul pluton. Chile. J. Geophys. Res. 123, 8548-8567. doi: 10.1029/2018JB016282

Glazner, A. F. (2014). Magmatic life at low Reynolds number. Geology 42, 935-938. doi: 10.1130/G36078.1

Glazner, A. F., Bartley, J. M., Law, B., and Coleman, D. S. (2012). Ladder dikes, crazy geochemistry, and liquid immiscibility (?) in otherwise sane granites. Geol. Soc. Am. Abst. Progr. 44:21.

Graham, J. (2012). Yosemite National Park: Geologic resources inventory report. Natural Resource Report NPS/NRSS/GRD/NRR-2012/560. Fort Collins, CL: National Park Service. 
Gray, W., Glazner, A. F., Coleman, D. S., and Bartley, J. M. (2008). Long-term geochemical variability of the Late Cretaceous Tuolumne intrusive suite, central Sierra Nevada, California. Geol. Soc. Lond. Spec. Publ. 304, 183-201. doi: 10. 1144/SP304.10

Griffiths, R. W. (1986). Thermals in extremely viscous fluids, including the effects of temperature-dependent viscosity. J. Fluid Mech. 166, 115-138. doi: 10.1017/ S002211208600006X

Hartman, S. M., Paterson, S. R., Holk, G. J., and Kirkpatrick, J. D. (2018). Structural and hydrothermal evolution of a strike-slip shear zone during a ductile-brittle transition, Sierra Nevada, CA. J. Struct. Geol. 113, 134-154. doi: 10.1016/j.jsg. 2018.05.010

Hodge, K. F., Carazzo, G., Montague, X., and Jellinek, A. M. (2012). Magmatic structures in the Tuolumne Intrusive Suite, California: a new model for the formation and deformation of ladder dikes. Contribut. Mineral. Petrol. 164, 587-600. doi: 10.1007/s00410-012-0760-6

Holness, M. B. (2018). Melt segregation from silicic crystal mushes: a critical appraisal of possible mechanisms and their microstructural record. Contribut. Mineral. Petrol. 173:48. doi: 10.1007/s00410-018-1465-2

Holness, M. B., Vukmanovic, Z., and Mariani, E. (2017). Assessing the role of compaction in the formation of adcumulates: a microstructural perspective. J. Petrol. 58, 643-673. doi: 10.1093/petrology/egx037

Hurai, V., Simon, K., Wiechert, U., Hoefs, J., Konečný, P., Huraiová, M., et al. (1998). Immiscible separation of metalliferous Fe/Ti-oxide melts from fractionating alkali basalt: P-T-f O2 conditions and two-liquid elemental partitioning. Contribut. Mineral. Petrol. 133, 12-29. doi: 10.1007/ s004100050433

Irvine, T. N., Andersen, J. C. Ø, and Brooks, C. K. (1998). Included blocks (and blocks within blocks) in the Skaergaard intrusion: geologic relations and the origins of rhythmic modally graded layers. Geol. Soc. Am. Bull. 110, 1398-1447. doi: 10.1130/0016-76061998110<1398:IBABWB<2.3.CO;2

Jackson, M. D., Blundy, J., and Sparks, R. S. J. (2018). Chemical differentiation, cold storage and remobilization of magma in the Earth's crust. Nature 564, 405-409. doi: 10.1038/s41586-018-0746-2

Karlstrom, L., Paterson, S. R., and Jellinek, A. M. (2017). A reverse energy cascade for crustal magma transport. Nat. Geosci. 10, 604-608. doi: 10.1038/ngeo2982

Kawabata, H., Nishiura, D., Sakaguchi, H., and Tatsumi, Y. (2013). Self-organized domain microstructures in a plate-like particle suspension subjected to rapid simple shear. Rheol. Acta 52, 1-21. doi: 10.1007/s00397-012-0657-3

Kelemen, P. B., Whitehead, J. A., Aharonov, E., and Jordahl, K. A. (1995). Experiments on flow focusing in soluble porous media, with applications to melt extraction from the mantle. J. Geophys. Res. 100, 475-496. doi: 10.1029/ 94JB02544

Kendall, C., Sklash, M. G., and Bullen, T. D. (1995). "Isotope tracers of water and solute sources in catchments," in Solute Modelling in Catchment Systems, Ed. S. Trudgill (New York, NY: John Wiley and Sons), 261-303.

Kistler, R. W., Chappell, B. W., Peck, D. L., and Bateman, P. C. (1986). Isotopic variation in the Tuolumne intrusive suite, central Sierra Nevada, California. Contribut. Mineral. Petrol. 94, 205-220. doi: 10.1007/BF00592937

Kistler, R. W., and Fleck, R. J. (1994). Field guide for a transect of the central Sierra Nevada. California. Geochronol. Isotope Geol. 94, 267. doi: 10.3133/ofr94267

Li, X. C., Zhou, M. F., Yang, Y. H., Zhao, X. F., and Gao, J. F. (2018). Disturbance of the Sm-Nd isotopic system by metasomatic alteration: A case study of fluorapatite from the Sin Quyen Cu-LREE-Au deposit, Vietnam. Am. Mineral. 103, 1487-1496. doi: 10.2138/am-2018-6501

Lipman, P. W. (2007). Incremental assembly and prolonged consolidation of Cordilleran magma chambers: Evidence from the Southern Rocky Mountain volcanic field. Geosphere 3, 42-70. doi: 10.1130/GES00061.1

Loetterle, J. (2004). Sedimentary Structures in a Layered Granodiorite: A Window Into Physical Conditions Present During the Development of the Tuolumne Intrusive Suite, Sierra Nevada, California. MSc thesis, University of Washington, Washington, DC.

Loetterle, J., and Bergantz, G. W. (2003). Sedimentary structures in a layered granodiorite: an example of magma multiphase dynamics from the Tuolumne Intrusive Suite, Sierra Nevada, California. Geol. Soc. Am. Abst. Progr. 35:555.

Marsh, B. D. (1981). On the crystallinity, probability of occurrence, and rheology of lava and magma. Contribut. Mineral. Petrol. 78, 85-98. doi: 10.1007/ BF00371146
Marsh, B. D. (1996). Solidification fronts and magmatic evolution. Mineral. Magaz. 60, 5-40. doi: 10.1180/minmag.1996.060.398.03

Matzel, J., Miller, J. S., Mundil, R., and Paterson, S. R. (2006). Zircon saturation and the growth of the Cathedral Peak pluton. CA. Geochim. Cosmochim. Acta 70:403. doi: 10.1016/j.gca.2006.06.813

Matzel, J., Mundil, R., Paterson, S., Renne, P., and Nomade, S. (2005). Evaluating pluton growth models using high resolution geochronology: Tuolumne intrusive suite, Sierra Nevada, CA. Geol. Soc. Am. Abst. Progr. 37:131.

McBirney, A. R., and Noyes, R. M. (1979). Crystallization and layering of the Skaergaard intrusion. J. Petrol. 20, 487-554. doi: 10.1093/petrology/20.3.487

McColl, J. A. R. (2017). Geological mapping in Yosemite National Park, Sierra Nevada, California: Geologic history of the Mount Dana area and magmatic structure kinematics in the Tuolumne Intrusive Suite. Durham: Durham University.

McIntire, M. Z., Bergantz, G. W., and Schleicher, J. M. (2019). On the hydrodynamics of crystal clustering. Philos. Trans. R. Soc. A 377:20180015. doi: $10.1098 /$ rsta.2018.0015

Memeti, V. (2009). Growth of the Cretaceous Tuolumne Batholith and Synchronous Regional Tectonics, Sierra Nevada, CA: A Coupled System in a Continental Margin Arc Setting. Ph.D. thesis, University of Southern California, California.

Memeti, V., Paterson, S., Matzel, J., Mundil, R., and Okaya, D. (2010). Magmatic lobes as "snapshots" of magma chamber growth and evolution in large, composite batholiths: an example from the Tuolumne intrusion. Sierra Nevada, California. Geol. Soc. Am. Bull. 122, 1912-1931. doi: 10.1130/B30004.1

Memeti, V., Paterson, S., Mundil, R., Paterson, S. R., and Putirka, K. D. (2014). "Day 4: magmatic evolution of the tuolumne intrusive complex," in Formation of the Sierra Nevada Batholith: Magmatic and Tectonic Processes and Their Tempos, Vol. 34, eds V. Memeti, S. R. Paterson, and K. D. Putirka (Boulder, CL: Geological Society of America Field Guide), 43-74. doi: 10.1130/2014.0034(04)

Miller, J. S., Matzel, J. E., Miller, C. F., Burgess, S. D., and Miller, R. B. (2007). Zircon growth and recycling during the assembly of large, composite arc plutons. J. Volcanol. Geother. Res. 167, 282-299. doi: 10.1016/j.jvolgeores.2007.04.019

Miller, R. B., and Paterson, S. R. (2001). Construction of mid-crustal sheeted plutons: examples from the North Cascades, Washington. Geol. Soc. Am. Bull. 113, 1423-1442. doi: 10.1130/0016-76062001113<1423:COMCSP<2.0.CO;2

Murase, T., McBirney, A. R., and Melson, W. G. (1985). Viscosity of the dome of Mount St. Helens. J. Volcanol. Geother. Res. 24, 193-204. doi: 10.1016/03770273(85)90033-2

Namur, O., Abily, B., Boudreau, A. E., Blanchette, F., Bush, J. W., Ceuleneer, G., et al. (2015). "Igneous layering in basaltic magma chambers," in Layered Intrusions, eds R. Latypov, O. Namur, B. Charlier, and C. Tegner (Dordrecht: Springer), 75-152. doi: 10.1007/978-94-017-9652-1_2

Naney, M. T. (1983). Phase equilibria of rock-forming ferromagnesian silicates in granitic systems. Am. J. Sci. 283, 993-1033. doi: 10.2475/ajs.283.10.993

O’Driscoll, B., and VanTongeren, J. A. (2017). Layered intrusions: from petrological paradigms to precious metal repositories. Elements 13, 383-389. doi: 10.2138/ gselements.13.6.383

Oliver, H. W. (1977). Gravity and magnetic investigations of the Sierra Nevada batholith, California. Geol. Soc. Am. Bull. 88, 445-461. doi: 10.1130/00167606197788<445:GAMIOT<2.0.CO;2

Oppenheim, L. F., Memeti, V., Barnes, C. G., Chambers, M., Werts, K., and Esposito, R. (in review). Feldspar recycling across magma mush bodies during the voluminous Half Dome and Cathedral Peak stages of the Tuolumne Intrusive Complex, Yosemite National Park, California. Geosphere.

Otamendi, J. E., Ducea, M. N., Tibaldi, A. M., Bergantz, G. W., Jesús, D., and Vujovich, G. I. (2009). Generation of tonalitic and dioritic magmas by coupled partial melting of gabbroic and metasedimentary rocks within the deep crust of the Famatinian magmatic arc, Argentina. J. Petrol. 50, 841-873. doi: 10.1093/ petrology/egp022

Paterson, S., Memeti, V., Mundil, R., and Žák, J. (2016). Repeated, multiscale, magmatic erosion and recycling in an upper-crustal pluton: implications for magma chamber dynamics and magma volume estimates. Am. Mineral. 101, 2176-2198. doi: 10.2138/am-2016-5576

Paterson, S. R. (2009). Magmatic tubes, pipes, troughs, diapirs, and plumes: latestage convective instabilities resulting in compositional diversity and permeable networks in crystal-rich magmas of the Tuolumne batholith. Sierra Nevada, California. Geosphere 5, 496-527. doi: 10.1130/GES00214.1 
Paterson, S. R., Ardill, K., Vernon, R., and Žák, J. (2018). A review of mesoscopic magmatic structures and their potential for evaluating the hypersolidus evolution of intrusive complexes. J. Struct. Geol. 125, 134-147. doi: 10.1016/j. jsg.2018.04.022

Paterson, S. R., Fowler, T. K. Jr., Schmidt, K. L., Yoshinobu, A. S., Yuan, E. S., and Miller, R. B. (1998). Interpreting magmatic fabric patterns in plutons. Lithos 44, 53-82. doi: 10.1016/S0024-4937(98)00022-X

Paterson, S. R., Memeti, V., Pignotta, G., Erdmann, S., Žák, J., Chambers, J., et al. (2012). Formation and transfer of stoped blocks into magma chambers: The high-temperature interplay between focused porous flow, cracking, channel flow, host-rock anisotropy, and regional deformation. Geosphere 8, 443-469. doi: 10.1130/GES00680.1

Paterson, S. R., Okaya, D., Memeti, V., Economos, R., and Miller, R. B. (2011). Magma addition and flux calculations of incrementally constructed magma chambers in continental margin arcs: combined field, geochronologic, and thermal modeling studies. Geosphere 7, 1439-1468. doi: 10.1130/GES00696.1

Paterson, S. R., Vernon, R. H., and Žák, J. (2005). Mechanical instabilities and physical accumulation of K-feldspar megacrysts in granitic magma, Tuolumne Batholith, California, USA. J. Virt. Expl. 18, 1-18. doi: 10.3809/jvirtex.2005. 00114

Paterson, S. R., Žák, J., and Janoušek, V. (2008). Growth of complex sheeted zones during recycling of older magmatic units into younger: Sawmill Canyon area, Tuolumne batholith, Sierra Nevada, California. J. Volcanol. Geother. Res. 177, 457-484. doi: 10.1016/j.jvolgeores.2008.06.024

Peck, D. L., and Van Kooten, G. K. (1983). Merced Peak Quadrangle, Central Sierra Nevada, California: Analytic Data, No. 1170, US Geological Survey. Reston, VI: USGS.

Petford, N. (2003). Rheology of granitic magmas during ascent and emplacement. Ann. Rev. Earth Planet. Sci. 31, 399-427. doi: 10.1146/annurev.earth.31.100901. 141352

Petford, N. (2009). Which effective viscosity? Mineral. Magaz. 73, 167-191. doi: 10.1180/minmag.2009.073.2.167

Petford, N., Koenders, M. A., and Clemens, J. D. (2020). Igneous differentiation by deformation. Contribut. Mineral. Petrol. 175, 1-21. doi: 10.1007/s00410-0201674-3

Piccoli, P., and Candela, P. (1994). Apatite in felsic rocks; a model for the estimation of initial halogen concentrations in the Bishop Tuff (Long Valley) and Tuolumne Intrusive Suite (Sierra Nevada Batholith) magmas. Am. J. Sci. 294, 92-135. doi: 10.2475/ajs.294.1.92

Pinotti, L. P., D’Eramo, F. J., Weinberg, R. F., Demartis, M., Tubía, J. M., Coniglio, J. E., et al. (2016). Contrasting magmatic structures between small plutons and batholiths emplaced at shallow crustal level (Sierras de Córdoba. Argentina). J. Struct. Geol. 92, 46-58. doi: 10.1016/j.jsg.2016.09.009

Pitcher, W. S. (1997). The Nature and Origin of Granite. Berlin: Springer Science \& Business Media.

Pons, J., Barbey, P., Nachit, H., and Burg, J. P. (2006). Development of igneous layering during growth of pluton: the Tarcouate Laccolith (Morocco). Tectonophysics 413, 271-286. doi: 10.1016/j.tecto.2005.11.005

Putirka, K. (2016). Amphibole thermometers and barometers for igneous systems and some implications for eruption mechanisms of felsic magmas at arc volcanoes. Am. Mineral. 101, 841-858. doi: 10.2138/am-2016-5506

Reid, J. B. Jr., Murray, D. P., Hermes, O. D., and Steig, E. J. (1993). Fractional crystallization in granites of the Sierra Nevada: how important is it? Geology 21, 587-590. doi: 10.1130/0091-76131993021<0587:FCIGOT<2.3.CO;2

Rocher, S., Alasino, P. H., Grande, M. M., Larrovere, M. A., and Paterson, S. R. (2018). K-feldspar megacryst accumulations formed by mechanical instabilities in magma chamber margins, Asha pluton, NW Argentina. J. Struct. Geol. 112, 154-173. doi: 10.1016/j.jsg.2018.04.017

Rosenberg, C. L., and Handy, M. R. (2005). Experimental deformation of partially melted granite revisited: implications for the continental crust. J. Metamorphic Geol. 23, 19-28. doi: 10.1111/j.1525-1314.2005.00555

Ryerson, F. J., and Hess, P. C. (1978). Implications of liquid-liquid distribution coefficients to mineral-liquid partitioning. Geochim. Cosmochim. Acta 42, 921932. doi: 10.1016/0016-7037(78)90103-5

Schindelin, J., Arganda-Carreras, I., Frise, E., Kaynig, V., Longair, M., Pietzsch, T., et al. (2012). Fiji: an open-source platform for biological-image analysis. Nat. Methods 9, 676-682. doi: 10.1038/nmeth.2019

Schleicher, J. M., Bergantz, G. W., Breidenthal, R. E., and Burgisser, A. (2016). Time scales of crystal mixing in magma mushes. Geophys. Res. Lett. 43, 1543-1550. doi: 10.1002/2015GL067372
Smith, T. E. (1974). The geochemistry of the granitic rocks of Halifax County, Nova Scotia. Can. J. Earth Sci. 11, 650-657. doi: 10.1139/e74-062

Solgadi, F., and Sawyer, E. W. (2008). Formation of igneous layering in granodiorite by gravity flow: a field, microstructure and geochemical study of the Tuolumne Intrusive Suite at Sawmill Canyon, California. J. Petrol. 49, 2009-2042. doi: 10.1093/petrology/egn056

Sparks, R. S. J., Annen, C., Blundy, J. D., Cashman, K. V., Rust, A. C., and Jackson, M. D. (2019). Formation and dynamics of magma reservoirs. Philos. Trans. $R$. Soc. A 377:20180019. doi: 10.1098/rsta.2018.0019

Spera, F. J., and Bohrson, W. A. (2018). Rejuvenation of crustal magma mush: a tale of multiply nested processes and timescales. Am. J. Sci. 318, 90-140. doi: 10.2475/01.2018.05

Sun, S. S., and McDonough, W. F. (1989). Chemical and isotopic systematics of oceanic basalts: implications for mantle composition and processes. Geol. Soc. Lond. Spec. Publ. 42, 313-345. doi: 10.1144/gsl.sp.1989.042.01.19

Van der Molen, I., and Paterson, M. S. (1979). Experimental deformation of partially-melted granite. Contribut. Mineral. Petrol. 70, 299-318. doi: 10.1007/ BF00375359

Vernon, R. H., and Paterson, S. R. (2006). Mesoscopic structures resulting from crystal accumulation and melt movement in granites. Earth Environ. Sci. Trans. R. Soc. Edinburgh 97, 369-381. doi: 10.1017/S026359330000 1516

Vukmanovic, Z., Holness, M. B., Monks, K., and Andersen, J. Ø (2018). The Skaergaard trough layering: sedimentation in a convecting magma chamber. Contribut. Mineral. Petrol. 173:43. doi: 10.1007/s00410-018-1466-1

Wager, L. R., and Brown, G. M. (1968). Layered igneous rocks. San Francisco: Freeman, 588. doi: 10.1180/minmag.1968.036.284.25

Wager, L. R., and Deer, W. A. (1939). Geological investigations in East Greenland. Part III. The petrology of the Skaergaard intrusion, Kangerdlussuaq, East Greenland. Meddelelser Grønland 105, 352.

Wahrhaftig, C. (1979). Significance of asymmetric schlieren for crystallization of granites in the Sierra Nevada batholith, California. Geol. Soc. Am. Abst. Progr. 11:133.

Weinberg, R. F., Sial, A. N., and Pessoa, R. R. (2001). Magma flow within the Tavares pluton, northeastern Brazil: compositional and thermal convection. Geol. Soc. Am. Bull. 113, 508-520. doi: 10.1130/0016-76062001113<0508: MFWTTP $<2.0 . \mathrm{CO} ; 2$

Werts, K., Barnes, C. G., Memeti, V., Ratschbacher, B., Williams, D., and Paterson, S. R. (2020). Hornblende as a tool for assessing mineral-melt equilibrium and recognition of crystal accumulation. Am. Mineral. 105, 77-91. doi: 10.2138/am2020-6972

Wiebe, R. A., and Collins, W. J. (1998). Depositional features and stratigraphic sections in granitic plutons: implications for the emplacement and crystallization of granitic magma. J. Struct. Geol. 20, 1273-1289. doi: 10.1016/S0191-8141(98)00059-5

Wiebe, R. A., Jellinek, A. M., and Hodge, K. F. (2017). New insights into the origin of ladder dikes: implications for punctuated growth and crystal accumulation in the Cathedral Peak granodiorite. Lithos 277, 241-258. doi: 10.1016/j.lithos. 2016.09.015

Wiebe, R. A., Jellinek, M., Markley, M. J., Hawkins, D. P., and Snyder, D. (2007). Steep schlieren and associated enclaves in the Vinalhaven granite, Maine: possible indicators for granite rheology. Contribut. Mineral. Petrol. 153:121. doi: 10.1007/s00410-006-0142-z

Žák, J., and Klomínský, J. (2007). Magmatic structures in the KrkonošeJizera Plutonic Complex, Bohemian Massif: evidence for localized multiphase flow and small-scale thermal-mechanical instabilities in a granitic magma chamber. J. Volcanol. Geother. Res. 164, 254-267. doi: 10.1016/j.jvolgeores.2007. 05.006

Žák, J., and Paterson, S. R. (2005). Characteristics of internal contacts in the Tuolumne Batholith, central Sierra Nevada, California (USA): implications for episodic emplacement and physical processes in a continental arc magma chamber. Geol. Soc. Am. Bull. 117, 1242-1255. doi: 10.1130/B25 558.1

Žák, J., and Paterson, S. R. (2010). Magmatic erosion of the solidification front during reintrusion: the eastern margin of the Tuolumne batholith, Sierra Nevada, California. Int. J. Earth Sci. 99, 801-812. doi: 10.1007/s00531-0090423-7

Žák, J., Paterson, S. R., Janoušek, V., and Kabele, P. (2009). The Mammoth Peak sheeted complex, Tuolumne batholith, Sierra Nevada, California: a record of initial growth or late thermal contraction in a magma 
chamber? Contribut. Mineral. Petrol. 158:447. doi: 10.1007/s00410-0090391-8

Žák, J., Paterson, S. R., and Memeti, V. (2007). Four magmatic fabrics in the Tuolumne batholith, central Sierra Nevada, California (USA): implications for interpreting fabric patterns in plutons and evolution of magma chambers in the upper crust. Geol. Soc. Am. Bull. 119, 184-201. doi: 10.1130/B25 773.1

Zhang, J., Humphreys, M. C., Cooper, G. F., Davidson, J. P., and Macpherson, C. G. (2017). Magma mush chemistry at subduction zones, revealed by new melt major element inversion from calcic amphiboles. Am. Mineral. 102, 1353-1367. doi: $10.2138 / \mathrm{am}-2017-5928$
Conflict of Interest: The authors declare that the research was conducted in the absence of any commercial or financial relationships that could be construed as a potential conflict of interest.

Copyright (๑) 2020 Ardill, Paterson, Stanback, Alasino, King and Crosbie. This is an open-access article distributed under the terms of the Creative Commons Attribution License (CC BY). The use, distribution or reproduction in other forums is permitted, provided the original author(s) and the copyright owner(s) are credited and that the original publication in this journal is cited, in accordance with accepted academic practice. No use, distribution or reproduction is permitted which does not comply with these terms. 